\title{
Exploring fatigue as a social construct
}

Citation for published version (APA):

Taylor, B. V. (2017). Exploring fatigue as a social construct: implications for work hour reform in postgraduate medical education. [Doctoral Thesis, Maastricht University]. Datawyse / Universitaire Pers Maastricht. https://doi.org/10.26481/dis.20170329tt

Document status and date:

Published: 01/01/2017

DOI:

10.26481/dis.20170329tt

Document Version:

Publisher's PDF, also known as Version of record

\section{Please check the document version of this publication:}

- A submitted manuscript is the version of the article upon submission and before peer-review. There can be important differences between the submitted version and the official published version of record.

People interested in the research are advised to contact the author for the final version of the publication, or visit the DOI to the publisher's website.

- The final author version and the galley proof are versions of the publication after peer review.

- The final published version features the final layout of the paper including the volume, issue and page numbers.

Link to publication

\footnotetext{
General rights Owners
rights.

- You may freely distribute the URL identifying the publication in the public portal. please follow below link for the End User Agreement:

www.umlib.nl/taverne-license

Take down policy

If you believe that this document breaches copyright please contact us at:

repository@maastrichtuniversity.nl

providing details and we will investigate your claim.
}

Copyright and moral rights for the publications made accessible in the public portal are retained by the authors and/or other copyright owners and it is a condition of accessing publications that users recognise and abide by the legal requirements associated with these

- Users may download and print one copy of any publication from the public portal for the purpose of private study or research.

- You may not further distribute the material or use it for any profit-making activity or commercial gain

If the publication is distributed under the terms of Article $25 \mathrm{fa}$ of the Dutch Copyright Act, indicated by the "Taverne" license above, 


\section{Exploring Fatigue as a Social Construct:}

Implications for Work Hour Reform in Postgraduate Medical Education

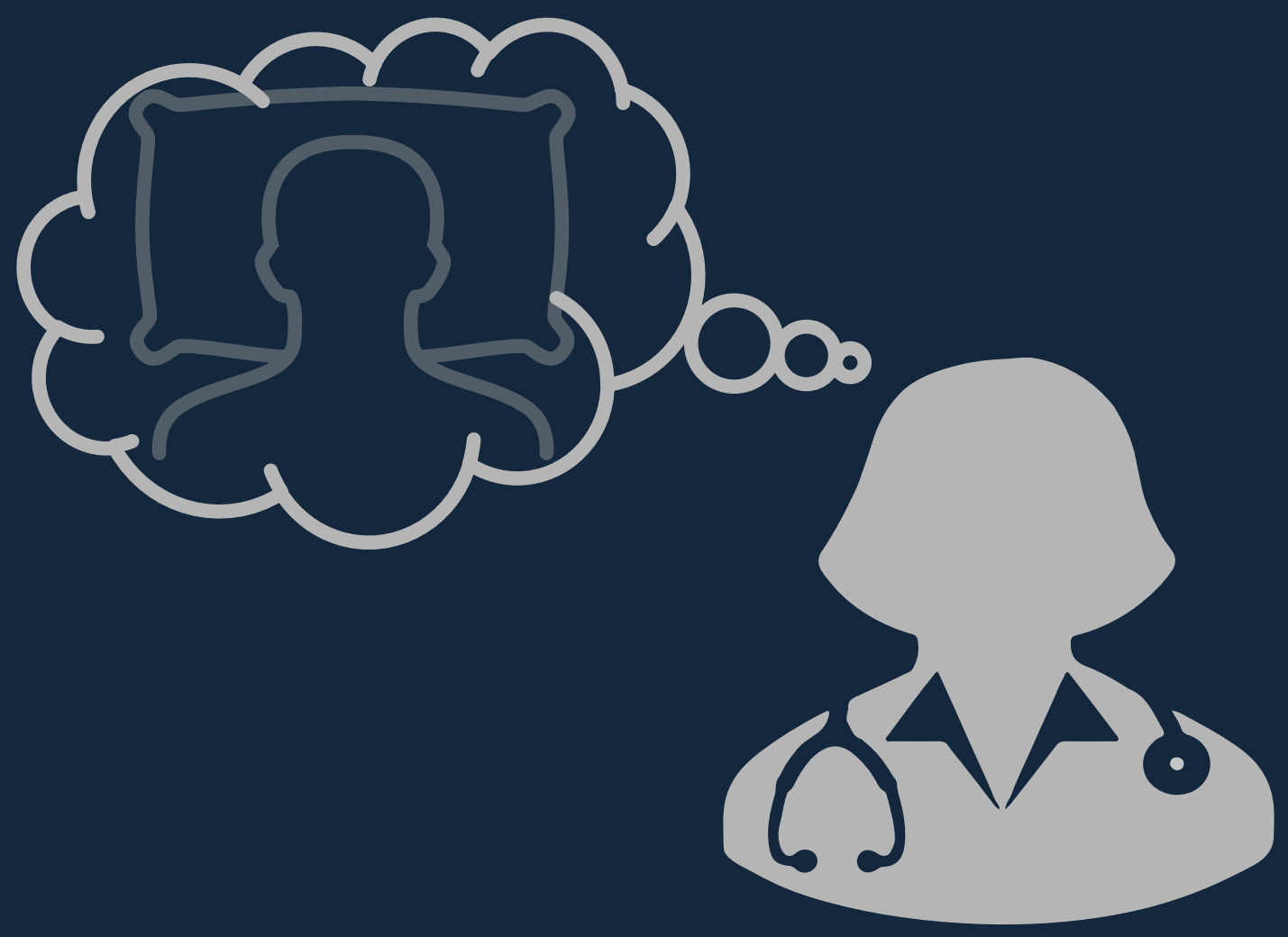


The research reported here was carried out at Maastricht University in Leanning!

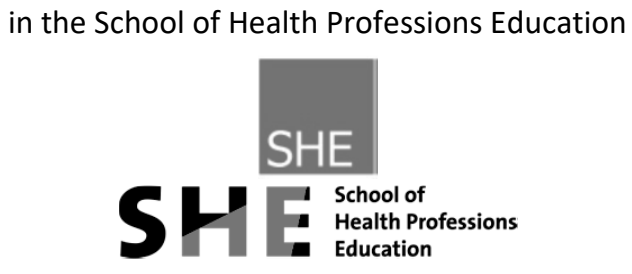

Cover: Lady Doctor by Karthik Srinivas from the Noun Project Sleep by Artem Kovyazin from the Noun Project

ISBN 9789461596697

Print Datawyse | Universitaire Pers Maastricht 


\section{Exploring Fatigue as a Social Construct \\ Implications for Work Hour Reform in Postgraduate Medical \\ Education}

Dissertation

to obtain the degree of Doctor at Maastricht University, on the authority of the Rector Magnificus, Prof. dr. Rianne M. Letschert in accordance with the decision of the Board of Deans, to be defended in public on Wednesday March 29 2017 , at 1600 hours

by

Taryn Suzanne Marie Taylor 


\section{Supervisors}

Prof. dr. Tim Dornan

Prof. dr. Lorelei Lingard, Ontario, Canada

\section{Co-supervisor}

dr. Pim W. Teunissen

\section{Assessment Committee}

Prof. dr. Erik Driessen (chair)

Dr. Janneke Frambach

Dr. Esther Helmich, UMC Groningen

Prof. dr. Ide Heyligers

Prof. dr. Fedde Scheele, VUMC Amsterdam 


\section{Postcall}

Postcall you come home diminished, wan, your hands

faltering at the lock. You feel the need to tell me each patient's history before you sleep,

the progress of each malignancy, the way the family spoke to you, the suffering that makes each death a release.

I understand. But I wait for you, Isabelle, not your stories of the progress of the dying.

I lead you to bed like a child, almost crying with fatigue and despair these anaemic mornings when you have donated all your strength and then come home to me, stricken, empty and grateful for the smallest gesture of tenderness, my easing your heel from your boot as you undress, holding you while you try to reclaim your membership as one who sleeps. Your limbs twitch like a dog's, hurrying into dreams, your lips part with sighs. I soothe you with my weight, whisper about the snow piling up outside. Your eyes close, it's late afternoon, slow repose beckons. But even in dreams your fingers pleat the quilt as if gathering the flesh of an arm before a shot. I understand. Accountability never leaves your hands.

-Rachel Rose

McGill/Queen's University Press

(excerpt from Giving My Body to Science) 



\section{Table of contents}

$\begin{array}{llr}\text { Chapter } 1 & \text { Introduction } & 9\end{array}$

Chapter 2 Reflexivity, Theoretical Framework and Methodology 23

Chapter 3 To Stay or Not to Stay? A Grounded Theory Study of Residents' 33

Postcall Behaviors and Their Rationalizations for Those Behaviors

Chapter 4 Recovery of Sleep or Recovery of Self? A Grounded Theory Study of 45 Residents' Decision-Making Regarding How to Spend Their Nonclinical Postcall Time

Chapter 5 Principles of Fatigue in Residency Education: A Qualitative Study

Chapter 6 Work Hour Regulations Complicate Residency Education: Lessons $\quad 73$ About the Social Construct of Fatigue in Europe

$\begin{array}{lll}\text { Chapter } 7 & \text { Discussion } & 87\end{array}$

$\begin{array}{ll}\text { Summary } & 105\end{array}$

$\begin{array}{ll}\text { Samenvatting } & 109\end{array}$

$\begin{array}{ll}\text { Valorisation } & 115\end{array}$

$\begin{array}{ll}\text { Acknowledgements } & 119\end{array}$

$\begin{array}{ll}\text { Curriculum vitae } & 121\end{array}$ 

Chapter 1

Introduction 
Regulation of resident work hours remains one of the most hotly debated issues within medical education over the last decade. These regulations challenge the long-standing tradition in which residents routinely work shifts longer than 24 hours during their training. In this tradition, working extended hours is a rite of passage ${ }^{1}$ and a proxy for dedication to professional ideals such as altruism. ${ }^{2}$ Unregulated work hours have been criticized for being outdated and dangerous in light of evidence that prolonged sleep deprivation may compromise patient safety and resident wellbeing. ${ }^{3-5}$ Public accountability has been another driving force that has led the United States (U.S.) and many jurisdictions in Europe to institute resident work hour regulations. ${ }^{6}$ In spite of these pressures, Canada has chosen not to adopt national work hour regulations and existing work hour policies in the U.S remain controversial. Researchers have invested a tremendous amount of resources into resolving this controversy. Increasingly, research efforts are focused on proving whether restrictions are good or bad for medical training and patient care. There is now growing concern that fewer and fewer studies favour work hour restrictions. Many of these studies fail to account for the social milieu that shapes how these work regulations are enacted; influences trainees' perceptions of and adherence to the regulations; and reinforces potential barriers to implementation. We need to broaden our focus from trying to prove whether restricting resident work hours is good or bad, in order to develop a more nuanced view of why existing regulations outside of Canada may have fallen short of expectations. In particular, understanding how the social learning environment shapes behaviours and offers insight into the limitations of policies that focus solely on work hours.

\section{Duty Hour Controversies}

The current body of literature that explores the impact of resident work hour regulations contains multiple lines of inquiry. Below I summarize four key debates that are most relevant to my program of research.

\section{Is Sleep Deprivation Dangerous?}

One position within this debate asserts that sleep is a physiologic need, and the drive to sleep can be as overpowering as hunger or thirst. There is evidence that fatigue from excessive sleep deprivation can lead to cognitive impairment. ${ }^{3,7}$ Studies have shown that increased rates of motor vehicle collisions and percutaneous needle-stick injuries correlate with prolonged sleep deprivation in medical trainees. ${ }^{4,8}$ Although some studies indicate that individuals can accurately self-assess their level of fatigue, they inaccurately estimate the negative impact of fatigue on their performance. ${ }^{9-11}$ In the setting of resident work hours, empirical data raises concerns about performance impairment for residents who are providing patient care after prolonged periods without sleep. ${ }^{5}$

Skeptics assert that sleep deprivation is less dangerous than earlier studies suggest. ${ }^{12}$ This emerging, contrary position is reflected by a new wave of research, which questions the link between sleep deprivation and impaired clinical performance. Psychomotor function ${ }^{3,13}$ and 
situational awareness, ${ }^{14}$ for example, may be unaffected by sleep deprivation. Others have demonstrated that certain operative complications are not increased after working a night on call. ${ }^{15}$ These results affirm the popular stance that long working hours enable trainees to build stamina and learn how to withstand prolonged periods of wakefulness. ${ }^{16,17}$ The controversy has inspired resource-intensive, large-scale studies that suggest prolonged work hours and subsequent sleep deprivation may not affect patient outcomes as profoundly as was once thought. ${ }^{18,19}$

There are many ways to reconcile the contradictory positions within the knowledge claim that sleep deprivation is dangerous. Firstly, most research that highlights the dangerous impact of sleep deprivation in non-physician subjects is situated within tightly controlled laboratory settings that may not reflect the realities of medical training. ${ }^{20}$ Secondly, when this type of research is performed with medical trainees, it is usually not feasible to provide a well-rested control group, due to the ubiquitous nature of chronic sleep deprivation amongst trainees. ${ }^{21}$ Finally, it is exceedingly difficult to identify tasks in the laboratory setting that replicate the complexity required of medical trainees when providing patient care.

The inherent complexity of patient care makes it difficult to parse out the impact of fatigued and sleep deprived individuals on medical errors. Researchers often rely on individuals' selfreported measures of fatigue or perceived error. ${ }^{8,22,23}$ Other studies use second-hand, nonblinded observer judgments of apparent alertness or decision-making quality for individual trainees. ${ }^{18}$ In practice, however, seldom do the erroneous actions of a single physician or trainee reach the patient in a simple, linear fashion. More commonly, clinical error results in an adverse outcome due to breakdown within a dynamic, interrelated system of individuals, protocols, and tools. And while a fatigued clinician may influence team functioning and working culture, the impact of the individual is difficult to isolate from the system in which he or she is embedded.

Thus, the lack of consensus about the impact of sleep deprivation results from a combination of artificial study environments, insufficiently rested controls, subjective measures, and a focus on the individual as the exclusive source of danger.

Does Resident Training Suffer From Work Hour Restrictions?

In part, the elimination of long duty periods and excessive sleep deprivation in training was intended to improve trainees' skill acquisition and knowledge retention. In a laboratory setting, research supports this notion. ${ }^{3}$ Sleep deprivation interferes with complex cognitive demands; it makes learning harder. ${ }^{3,24-26}$

Contrary to this position, there is medical education research that questions whether working long hours affects learning or cognitive performance. ${ }^{27}$ Moreover, there is a growing 
fear that reducing consecutive work hours is harmful to medical training. ${ }^{28}$ Surgical specialties have been particularly vocal about these concerns ${ }^{29,30}$; however, the negative impact on operative case volume may be overstated. ${ }^{31,32}$ One source of distress is the prevalence of time-based educational models. When clinical competence is implied by duration of training, work hour regulations are an obvious threat to competence. Perhaps the shift to competency based educational frameworks will alleviate some of these concerns. Medical training also relies heavily upon 'education by random opportunity', 33,34 as it is nearly impossible to ensure each trainee is exposed to the exact same constellation of clinical problems and procedures. In some ways, the math is simple: in the current system, fewer hours at work mean fewer random opportunities.

Unfortunately, measuring the educational impact of reduced work hours has proven challenging. Some researchers have looked to standardized test scores and pass rates. ${ }^{27,32,35}$ But comparing scores pre- and post-duty hour regulations, whether they are better or worse, tells only part of the story. Test scores are invariably the product of many influential features of the clinical learning environment. ${ }^{35}$ It is also unclear what constitutes an educationally relevant difference. Another approach to assessing the educational impact of work hour regulations has taken the form of surveying preceptors and trainees. ${ }^{19,28,36}$ While this is valuable information, it does not account for the cultural influences and confounding factors at play. For example, it is hard to imagine that residents might report a positive impact of work hour restrictions if they are simultaneously receiving a "constant stream of tacit messages about the substandard quality of their educational experiences" from preceptors who trained in an era before such restrictions. ${ }^{37(p 497)}$

While medical knowledge and procedural expertise are important considerations, we cannot afford to overlook the impact of work hour restrictions on professional identity development. Green ${ }^{38}$ speculated that the strongest argument in favour of reducing hours is that it will create space for trainees to develop professional integrity. He suggests that this space is otherwise difficult to access when long working hours are the norm. This concern is echoed by Gaba and Howard who caution that, "fatigue-related depression and anger result

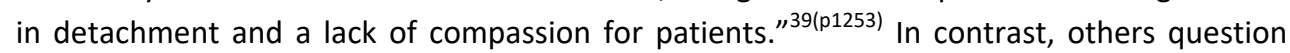
whether these restrictions threaten to extinguish residents' sense of altruism, commitment and accountability. ${ }^{16,40}$ Work hour restrictions are further problematized as an ethical dilemma, wherein residents are faced with the choice between following the restrictions or doing what they believe is in the patient's best interests. ${ }^{41}$

\section{Do Work Hour Restrictions Compromise Patient Care?}

One unintended consequence of fewer consecutive working hours is an increased frequency of patient care handoffs. Handoffs occur when patient information is passed from one team member to another during transitions of care. Many preventable adverse events have been attributed to communication failures during handoffs. ${ }^{42}$ Fortunately, enhanced handoff 
interventions have shown great promise in reducing medical error and adverse event rates. ${ }^{43,44}$ These interventions focus on team continuity of care and shared situational awareness, rather than relying on a single individual to maintain continuity. Unfortunately, antiquated notions of professionalism detract from enhanced handoff interventions in the era of work hour restrictions. Arora et al define nostalgic professionalism as "consistently placing a patient's or the profession's needs above one's own personal needs." ${ }^{\text {45(2195) }}$ As long as individual continuity is the gold standard, handoffs are likely to remain the weakest moments in patient care, which is exacerbated by work hour restrictions.

Many researchers are invested in measuring the impact of duty hour restrictions on patient care outcomes. As Baldwin et $\mathrm{al}^{46}$ caution, much of the research to date has focused on the clinical outcomes that are easiest to measure. They suggest that, while acute renal failure rates and surgical site infections are meaningful outcomes, the specific impact of work hour restrictions is more likely evident in outcomes such as percutaneous needlestick injuries or delays in patient care. Others argue that the most important outcome is patient death or serious morbidity. After the first three papers in this dissertation were published, Bilimoria et $\mathrm{al}^{19}$ released a landmark trial in the United States. The trial compared traditional restricted work hours with more flexible work hour arrangements that allowed general surgery residents to work beyond the established regulations for the sake of continuity of patient care. They demonstrated that more flexible work hour arrangements had noninferior patient outcomes compared to more restrictive duty hour arrangements. ${ }^{19}$ Unfortunately, because the study was designed as a non-inferiority trial, we cannot conclude whether these flexible work hours are in fact safer for patients. Schumacher et al ${ }^{47}$ question whether duty hours are solely responsible for the increasing fragmentation of patient care; they suggest that other issues may be at play, including the block structure of resident rotations. With the complexity of patient care and residency training nowadays, it is proving to be very difficult to unravel the specific impact of altered resident work hours amid the many other aspects of patient care that are constantly shifting.

\section{Can Fatigue Be Managed?}

Recently, the discourse on resident work hours in the Canadian context has shifted away from restrictions to focus on fatigue management plans. ${ }^{48,49}$ The thrust of this new movement is that workplace fatigue may be unavoidable but it can be mitigated and managed, in lieu of prescriptive work hour limits. ${ }^{48}$ Fatigue management plans are embedded within the occupational health and safety systems of many industries outside of medicine, including aviation, military, and the maritimes. ${ }^{25}$ Fatigue-proofing is one component of a fatigue management plan. It involves identifying fatigue-susceptible tasks in the workplace and implementing systems-level changes to alter these risks. ${ }^{25}$ For example, when long-haul pilots self-identify as fatigued, they inform their co-pilot to ensure an earlier preparation for descent and minimize the risk of error from fatigue. ${ }^{25}$ In these contexts, fatigue is seen as a modifiable hazard. 
Part of what makes fatigue management plans effective in other industries is the shared recognition that fatigue is hazardous. However, fatigue may not be so clearly defined within the context of medical training. ${ }^{12}$ It might be entangled with, and perhaps indistinguishable from, other issues of trainee supervision, workload compression and workplace inexperience. ${ }^{12}$ Varied perceptions about fatigue among clinicians and trainees serve to further complicate matters. Sexton et $\mathrm{al}^{50}$ found that $60 \%$ of medical respondents believed their performance during critical times was unaffected by fatigue. Rosen et $\mathrm{al}^{17}$ demonstrated that trainees shared a strong sense of being able to develop a tolerance to sleep deprivation. The latter concept contradicts established principles of sleep deprivation and lacks empirical support. ${ }^{20}$ It is unlikely that we can resolve the debate about whether fatigue in medicine can be managed until we have a better understanding of what we mean by fatigue in this context.

\section{Fatigue Through a Different Lens}

Predominant debates within the literature consider fatigue from an individualistic perspective. They are based on a shared underlying premise that individuals experience physiologic fatigue as a consequence of long working hours and sleep deprivation. As I have outlined above, there is considerable disagreement about how this plays out when a fatigued individual provides patient care while learning to practice medicine.

Another way of thinking about these problems would be to consider fatigue not only a physiologic state but also a social and collective phenomenon. There are glimpses of this perspective in the literature. For example, Puddester points out that the success of fatigue management plans depend upon "a workplace and training environment that encourages and promotes good health, including good sleep." ${ }^{49(p 2)}$ Lopez and Katz acknowledge that physicians are "embedded in a social environment that can either facilitate or hamper their commitment to the professional ideals of medicine."2(p316) By approaching the issue of fatigue from a different perspective, as a collective and social phenomenon, further insights await that would not otherwise be appreciated by a purely individualistic stance.

My thesis ${ }^{1}$ aims to explore fatigue as a social phenomenon. As an extension of this purpose, I explored interventions that are intended to modify fatigue, such as work hour restrictions and fatigue management plans through a similar lens. A more detailed discussion of my social constructivist stance and the impact this had on the chosen methodology for this research is provided in Chapter 2. The specific research questions that comprise this research program are outlined below and followed by a brief summary of each respective chapter.

\footnotetext{
${ }^{1}$ While this thesis was accomplished within a collaborative team, I will use the first person pronoun throughout to acknowledge my final responsibility for the thesis project.
} 


\section{Research Questions}

Research Question \#1

How do residents decide to stay or go following a 24-hour call shift?

We set out to understand how residents decide when to transition from on-duty to off-duty while scheduled for $24 \mathrm{~h}$ shifts. Because we chose to study this phenomenon in the Canadian context, where existing work hour rules are not legislated or consistently enforced, we were able to explore what motivates residents' decisions when they are enacted outside of highly regulated policies. This question is addressed in Chapter 3.

\section{Research Question \#2}

What do residents do when they leave the hospital following a $24 \mathrm{~h}$ call shift, how do they make these decisions and how do they understand them in the context of their own wellbeing?

We were fortunate to emerge from the first study with a rich data set in which participants spoke candidly about their decision-making at the end of a 24-hour call shift. While analyzing the data for the initial study, we appreciated that there were two distinct but related stories to be told. One story captured how residents decide when to transition to off duty, while another story illustrated how residents make this transition. In the second study, we therefore returned to the original data set and proceed with an analysis that sought to understand how residents transition to off-duty. We also explored the relationship between this decision and residents' perceived wellbeing. This question is addressed in Chapter 4.

Research Question \#3

How is fatigue socially constructed in the clinical training environment?

Fatigue featured both explicitly and implicitly in the two previous studies that explored when and how residents transitioned from on-duty to off-duty when working 24-hour shifts. Some residents had indicated that there were certain clinical duties that they would feel more or less comfortable performing if they were fatigued and had chosen to extend their duty period beyond 24 hours. This led us to wonder whether fatigue was more than an individual physiologic state, given that perspectives of risk shifted according to the workplace context. We therefore sought to explore how fatigue is socially constructed within a clinical learning environment without enforced work hour regulations. This question is addressed in Chapter 5 .

Research Question \#4

How are work hour regulations understood in the European context? 
When our earlier research was presented to international audiences, we often heard that trainees in contexts with longstanding work hour regulations did not struggle with issues of setting boundaries between on- and off-duty. There were mixed reports about whether the regulations truly reflected practice patterns. This led us to explore how work hour regulations are understood by sampling medical trainees from four European countries with established regulations. Rather than simply drawing comparisons between Canada and European experiences, we intended to further refine our understanding of the social phenomena at play within our earlier studies. This question is addressed in Chapter 6.

\section{Research Setting and Context}

Because the research comprising my thesis centres on the social learning environment, it is necessary to understand what is happening across the International, National and Local contexts where the research is situated. Salient and contemporary features of each context are described below.

\section{The International Context}

\section{Europe}

Employee safety and wellbeing was the main impetus for legislated work hour regulation, known as the European Working Time Directive (EWTD), which was implemented in $1998 .^{51}$ The Directive stipulates a maximum 48-hour work week and requires a minimum of 11 consecutive hours of rest daily, among other restrictions. ${ }^{52}$ Regulations are now enforced for all workers across the European Union, including medical residents and their consultants. Notably, Denmark is recognized with many years of compliance, the Netherlands has been compliant since 2011 and the United Kingdom only recently began enforcing the directive for medical trainees in 2009..$^{53,54}$ Ireland, on the other hand, has a reputation for poor compliance. Concerns about the EWTD go well beyond issues of compliance and enforcement. Brown et $a^{55}$ suggested that poorly designed, yet EWTD-compliant, work schedules did not solve the problem of trainee exhaustion. Other issues include shifting definitions of what counts towards on-duty versus off-duty hours and disagreement about whether sleeping during a call shift is responsible or a financial burden to the system. ${ }^{56}$

This is certainly a dynamic topic and beginning in 2015, there were two political disruptions of relevance to our research. First, the junior doctors in England's National Health Service (NHS) were engaged in a contract dispute with the UK government, which led to public scrutiny of junior doctors' work hour arrangements. Criticisms of the rejected contract included concerns that it was "an attempt to stretch existing staff over 7 days without increasing spending" and that, "acute specialties with ...arduous out-of-hours demand, such as anesthetics and intensive care, will be hardest hit under the new contract" ${ }^{\text {57(p211) }}$ Matters 
were complicated further when the UK population voted to leave the European Union in June 2016. Many individuals are now speculating that the European Working Time Directive will need to be reformed, given that the existing workforce in the UK will be reduced tremendously. ${ }^{58}$ This political turmoil added another layer of complexity during interviews with UK trainees because of the potential impact on work hour regulation.

\section{United States (U.S.)}

After the highly publicized and tragic death of Ms. Libby Zion, who died of undiagnosed serotonin syndrome in New York State, ${ }^{46,59}$ the Bell Commission was established to address systemic concerns about patient care delivery in U.S. training institutions. Although many recommendations emerged from the Bell Commission related to trainee supervision and patient care volume, New York State focused on imposing work hour regulations for all residents. $^{38,59}$ This was an unprecedented move, given that trainee sleep deprivation was never officially implicated in Ms. Zion's untimely death. ${ }^{38}$ In lieu of state-mandated legislation across the remaining states, training institutions are held to the Accreditation Council for Graduate Medical Education (ACGME) resident work hour regulations. ${ }^{60}$ For example, these regulations include a maximum 80-hour work week averaged over 4 weeks and at least 10 duty-free hours between work periods. ${ }^{53}$ Increasingly restrictive regulations have sparked ongoing debate and inspired resource-intensive studies about whether these policies are safe and necessary or detrimental and ill advised. ${ }^{18,19}$

\section{The Canadian Context}

Unlike the above-mentioned jurisdictions, Canada does not have a national resident work hour policy. Furthermore, the work hours of independent physicians (consultants) remain entirely unregulated. Resident work hours are negotiated between provincial associations of resident representatives and hospital organizations with limited enforcement of these arrangements. Independent physician (non-trainee) work hours remain unregulated. In 2011, an arbitrator in the province of Quebec declared that the standard 24h shifts worked by residents violated the Canadian Charter of Rights and Freedoms, which led the province to restrict residents' in-hospital shifts to $16 \mathrm{~h}^{61}$

In response to this arbitration, the Royal College of Physicians and Surgeons of Canada (RCPSC) created a National Steering Committee to address the issue of resident work hours and fatigue in the Canadian context. The subsequent recommendations did not favour prescriptive restrictions to resident work hours because the committee suggested that, "a tired doctor is not necessarily an unsafe doctor." ${ }^{48(p 28)}$ Instead, the committee advocated for fatigue risk management strategies to address the need for public accountability in defending the tradition of long working hours. Despite this shift in focus, the Canadian Association of Internes and Residents has maintained that all provinces and regions in Canada should "work toward a system that does not require residents to work more than 16 consecutive uninterrupted clinical hours at a time..." ${ }^{62(p 4)}$ Without clear infrastructure for 
accommodating and enforcing this recommendation, there appears to be little appetite for implementing such system-level change.

\section{The Local Context}

Three of the four studies were situated at Western University, a Licentiate of the Medical Council of Canada-accredited medical school, which encompasses three hospitals in London, Canada. Elected provincial resident representatives comprising the Professional Association of Residents of Ontario (PARO) negotiated the existing regulations around resident work hours with the Council of Academic Hospitals of Ontario (CAHO). ${ }^{63}$ According to the contract, residents who complete in-hospital call for 24 consecutive hours should be relieved from clinical duties no later than noon the following day. Residents who were scheduled for outof-hospital call were expected to return for a full working day, unless the shift was converted to an in-hospital shift. The frequency of $24 \mathrm{~h}$ in-hospital shifts was limited to 1 in 4 and the frequency of out-of-hospital shifts was capped at 1 in 3 , as averaged over a $28 \mathrm{~d}$ period. The senior residents generally created the resident call schedule for each program. Without a formal auditing process, it is unclear how these regulations were reinforced and the consequences for violating these regulations were equally ambiguous. Once again, the dynamic nature of work hour regulation meant that a new work contract was negotiated for resident participants in our Canadian studies; however, details around resident call shifts remained unchanged.

Participants had completed their medical school training and were enrolled at various stages of postgraduate training. Most participants had already completed additional rotations outside of their program, which allowed them to comment on a broader range of experiences. When this research began, most residents were aware that the Royal College of Physicians and Surgeons of Canada was reviewing the status of resident work hours across Canada and the assumption was that they would be enforcing regulations similar to the legislated changes in Quebec. As a result, some programs were considering, or already transitioning to, alternative call models; however, participants were asked to reflect on their experiences as they related to the 24-hour call system.

\section{References}

1. Schwartz A, Pappas C, Bashook PG, et al. Conceptual frameworks in the study of duty hours changes in graduate medical education: A review. Acad Med. 2011;86(1):18-29.

2. Lopez L, Katz JT. Perspective: creating an ethical workplace: reverberations of resident work hours reform. Academic medicine : journal of the Association of American Medical Colleges. 2009;84(3):315-319.

3. Sugden C, Housden CR, Aggarwal R, Sahakian BJ, Darzi A. Effect of pharmacological enhancement on the cognitive and clinical psychomotor performance of sleep- 
deprived doctors: a randomized controlled trial. Annals of surgery. 2012;255(2):222227.

4. Ayas NT, Barger LK, Cade BE, et al. Extended work duration and the risk of selfreported percutaneous injuries in interns. JAMA. 2006;296(9):1055-1062.

5. Landrigan $\mathrm{CP}$, Rothschild JM, Cronin JW, et al. Effect of reducing interns' work hours on serious medical errors in intensive care units. The New England journal of medicine. 2004;351(18):1838-1848.

6. Blum $A B$, Raiszadeh $F$, Shea $S$, et al. US public opinion regarding proposed limits on resident physician work hours. BMC medicine. 2010;8:33.

7. Lockley SW, Barger LK, Ayas NT, Rothschild JM, Czeisler Ca, Landrigan CP. Effects of health care provider work hours and sleep deprivation on safety and performance. Joint Commission Journal on Quality and Patient Safety. 2007;33(11 Suppl):7-18.

8. Baldwin DC, Daugherty SR. Sleep deprivation and fatigue in residency training: results of a national survey of first- and second-year residents. Sleep. 2004;27(2):217-223.

9. Veasey S, Rosen R, Barzansky B, Rosen I, Owens J. Sleep loss and fatigue in residency training: a reappraisal. JAMA : the journal of the American Medical Association. 2002;288(9):1116-1124.

10. Howard SK. Sleep deprivation and physician performance: Why should I care? Paper presented at: Baylor University Medical Centre Proceedings; 2005; Dallas.

11. Dorrian J, Lamond N, Dawson D. The ability to self-monitor performance when fatigued. Journal of Sleep Research. 2000;9(2):137-144.

12. Osborne R, Parshuram CS. Delinking resident duty hours from patient safety. $B M C$ Med Educ. 2014;14 Suppl 1:S2.

13. Amirian I, Andersen LT, Rosenberg J, Gögenur I. Laparoscopic skills and cognitive function are not affected in surgeons during a night shift. Journal of surgical education. 2014;71(4):543-550.

14. Stratton A, Furey A, Hogan M. The effect of sleep deprivation on a resident's situational awareness in a trauma scenario. Journal of orthopaedic trauma. 2014;28(7):e160-163.

15. Vinden C, Nash DM, Rangrej J, et al. Complications of Daytime Elective Laparoscopic Cholecystectomies Performed by Surgeons Who Operated the Night Before. JAMA. 2013;310(17):1837-1841.

16. Caldicott CV, Holsapple JW. Training for fitness: reconsidering the 80-hour work week. Perspectives in biology and medicine. 2008;51(1):134-143.

17. Rosen IM, Bellini LM, Shea Ja. Sleep behaviors and attitudes among internal medicine housestaff in a U.S. university-based residency program. Academic medicine : journal of the Association of American Medical Colleges. 2004;79(5):407-416.

18. Parshuram CS, Amaral AC, Ferguson ND, et al. Patient safety, resident well-being and continuity of care with different resident duty schedules in the intensive care unit: a randomized trial. CMAJ. 2015;187(5):321-329. 
19. Bilimoria KY, Chung JW, Hedges LV, et al. National Cluster-Randomized Trial of DutyHour Flexibility in Surgical Training. N Engl J Med. 2016;374(8):713-727.

20. Philibert I. Sleep loss and performance in residents and nonphysicians: a metaanalytic examination. Sleep. 2005;28(11):1392-1402.

21. Owens Ja, Veasey SC, Rosen RC. Physician, heal thyself: sleep, fatigue, and medical education. Sleep. 2001;24(5):493-495.

22. Baldwin DC, Daugherty SR, Ryan PM, Yaghmour Na. What do residents do when not working or sleeping? A multispecialty survey of 36 residency programs. Acad Med. 2012;87(4):395-402.

23. Gander P, Briar C, Garden A, Purnell H, Woodward A. A gender-based analysis of work patterns, fatigue, and work/life balance among physicians in postgraduate training. Academic medicine : journal of the Association of American Medical Colleges. 2010;85(9):1526-1536.

24. Kramer M. Sleep loss in resident physicians: the cause of medical errors? Frontiers in neurology. 2010;1(October):128.

25. Dawson D, Chapman J, Thomas MJ. Fatigue-proofing: a new approach to reducing fatigue-related risk using the principles of error management. Sleep Med Rev. 2012;16(2):167-175.

26. Harrison $\mathrm{Y}$, Horne J. One night of sleep loss impairs innovative thinking and flexible decision making. Organizational Behaviour and Human Decision Processes. 1999;78(2):128-145.

27. Stone MD, Doyle J, Bosch RJ, Bothe A, Steele G. Effect of resident call status on ABSITE performance. Surgery. 2000;128(3):465-471.

28. Antiel RM, Van Arendonk KJ, Reed DA, et al. Surgical training, duty-hour restrictions, and implications for meeting the Accreditation Council for Graduate Medical Education core competencies: views of surgical interns compared with program directors. Archives of Surgery. 2012;147(6):536-541.

29. Ahmed N, Devitt KS, Keshet I, et al. A systematic review of the effects of resident duty hour restrictions in surgery: impact on resident wellness, training, and patient outcomes. Annals of surgery. 2014;259(6):1041-1053.

30. Coverdill JE, Bittner JG, Park MA, Pipkin WL, Mellinger JD. Fatigue as impairment or educational necessity? Insights into surgical culture. Acad Med. 2011;86(10 Suppl):S69-72.

31. Philibert I, Nasca T, Brigham T, Shapiro J. Duty-hour limits and patient care and resident outcomes: can high-quality studies offer insight into complex relationships? Annual review of medicine. 2013;64:467-483.

32. Lindeman BM, Sacks BC, Hirose K, Lipsett PA. Multifaceted longitudinal study of surgical resident education, quality of life, and patient care before and after July 2011. J Surg Educ. 2013;70(6):769-776. 
33. Diachun L, Charise A, Goldszmidt M, Hui Y, Lingard L. Exploring the Realities of Curriculum-by-Random-Opportunity: The Case of Geriatrics on the Internal Medicine Clerkship Rotation. Canadian Geriatrics Journal. 2014;17(4):126.

34. Murphy AA, Halamek LP. Educational Perspectives: Simulation-based Training in Neonatal Resuscitation. NeoReviews. 2005;6(11):e489-e492.

35. Lewis FR, Klingensmith ME. Issues in general surgery residency training-2012. Annals of surgery. 2012;256(4):553-559.

36. Lachance S, Latulippe J-F, Valiquette L, et al. Perceived Effects of the 16-Hour Workday Restriction on Surgical Specialties: Quebec's Experience. Journal of surgical education. 2014;71(5):707-715.

37. Hafferty FW. Duty hours, distant voices, and an alternative future. Archives of Surgery. 2012;147(6):496-497.

38. Green MJ. What (If Anything) Is Wrong with Residency Overwork? Annals of Internal Medicine. 1995;123(7):512-517.

39. Gaba DM, Howard SK. Fatigue among clinicians and the safety of patients. New England Journal of Medicine. 2002;347(16):1249-1255.

40. Coverdill JE, Carbonell AM, Cogbill TH, et al. Professional values, value conflicts, and assessments of the duty-hour restrictions after six years: A multi-institutional study of surgical faculty and residents. American Journal of Surgery. 2011;201(1):16-23.

41. Carpenter RO, Spooner J, Arbogast PG, Tarpley JL, Griffin MR, Lomis KD. Work hours restrictions as an ethical dilemma for residents: A descriptive survey of violation types and frequency. Current surgery. 2006;63(6):448-455.

42. Arora V, Johnson J, Lovinger D, Humphrey H, Meltzer D. Communication failures in patient sign-out and suggestions for improvement: a critical incident analysis. Quality and Safety in Health Care. 2005;14(6):401-407.

43. Arora VM, Reed DA, Fletcher KE. Building continuity in handovers with shorter residency duty hours. BMC Med Educ. 2014;14 Suppl 1:S16.

44. Starmer AJ, Spector ND, Srivastava R, et al. Changes in medical errors after implementation of a handoff program. New England Journal of Medicine. 2014;371(19):1803-1812.

45. Arora VM, Farnan JM, Humphrey HJ. Professionalism in the era of duty hours. JAMA. 2012;308(21):2195-2196.

46. Baldwin K, Namdari S, Donegan D, Kamath AF, Mehta S. Early effects of resident work-hour restrictions on patient safety: a systematic review and plea for improved studies. The Journal of bone and joint surgery American volume. 2011;93(2):e5.

47. Schumacher DJ, Slovin SR, Riebschleger MP, Englander R, Hicks PJ, Carraccio C. Perspective: beyond counting hours: the importance of supervision, professionalism, transitions of care, and workload in residency training. Academic medicine : journal of the Association of American Medical Colleges. 2012;87(7):883-888. 
48. National Steering Committee on Resident Duty H. Fatigue, Risk and Excellence: Towards a Pan-Canadian Consensus on Resident Duty Hours. Ottawa, Ontario: The Royal College of Physicians and Surgeons of Canada; 2013:1-52.

49. Puddester D. Managing and mitigating fatigue in the era of changing resident duty hours. BMC Med Educ. 2014;14 Suppl 1:S3.

50. Sexton JB, Thomas EJ, Helmreich RL. Error, stress, and teamwork in medicine and aviation: cross sectional surveys. Bmj. 2000;320(7237):745-749.

51. Datta ST, Davies SJ. Training for the future NHS: training junior doctors in the United Kingdom within the 48-hour European working time directive. BMC Med Educ. 2014;14 Suppl 1:S12.

52. What is the European Working Time Directive. 2009;

http://webarchive.nationalarchives.gov.uk/+/www.dh.gov.uk/en/Managingyourorga nisation/Workforce/Workforceplanninganddevelopment/Europeanworkingtimedirec tive/DH_077304. Accessed September 19, 2016, 2016.

53. Temple J. Resident duty hours around the globe: where are we now? BMC Med Educ. 2014;14 Suppl 1:S8.

54. MacDonald R. How protective is the working time directive? British medical journal. 2004;329(7461):301-302.

55. Brown M, Tucker $\mathrm{P}$, Rapport $\mathrm{F}$, et al. The impact of shift patterns on junior doctors' perceptions of fatigue, training, work/life balance and the role of social support. Quality \& safety in health care. 2010;19(6):e36.

56. Douglas NJ. Sleep, performance and the European Working Time Directive. Clinical Medicine. 2005;5(2):95-96.

57. Lancet T. Brexit and junior doctors' contracts: the real threats to the NHS. The Lancet. 2016;388(10041):211.

58. Gulland A. What Brexit would mean for employment of doctors. BMJ. 2016;353:i2928.

59. Bell BM. Reconsideration of the New York State Laws Rationalizing the Supervision and the Working Conditions of Residents. Einstein Journal of Biology and Medicine. 2003;20:36-40.

60. Iglehart JK. The ACGME's final duty-hour standards -- Special PGY-1 limits and strategic napping. New England Journal of Medicine. 2010;363(17):1589-1591.

61. Dussault C, Saad N, Carrier J. 16-hour call duty schedules: the Quebec experience. BMC Med Educ. 2014;14 Suppl 1:S10.

62. Masterson MF, Shrichand P, Maniate JM. Resident duty hours in Canada: a survey and national statement. BMC Med Educ. 2014;14 Suppl 1:S9.

63. 2013-2016 PARO-CAHO Agreement. http://www.myparo.ca/Contract/PAROCAHO_Agreement. Accessed September 19, 2016. 
Chapter 2

Reflexivity, Theoretical Framework and Methodology 
This program of research is comprised of four interconnected studies that use a constructivist grounded theory approach to qualitative research. The main data were individual semi-structured interviews with postgraduate trainees. In keeping with my constructivist epistemological stance, I will preface this thesis by positioning myself within this research program and discuss how my insider role as a resident played out in the research. This is a process known as reflexivity, which requires "critical reflection both on the kind of knowledge produced from research and how that knowledge is generated". ${ }^{1 \text { (p274) }}$ Because the researcher is a central influence over every decision made through the course of research, reflexivity is a critical component of a rigour. ${ }^{2}$ It ensures that the reader has a sense of "what and who is represented in a research study". ${ }^{2(p 1000)}$

Once I've positioned myself within the research, I will describe the theoretical frameworks of sociocultural learning and social constructivism that shaped the course of the dissertation. Finally, I will outline the underpinnings of constructivist grounded theory (CGT) research, explain why this was our chosen methodology and elaborate on sampling challenges that are most salient to a rigorous research program.

\section{Reflexivity}

"Our research interests and the research questions we pose, as well as the questions we discard, reveal something about who we are ${ }^{11(p 274)}$

It is no coincidence that I began a research program to explore how residents grapple with issues of fatigue and work hour regulations during my second year as an obstetrics and gynecology resident. At the time, I was routinely working 24- to 27-hour shifts at a highvolume tertiary care centre. There were days when the burden of my exhaustion was both palpable and painful. During grand rounds, I watched sympathetically as my colleagues unsuccessfully fought to keep their eyes open post-call. I often lost the same battle. Once I was released from my duties post-call, I resented my exhaustion as it hindered my full participation in the world outside of the hospital. I felt compelled to make up for lost time, rather than lost sleep. In spite of this, I usually succumbed to sleep and ended up cancelling the litany of plans that I had made in anticipation of my post-call day. I was deeply fascinated by this perplexing pattern and a few informal discussions with colleagues suggested that I was not alone in this experience. And with that, my first few research questions began to take shape.

Meanwhile, I followed the arbitration ruling around resident work hours in Quebec, Canada with great interest. Once the arbitrator decreed that 24-hour shifts violated the Canadian Charter of Rights and Freedoms, many residency programs in other Provinces assumed that national legislation was inevitable. My residency program was no exception. I proposed and helped implement an alternative night float call model that limited continuous duty periods to a maximum of 16 hours in keeping with the arbitration. At the time, I saw this as 
completely separate from my research. I saw myself as less of a champion for duty hour reform but more of an advocate who wanted our program to be prepared for legislated policy.

During this transition to a new call system, I started graduate studies and my clinical training trajectory underwent its own metamorphosis. On paper, this arrangement looked tidy and compartmentalized. Certain months were dedicated to research and these research blocks were interspersed among my core clinical rotations. In reality, the two domains were messy and intertwined. During clinical rotations, I wrote analytical memos whenever I caught glimpses of my research playing out in the clinical environment. For example, one night in the delivery room I overheard the nurses talking about our anesthesia resident. Apparently he had told a laboring patient that he was planning to sleep, so she must decide at that moment if she wanted an epidural. I was struck by how profoundly this offended the nurses and I wondered if this would have been seen as responsible fatigue mitigation in a different context. Access to such moments made me particularly appreciative of my hybrid status as clinical resident and graduate student.

Being a resident positioned me as an insider to the research, particularly within the Canadian context. In many ways, this was an advantage, as it facilitated access to participants and likely enhanced their candidness during individual interviews. ${ }^{3}$ Because I conducted research within my peer group, establishing legitimacy was less of an issue. However, I also grappled with one of the greatest challenges of conducting insider research: I needed to avoid assuming that I already knew the culture. ${ }^{4}$ It required me to dig deeper, beyond what might seem to be shared understandings. After my first few interviews, I realized that I needed to flag this for my resident participants up front. Otherwise, they seemed baffled when I asked them to elaborate on certain colloquialisms or concepts that should have been self-evident to a fellow resident. Fortunately, my co-investigators were more removed from the research setting, which also helped me to see the data from a non-insider perspective. My insider status was also dynamic; it shifted as I transitioned from a junior to senior resident and then became a licensed obstetrician/ gynecologist during the research. The insideroutsider dichotomy was further complicated by the various subcultures within the studied context to which I was an outsider. ${ }^{3}$ Thus, conducting research within my peer group required me to attend to the affordances and challenges of my insider status.

Of course, I am also represented in the research in ways that are unrelated to my status as an insider. My personal experiences and perspectives inevitably shaped the research at every stage, from initial conception to data collection and analysis to manuscript writing. This influence is neither good nor bad; however, it requires thoughtful consideration through reflexivity. I used memo-writing as one way of thinking critically about my role in the research. ${ }^{5}$ While writing memos, I gave myself permission to question everything. This allowed me to identify some of my blind spots and further probe some of my assumptions 
around fatigue and work hours. While conducting the interviews, I tried hard to remain neutral about work hour reform because I wanted the participants to freely share their perspective. When it came to memo-writing, however, I did not impose the same neutrality but instead I tried to maintain a curious skepticism about my own perspective (Memo: December 2014). When I began this research, I believed that Canada was foolish for not having work hour restrictions. Looking back through the memos, it's apparent that my stance on work hours has been complicated and transformed by the research. For example, in "Memo: October 15, 2012", I maintained a straightforward stance about what it meant to abide by work hour regulation, but in "Memo: August 27, 2016", I'm starting to consider the complexity of this issue. I see this as further evidence of my willingness to remain open and receptive to other truths without denying my "catalytic influence" over the research process. $^{2(p 1004)}$

Memo: October 15, 2012

I find it interesting that "shift-work mentality" is considered such a pejorative term. To me, a physician who is able to clearly delineate between work-life and home-life, uses his or her time at work to its fullest. Our profession attracts "the cream of the crop" in that we are collectively a highly motivated, innovative and intelligent group. However, we are notoriously poor at gaging our own limitations and accepting our shortcomings. The shift-worker, then, represents a new breed of physician who acknowledges that we are unable to self-assess the affects of fatigue on performance and learning. By accepting this truth, the physician places patient safety ahead of their personal educational agenda or financial gain, thereby embodying a standard of professionalism not widely role-modeled in medicine. However, it is this same individual who will be criticized for leaving work on time...

Memo: May 6, 2014

At times, I've noticed the participants tiptoe around the "patient safety" elephant in the room ... in the more recent transcripts I am really hesitant to call out this elephant in the room by being explicit about the patient safety factor. Mostly I think this is because this is a loaded term and feels a bit threatening because essentially I want to know/ask, "have you ever considered the impact of your decision on patient safety?' which may come across as a criticism or indictment for residents whose predominant discourse around work and work hours seems to exclude the patient safety factor. I also recognize that it's a nebulous concept ... I also don't want to injure the rapport that I work hard to build in residents who are particularly explicit about the educational value of working long hours (since these are the ones who are least likely to lead in with details about the implications on patient safety but I suspect are most likely to become defensive if the question is raised) 
I'm also aware of this personal tension that exists as I struggle to decide how to represent my participants without suggesting that they are hypocrites or completely uncritical about the nuances of fatigue in their working environment. I want to avoid this on a personal level because they are colleagues but I also believe this to be a very superficial interpretation of a more complicated issue. There are many cases in which I perceived inconsistencies in how residents described the experience of fatigue and subsequently dismissed harmful notions associated with that experience, when it suited their 'hero narrative'. I'm also aware that these are only inconsistencies because that fits with my belief that the potential for harm still exists, whether we deny it or not. I want to remain attuned to my own perceptions on this issue, because it has the possibility to prevent me from seeing other things in the data.

[This memo led me to return to the data and re-analyze from the perspective that fatigue is not inherently dangerous]

Memo: August 27, 2016

I want to believe there are deviant examples and cases that would show duty hours are not all bad and it's possible to have it all - to be passionate about what you do, find work fulfilling, not have to deny your own humanity and vulnerability/personal limits in order to fulfill the social contract with the patients and system at large.

This might also explain why these entities (contradictions) are sustained and why there may be little attention paid to information in the working environment that suggests something to the contrary/challenges these notions... why they go unchallenged (e.g. fatigue is dangerous to patients - can't make meaning of this in the context of 'do no harm' credo. The two thoughts are incompatible - that something we don't have control over could harm the patient. So we reconcile it by either assuming we have control over it, or self-confirming that it isn't dangerous to patients!!!

\section{Sociocultural Perspective}

In the first chapter of this thesis, I reviewed the research on the topic of duty hour restrictions and highlighted a lack of sociocultural perspectives in the literature. This gap in the current perspectives resonated with my own experiences coming into this research. Rather than focusing on the individual experience of fatigue and personal implications of work hour practices, I took a sociocultural orientation to this research. In doing so, I focused on the social and cultural dynamics of the learning environment to sharpen our understanding of resident decision-making around work hours, boundary-setting between on- and off-duty, and fatigue. 
Sociocultural perspectives in medical education envision learning as a social process of participation and engagement within a learning environment. ${ }^{6}$ This participation is enabled by a full spectrum of formal and informal processes. For medical residents, this might include attending orientation sessions, wearing scrubs and an ID badge, being buddied with a senior colleague, watching a case presentation, or socializing during coffee breaks. This participation "shapes not only what we do, but also who we are and how we interpret what we do". 7 (p211) By using a sociocultural lens in this research, issues of social norms, political forces, power dynamics, and invoked values were foregrounded in the analysis and resulting theory.

In taking a sociocultural orientation to this research, I am positioning myself as part of a contemporary movement in medical education. ${ }^{8-10}$ Until recently, individualistic perspectives have dominated medical education. ${ }^{11}$ The persistence of such perspectives is not surprising given that they align with espoused values in the medical profession such as autonomy and self-regulation. ${ }^{6}$ This sociocultural turn challenges individualistic theoretical perspectives about learning and provides a useful way of grappling with socially situated questions.

\section{Social Constructivism}

Social constructivism provides a complementary theoretical framework to the sociocultural perspective I brought to this research. Constructivism attends to the subjective knowledge that is generated between the participant and the researcher. It rejects the notion that truth is an objective reality waiting to be exposed by the researcher who asks the right question or finds the ideal informant. Instead, constructivism accepts that the researcher and participants are both situated within the research and engaged in co-creating what can be known. ${ }^{5}$ By extension, social constructivism examines the reality that is established and reinforced through participation in the sociocultural environment. ${ }^{12}$

In seeking to understand how a phenomenon is socially constructed, one must explore shared realities and truths that have become reified over time. ${ }^{12}$ These social constructions are of critical importance because they become "a powerful force in support of maintaining the status quo". 12 (paragraphk SectionB) Using this theoretical framework brought into focus the explicit and implicit forces that maintained the status quo related to fatigue and work hour policy within the clinical learning environment

\section{Methodological Framework}

In line with the sociocultural and social constructivist starting points in this thesis, the methodological approach throughout our research was Constructivist Grounded Theory (CGT). Grounded theory emerged in the 1960 s as a qualitative research methodology that is well suited for grappling with socially-oriented research questions that are insufficiently explained by existing theory. Glaser and Strauss ${ }^{13}$ carved out a new space for researchers 
who felt constrained by the predominant focus on verification of theory and instead sought to generate explanatory theory from data. Their approach to grounded theory is notoriously systematic and rooted in a desire to ensure that theory generation is deemed a "legitimate enterprise". 13 (purposes of this book,paragraph2)

Comparative analysis is a defining aspect of grounded theory. ${ }^{13}$ Glaser and Strauss were quick to clarify what makes comparative analysis in grounded theory different than other logico-deductive approaches to theory generation and verification. Specifically, they emphasize that comparison for the sole purpose of establishing generalizations, validating data, specifying units of analysis, or disproving theory detracts from the ultimate goal of generating theory. The process of iterative data collection and analysis is another cornerstone of grounded theory, which supports constant comparative analysis. This nonlinear approach permits researchers to seek out different informants or alter subsequent interview questions in response to the emergent theory.

The positivist epistemological stance inherent in Glaser and Strauss' approach to grounded theory did not resonate with all social scientists. This inspired other versions of grounded theory, including constructivist grounded theory (CGT), which "adopts the inductive, comparative, emergent and open-ended approach of Glaser and Strauss' (1967) original statement." 5 (p12) Unlike the earlier representations of grounded theory, however, CGT both acknowledges and accepts that the researcher is necessarily positioned within the work. ${ }^{5}$ This acknowledgement is purposeful, as it sets an expectation for the researcher to remain reflexive about their role in shaping the research. ${ }^{5}$

\section{Justification for chosen methodology}

We chose CGT as our methodology because our research questions were socially situated. Rather than a mere descriptions of events, we were interested in the social forces at play while residents make post-call decisions and conceptualize the fatigue they experience during training. Furthermore, based on our review of the literature, there had been very little exploration of the questions we were poised to ask and therefore minimal preexisting theory. As a resident enrolled in the same institution as the Canadian participants, I maintained an insider role in the research setting for the first 3 studies, which I outlined above in the Reflexivity section. Fortunately, constructivist approaches to grounded theory consider every researcher an insider to some degree. Embracing my insider status certainly felt more authentic than an approach that would require me to set aside the perspectives I bring to the research.

Finally, the interconnected nature of these four research studies is no coincidence. Because we took a constructivist grounded theory approach to this research, each study intentionally builds upon the insights gained from the previous study. It meant that our research 
questions were informed by preceding studies, which also influenced how our sampling shifted where applicable.

\section{Theoretical Sampling and Theoretical Sufficiency}

Theoretical sampling and sampling to sufficiency are two closely related issues of rigour in CGT that we grappled with during the course of this research. Before I explain how we negotiated these issues, I'll explain their significance.

All CGT research begins with initial sampling that is both selective and purposive. ${ }^{5}$ This sampling approach seeks out participants who are well-spoken, thoughtful and open to sharing their experiences. ${ }^{14}$ Predetermined inclusion and exclusion criteria are also taken into account. The iterative process of data collection and analysis in CGT facilitates a shift from initial purposive sampling to theoretical sampling based on the emerging codes and theory. ${ }^{14}$ Unlike initial sampling, theoretical sampling is not determined a priori; instead it takes its cue from the ongoing analysis. ${ }^{5}$ As the study evolves, revisions to the interview guide serve to complement theoretical sampling strategies. ${ }^{14}$ Revisions may include removing, re-phrasing, or adding new questions based on how they relate to the emerging codes and categories. Revising the interview guide and proceeding with theoretical sampling allows the investigator to focus on the most salient emerging codes from multiple angles. ${ }^{5}$ Charmaz ${ }^{5}$ cautions that theoretical sampling is not intended to create generalizability, but rather it is intended to ensure a more in-depth, cohesive theory that remains grounded in the data.

Not only does theoretical sampling lead to a more detailed capture of the phenomenon in question but it is also the most efficient way to reach theoretical saturation. ${ }^{15}$ Theoretical saturation is reached when "fresh data no longer sparks new theoretical insights". ${ }^{5 \text { (p213) }}$ Of course, this precludes a priori estimation of sample size. However, Morse ${ }^{15}$ is quick to point out that saturation is not an issue of quantity. A category or code may reach theoretical saturation from a single, richly descriptive instance within the data. ${ }^{15}$ Dey $^{16}$ takes issue with the sense of completeness and certainty implied by theoretical saturation. He offers theoretical sufficiency as an alternative, which he defines as the "stage at which categories seem to cope adequately with new data without requiring continued extensions and modifications". 16 (p117)

For each study, our purposive sampling involved recruiting postgraduate trainees of both genders, from a range of clinical programs and training level. Our research question dictated the inclusion criteria; we limited recruitment to willing, English-speaking medical residents. As analysis progressed, we refined our sampling strategy and interview guide to ensure we were seeking informants and asking questions that would help to further the emerging theory. For the first two studies, we conducted individual semi-structured interviews with residents across 6 disciplines (general surgery, internal medicine, pediatrics, urology, 
orthopedic surgery, and obstetrics/gynecology) enrolled at a single training institution in Canada. All residents were routinely scheduled to work 24-hour shifts, as this was critical to our research question. The third study involved a theoretically-informed sampling of residents from psychiatry, radiology and critical care, in addition to residents from pediatrics, internal medicine, general surgery, and orthopedic surgery. These residents were enrolled at the same institution as in the previous studies. Residents from the three additional disciplines were sought after because of the unique nature of their on-call responsibilities. This led to a more inclusive understanding of how social constructs of fatigue play out in different clinical contexts with varied clinical demands. In our fourth study, we wanted to explore how work hour regulations influence the social construct of fatigue. Thus we sought out participants who were training in contexts with established work hour regulations to which both residents and their supervisors are supposedly held.

\section{References}

1. Guillemin M, Gillam L. Ethics, reflexivity, and "ethically important moments" in research. Qualitative inquiry. 2004;10(2):261-280.

2. Mantzoukas S. Issues of representation within qualitative inquiry. Qualitative health research. 2004;14(7):994-1007.

3. Dwyer SC. The space between: On being an insider-outsider in qualitative research. International Journal of Qualitative Methods. 2009;8(1):54-63.

4. Asselin ME. Insider research: Issues to consider when doing qualitative research in your own setting. Journal for Nurses in Professional Development. 2003;19(2):99-103.

5. Charmaz K. Constructing grounded theory. Sage; 2014. Kindle ed.

6. Mann KV. Theoretical perspectives in medical education: past experience and future possibilities. Med Educ. 2011;45(1):60-68.

7. Wenger E. A social theory of learning. Contemporary theories of learning. 2009:209218.

8. Van der Zwet J, Zwietering P, Teunissen P, Van Der Vleuten C, Scherpbier A. Workplace learning from a socio-cultural perspective: creating developmental space during the general practice clerkship. Advances in Health Sciences Education. 2011;16(3):359-373.

9. Watling C. Tackling medical student stress: beyond individual resilience. Perspectives on medical education. 2015;4(3):105.

10. Vanstone M, Watling C, Goldszmidt M, Weijer C, Lingard L. Resigned professionalism? Non-acute inpatients and resident education. Advances in Health Sciences Education. 2014;19(4):529-539.

11. Swanwick T. Informal learning in postgraduate medical education: from cognitivism to 'culturism'. Medical education. 2005;39(8):859-865.

12. Lincoln YS, Guba EG. The constructivist credo. Left Coast Press; 2013. Kindle ed. 
13. Glaser BG, Strauss AL. The Discovery of Grounded Theory: Strategies for Qualitative Research. Vol reprint. New Brunswick, USA: Transaction Publishers; 2009. Kindle ed.

14. Coyne IT. Sampling in qualitative research. Purposeful and theoretical sampling; merging or clear boundaries? Journal of advanced nursing. 1997;26(3):623-630.

15. Morse JM. The Significance of Saturation. Qualitative Health Research. 1995;5(2):147149.

16. Dey I. Grounding grounded theory: Guidelines for qualitative inquiry. Academic Press; 1999. 


\section{Chapter 3}

To Stay or Not to Stay? A Grounded Theory Study of Residents' Postcall Behaviors and Their Rationalizations for Those Behaviors

Published as:

Taylor TS, Nisker J, Lingard L. To stay or not to stay? A grounded theory study of residents' postcall behaviors and their rationalizations for those behaviors. Academic Medicine. 2013 Oct;88(10):1529-33. 


\begin{abstract}
Purpose

While policies to restrict residents' duty hours are pervasive, resident adherence to restricted duty hours has proved challenging. The authors sought to describe residents' postcall behaviors and understand the dominant rationalizations underpinning their decisions to stay or not to stay after a 24-hour shift.
\end{abstract}

\title{
Methods
}

Using constructivist grounded theory methodology, the authors conducted semi-structured interviews with 24 residents across six surgical and non-surgical specialty programs at one Canadian institution during 2012. They analyzed transcripts iteratively using a constant comparative method of identifying and refining key themes as the data set accrued, and theoretically sampling until theme saturation.

\section{Results}

Abiding by cultural norms was the dominant rationalization for both choosing to continue to work post call or to go home. Cutting across this dominant theme were three subcategories (infrastructure, invoking values, and negotiating tension) with a pattern of residents invoking similar values of patient safety and education regardless of the cultural norms of their program, the infrastructure within which they worked, or the tensions they were navigating.

\section{Conclusions}

While central to residents' rationalizations, values appear to be versatile, amenable to multiple, even conflicting, applications. Residents perceived that they were upholding the values of patient safety and education regardless of which post-call behavior they chosestaying or going. Based on this, for duty hour reform initiatives to be successful, a shift to emphasizing organizational changes will be required to reduce the circumstances in which post-call behavior is an individual, values-based decision. 


\section{Introduction}

Duty hour reform is predicated on the assumption that working fewer consecutive hours will result in more and better-quality sleep hours, which will yield residents who will provide safer patient care. ${ }^{1-3}$ Existing research is focused primarily on interventions and outcomes related to residents' on-duty experiences; results of these studies are conflicting, and have been used variably to justify or criticize duty-hour reform. ${ }^{2,4-8}$ With very little research into what residents actually do post-call and how they decide what to do, we do not know what influences residents' decisions about their post-call time. Consequently, it is unclear whether post-call behaviors are particularly entrenched, or what educational or organizational strategies might be implemented to influence them. The lack of such insight is a critical gap in the literature, as researchers have recently found that residents were unlikely to change or improve their sleep habits based solely on an educational intervention to improve their knowledge of sleep physiology principles. ${ }^{9}$ This result begs the ubiquitous knowledge translation question: if improved knowledge is not influential in changing residents' behavior, then what would be?

Answering this question requires research that explores not only what residents decide to do post-call, but also how they understand these decisions. This knowledge is necessary to inform policy regarding residents' duty hour restrictions; without it, policy risks being irrelevant and failing in its goal to optimize residents' well being, competency and patients' safety.

This study sought to describe residents' post-call behaviors and to understand the dominant rationalizations that residents offered to justify their decisions to continue to work or leave the hospital.

\section{Methods}

We used a constructivist grounded theory approach, to acknowledge the socially situated nature of the studied phenomenon, and the researcher's insider role in shaping the resulting theory. ${ }^{10-12}$ Health Sciences Research Ethics Board approval was obtained for the study at the study institution.

We recruited 24 residents from a single Canadian institution, representing both sexes, all training years, and 6 specialties: general surgery (GS), obstetrics and gynecology (OB), orthopedic surgery (OS), urology (UR), pediatrics (PD) and internal medicine (IM). Participants worked clinically at three affiliated hospitals. Initially, purposive and convenience sampling included a balance of surgical and non-surgical residents with comparable frequency of 24-hour call shifts. Theoretical sampling supported further development of concepts as iterative analysis proceeded. ${ }^{10}$ We determined sample 
adequacy by continuing data collection until saturation was achieved and no new theoretical insights were emerging. ${ }^{13}$

One of us (TT) conducted individual semi-structured interviews with participants. As a resident in one of the sampled programs, she knew some participants and was introduced to others as a fellow resident conducting master's research. Interviews were audio-taped and transcribed verbatim. Data analysis using NVivo proceeded iteratively, alongside data collection. ${ }^{10}$ All three of us held joint discussions throughout the analysis to refine emerging concepts, guide theoretical sampling and develop new interview prompts as necessary. We conducted a member check to confirm resonance of findings and refine key themes.

\section{Results}

The richest and most animated part of the interview discussions was not residents' descriptions of their post-call behaviors, but their rationalizations of why they chose these behaviors. Using representative quotations from both surgical and non-surgical participants, we describe this finding in detail in this section.

Abiding by cultural norms characterizes the dominant rationalization that residents offered to justify their decisions. We defined cultural norms as shared post-call expectations of the postgraduate training environment, which were understood by residents through explicit messages (e.g., enforced rules) or tacit (e.g., role-modeling or organizational structures) ones. This dominant rationalization cut across nearly all of the reported staying or going behaviors in our data set and, therefore, offers insight into how residents decided to act regardless of their particular actions. Abiding by cultural norms included three thematic subcategories: infrastructure, invoking values, and negotiating tension. Each of these is defined and illustrated with examples cited by resident participant code.

\section{Infrastructure}

The infrastructure subtheme highlights the organizational elements of the clinical or educational environment that implicitly reinforced and reproduced cultural norms. Team structure was referenced recurrently in the interviews. A relay-team structure, with routines that clearly delineated the beginning and end of duty, supported residents in going home post-call: "... all you need to do is hand-over...before you leave. If there's consults that need to be called in or anything like that, as soon as 8:30 hits, it's not your responsibility anymore." (R007). When teams did not have the "adequate redundancy in manpower" (R006) to permit a simple passing of the baton, the manpower arrangement created a cultural norm of team obligation to stay post-call: 
So, even if you're up operating all night, you're kind of expected/needed the following day... you need to round on your patients, give your team something to do, come up with a plan for the day, and then either operate, scope, help run clinics. (R003)

Organizational characteristics of the educational environment also reinforced post-call cultural norms. When privileged learning opportunities were reserved for more senior trainees, going home was felt to negatively affect a resident's education:

You only get a limited two-year span, as a senior, to really learn how to operate. Certainly, the impression I get from the current seniors is that they want to be there because this is all they get, training-wise and surgically, so they want to be there for every minute that they can. (R004)

Thus, team structures and perceived limitation of available learning opportunities had a substantial impact on how residents rationalized their enactment of post-call cultural norms.

\section{Invoking values}

Cultural norms are predicated on core values, which residents recurrently invoked as they reflected on their post-call decisions. Where the cultural norm was to go home, residents invoked the value of patient safety to rationalize their behavior. Going home, these residents argued, minimized the potentially negative impact of sleep deprivation on their clinical performance and patient care. Accordingly, perceptions of inherent risk meant that the choice to stay and provide patient care while post-call was deemed indefensible:

I just don't see how it's safe and don't see how you can defend, like, I just wouldn't be able to live with myself if I thought that I had made an error or missed something because I chose to work post-call, when it's not my patient's fault that I had been up all night. (R005)

Yet residents abiding by a cultural norm to stay post-call justified their decision by invoking the value of educational opportunities, which was offered by the chance to expand their clinical repertoire through extended work hours. Time spent outside of the hospital meant educational opportunities were irrevocably lost. As one resident succinctly put it:

The educational incentive is huge. For example, tonight I'll probably end up being awake for more than an hour after midnight. Realistically, l'll get a few hours of sleep, but if I don't go to work tomorrow, then I'm going to miss out on an entire operating day. Those are cases I don't get to do. I'm never going to get to do those cases again. (R021) 
The values of educational opportunity and patient safety were present, but invoked differently, in programs regardless of whether the cultural norm was to stay or go post-call. For instance, the value of educational opportunity was also recognized by residents abiding by the cultural norm of going home post-call; however, it was invoked to argue that their fatigue-related impairment would preclude any valuable learning during the post-call period and possibly well afterwards:

I know that for me, when I was post-call I was completely ineffective anyway, so staying would not be a learning opportunity, it would just be an opportunity not to rest and then you wouldn't be efficient the following day. (R002)

For residents rationalizing the decision to stay post-call, the value of educational opportunity had another dimension. In addition to improving clinical skills and knowledge, residents asserted that long-working hours were educationally necessary to prepare them for the realities of practice, including sleep deprivation:

...it's one of those things where you learn in residency to function off little sleep, and you apply it for those rare circumstances where you're staff and you're up all night dealing with something. (R001)

\section{Negotiating tension}

A number of tensions were evident in residents' rationalizations of whether to stay or go post-call. Tensions arose in three distinct situations: (1) when cultural norms conflicted with local institutional post-call policy, (2) when cultural values were in question, (3) and when cultural norms were in flux. This sub-theme, negotiating tension, captures these tensions and how residents accommodated them in their thinking.

In circumstances where the cultural norm to stay conflicted with explicit local duty hour policies, residents defended an unwavering dedication to stay based on the value of educational opportunity:

Learning how to do procedural skills... is a very difficult thing, and I think you appreciate that more and more the more you actually learn because you realize it takes a lot of time and effort. To sit there and turn down a whole day of operating, I know personally, is something I don't think I'll ever do...People who are making these policies, I don't know if they actually get what's involved in training to do a procedure. (R001)

Not only does the value of educational opportunity support the cultural norm of staying, but, as this resident implied, anyone who doesn't recognize this simply hasn't learned enough to realize, or doesn't "actually get what's involved" (R001). Those inside the culture know; those outside do not. 
However, not all residents who stayed post-call fully endorsed the value of educational opportunity to justify their decision. They expressed skepticism about the educational benefit of staying post-call and reservations about the effect on patient care. Yet these residents still chose to abide by cultural norms because to do otherwise would not "look good" (R018):

And then, I know myself, I'm terrified of making a mistake ... when I'm post-call. And I'll never know... would I have made that mistake on a regular day, or did I make that just because I was too tired and I was being careless? ... I mean, I've been asked to do an operation and I've said no before because I was too tired. I said I would happily retract but there is no way that I'm going to operate. So, again, a total waste of a day operating, so not improving skills, just being a human retractor. (R018)

Residents experiencing a tension with the cultural norms of their context sometimes invoked values in unexpected ways to rationalize abiding by these norms. For example, the resident quoted below justified his decision to stay post-call based on the anticipated benefit for future patients:

You have to think to yourself, in these five years, if I do less call and am constrained to how many hours I do, am I going to be a competent surgeon when I come out? That's the real question. Not how safe the patients are when you're in a teaching hospital but how safe the patients are when you're outside. And I don't think you're going to be a safe surgeon unless you operate enough. (R019)

This rationalization, in which the safety of current patients is weighed against that of future patients, is in stark contrast to the rationalization of residents who invoke the value of patient safety in favor of going home post-call. As the resident quoted below asserted, no amount of perceived risk to current patients was considered tolerable:

The patient should come first. Yes, we're here to be educated, but we're not here to be educated at the expense of others. Especially not people who trust us and are counting on us to make the right decisions and to think things through well. (R023)

Tensions also arose when residents belonged to a culture in flux. A recent change in local post-call policy meant that some junior residents abided by cultural norms contrary to the practices of their consultants and senior colleagues. Staying post-call was the predominant cultural norm modeled by consultants in these situations, which provoked residents to consider their future work hours. Many voiced intentions to work post-call as staff, regardless of their current cultural norms as residents. Furthermore, some residents were able to imagine a different future post-call behavior while continuing to uphold the value 
that supported their current post-call behavior. Referencing the value of patient safety, the resident quoted below rationalized why working post-call might be reasonable in the future:

The volume of what is expected of me when I am on call will be much less, and that is my preference compared to this type of a system. It will be 24-hour call and I will not necessarily have the following day off, but I think it will be few and far between that I'm actually up all night and then expected to work the following day. (R008)

\section{Discussion}

Our study was designed to explore how residents spend their post-call day and why they make these choices-what Coverdil et al ${ }^{14,15}$ characterized as the "stay or go dilemma" for residents. Our results highlight residents' rationale of abiding by cultural norms to support their inclinations to stay or go home post-call. Intriguingly, the same values of patient safety and education were used to support opposite behaviors.

Others have recognized that the post-call stay or go decision offers insight into residents' professional values. ${ }^{14,15}$ Our multi-program study confirms this finding previously described only in general surgery residents ${ }^{14,15}$. Our unique contribution is the finding that residents perceive that they are demonstrating a commitment to patient safety and their education regardless of which post-call behavior they advocate-staying or going. As others have described, in situations where value conflict may potentially arise between two equally important values, individuals often remedy this tension by reasoning that the values are intimately linked. ${ }^{16}$ In this case, for residents who stay, educational value is seen as an instrumental value that is a means to achieving a terminal value of patient safety. This strategic application of professional values is a critically important insight, as it calls into question the dominant rhetoric underpinning duty hour reform initiatives: the invocation of, in most cases, a single benefit of restricted duty hours: patient safety. ${ }^{9,17-20}$

Current rhetoric around duty hour reform tends to imply that there is one right culture to which all residents and training programs should aspire. As evidenced in our study, however, a simple right or wrong characterization does not ring true for residents when the same professional values can be-and are-used to justify opposing cultural norms. While many have called for a shift in professional attitudes and values about sleep and work hours to facilitate duty hour reform, ${ }^{9,17-19}$ our results underscore Arora et al's caution that "old values do not simply die in a new system." ${ }^{17}$ Not only do values not die, but their persistence in both post-call cultures suggests there is something more at play. Previous studies indicate that, while individuals may regard similar values as important, it is the relevance an individual assigns to a given value that defines that individual's attitudes and subsequent behaviours. ${ }^{16}$ This suggests, for example, that residents who rationalized their decision to stay based on the value of educational opportunity may have felt that the value of patient 
safety was no less important, but simply less relevant to their actions. Thus, while initiatives focused on redefining residents' values are unlikely to result in behavioral change, interventions that eliminate the need for residents to determine the relevance of particular values in the stay or go dilemma may lead to greater duty hour compliance.

Our findings may help to explain the disappointing results of recent duty hour initiatives. For instance, a previous educational intervention sought to teach residents about the impact of sleep deprivation and fatigue on performance, with negligible impact on residents' off-duty sleeping habits. ${ }^{9}$ Our findings suggest why this and other similar interventions may prove ineffective; knowledge-based facts are easily accommodated by residents who believe them to be irrelevant to themselves or to the values they choose to uphold. Similarly, initiatives to change attitudes, for which many have advocated, ${ }^{17,19,21}$ may fail because they rely on an appeal to values that tacitly assumes such values are stable entities. In contrast to this assumption, our findings suggest that values are versatile, and therefore amenable to multiple applications and shifting perceptions of relevance. Finally, the creation of more stringent guidelines and punitive measures ${ }^{22}$ is unlikely to optimize duty hour compliance, since residents may feel that values of professional autonomy, education and patient safety are more relevant to their attitudes about duty hours than the value of abiding by policy.

We suggest that it might be productive to refocus our efforts away from individual residents having the right values or making the right post-call decisions, and towards removing the stay or go burden from residents' shoulders. Changes to program curricula, team organization, and infrastructure would be instrumental towards such an end; for instance, offering off-duty procedural simulation skills training may help with the problem of residents feeling forced to choose between abiding by policy and obtaining valuable training opportunities. As well, relay team structures may better allow residents to leave the hospital post-call without fears of compromising patient care. Given that residents are unable to accurately self-assess their fitness for duty when faced with the stay or go decision, ${ }^{19,23,24}$ we may even need to consider more extreme infrastructural changes, such as electronic monitoring with swipe cards, to restrict access to active patient care areas beyond duty hour limits. While such changes would conflict with strongly held values of physician autonomy and self-regulation, they should at least be debated in light of the pitfalls of a values-based approach to self-regulation suggested by our findings.

There are inherent limitations in drawing conclusions based on residents' post-hoc rationalizations. However, we believe these data provide useful insights into how residents understand their own decisions in context, and our member check suggested that our findings authentically represented the thinking that happens in stay or go dilemmas. We attempted to minimize any program-specific influences by sampling from six residency programs across three hospital settings; however, our results are likely influenced by the culture of the overarching institution in which all participants were enrolled. Future research 
will need to determine the transferability of our findings to other institutional settings. We deliberately chose a resident as the interviewer due to the anticipated benefit of encouraging participants to speak freely with one of their own. ${ }^{25}$ Although we recognized the potential for her to introduce her own perspective into the interviews and the analysis, our constructivist grounded theory methodology affords strategies for accounting for this influence, such as the inclusion of other analytical perspectives in the analysis. ${ }^{26}$ Researcher reflexivity, another grounded theory technique, involves the creation of memos and field notes that allow the researcher to engage in continuous self-awareness and acknowledgement of his or her role in co-constructing the emerging theory. ${ }^{26}$

\section{Conclusions}

Cultural norms strongly influence how residents enact shared professional values such as patient safety and education in their post-call decisions. These values appear to be versatile and amenable to multiple, even conflicting applications. Thus, we suggest that for duty hour reform initiatives to be successful, the current values-based rhetoric may need to shift in favor of organizational changes that reduce the circumstances in which post-call behavior is an individual, values-based decision.

\section{References}

1. Baldwin DC, Jr, Daugherty SR, Tsai R, Scotti MJ, Jr. A national survey of residents' selfreported work hours: Thinking beyond specialty. Acad Med. 2003;78:1154-1163.

2. Landrigan $\mathrm{CP}$, Rothschild JM, Cronin JW, et al. Effect of reducing interns' work hours on serious medical errors in intensive care units. N Engl J Med. 2004;351:1838-1848.

3. Lockley SW, Landrigan CP, Barger LK, Czeisler CA; Harvard Work Hours Health and Safety Group. When policy meets physiology: The challenge of reducing resident work hours. Clin Orthop Relat Res. 2006;449:116-127.

4. Ayas NT, Barger LK, Cade BE, et al. Extended work duration and the risk of selfreported percutaneous injuries in interns. JAMA. 2006;296:1055-1062.

5. Barger LK, Cade BE, Ayas NT, et al. Extended work shifts and the risk of motor vehicle crashes among interns. N Engl J Med. 2005;352:125-134.

6. Richardson GS, Wyatt JK, Sullivan JP, et al. Objective assessment of sleep and alertness in medical house staff and the impact of protected time for sleep. Sleep. 1996;19:718-726.

7. Schwartz A, Pappas C, Bashook PG, et al. Conceptual frameworks in the study of duty hours changes in graduate medical education: A review. Acad Med. 2011;86:18-29.

8. Hegar MV, Truitt MS, Mangram AJ, Dunn EL. Resident fatigue in 2010: Where is the beef? Am J Surg. 2011;202:727-731; discussion 731-732. 
9. Arora VM, Georgitis E, Woodruff JN, Humphrey HJ, Meltzer D. Improving sleep hygiene of medical interns: Can the sleep, alertness, and fatigue education in residency program help? Arch Intern Med. 2007;167:1738-1744.

10. Charmaz K. Constructing grounded theory: A Practical Guide Through Qualitative Analysis. 1st ed. Thousand Oaks, CA: Sage; 2006.

11. Straus A., Corbin J. Basics of Qualitative Research: Grounded Theory Procedures and Techniques. Thousand Oaks, CA: Sage; 1990.

12. Watling CJ, Lingard L. Grounded theory in medical education research: AMEE guide no. 70. Med Teach. 2012;34:850-861.

13. Morse JM. The significance of saturation. Qual Health Res. 1995;5:147-149.

14. Coverdill JE, Carbonell AM, Cogbill TH, et al. Professional values, value conflicts, and assessments of the duty-hour restrictions after six years: A multi-institutional study of surgical faculty and residents. Am J Surg. 2011;201:16-23.

15. Coverdill JE, Carbonell AM, Fryer J, et al. A new professionalism? Surgical residents, duty hours restrictions, and shift transitions. Acad Med. 2010;85(10 Suppl):S72-S75.

16. Kristiansen CM, Zanna MP. The rhetorical use of values to justify social and intergroup attitudes. J Soc Iss. 1994;50:47-65.

17. Arora VM, Farnan JM, Humphrey HJ. Professionalism in the era of duty hours: Time for a shift change? JAMA. 2012;308:2195-2196.

18. Coverdill JE, Bittner JG, Park MA, Pipkin WL, Mellinger JD. Fatigue as impairment or educational necessity? Insights into surgical culture. Acad Med. 2011;86(10 Suppl):S69-S72.

19. Papp KK, Stoller EP, Sage P, et al. The effects of sleep loss and fatigue on residentphysicians: A multi-institutional, mixed-method study. Acad Med. 2004;79:394-406.

20. Carpenter RO, Spooner J, Arbogast PG, Tarpley JL, Griffin MR, Lomis KD. Work hours restrictions as an ethical dilemma for residents: A descriptive survey of violation types and frequency. Curr Surg. 2006;63:448-455.

21. Rosenbaum JR. Can residents be professional in 80 or fewer hours a week? Am J Med. 2004;117:846-850.

22. Iglehart JK. The ACGME's final duty-hour standards-special PGY-1 limits and strategic napping. N Engl J Med. 2010;363:1589-1591.

23. Hawkins MR, Vichick DA, Silsby HD, Kruzich DJ, Butler R. Sleep and nutritional deprivation and performance of house officers. J Med Educ. 1985;60:530-535.

24. Van Dongen HP, Maislin G, Mullington JM, Dinges DF. The cumulative cost of additional wakefulness: Dose-response effects on neurobehavioral functions and sleep physiology from chronic sleep restriction and total sleep deprivation. Sleep. 2003;26:117-126.

25. Drake P. Grasping at methodological understanding: A cautionary tale from insider research. Int J Res Meth Educ. 2010;33:85-99.

26. Dwyer SC, Buckle JL. The space between: On being an insider-outsider in qualitative research. Int J Qual Meth. 2009;8:54-63. 



\section{Chapter 4}

\section{Recovery of Sleep or Recovery of Self? A Grounded Theory Study of Residents' Decision-Making Regarding How to Spend Their Nonclinical Postcall Time}

Published as:

Taylor TS, Nisker J, Teunissen PW, Dornan T, Lingard L. Recovery of Sleep or Recovery of Self? A Grounded Theory Study of Residents' Decision Making Regarding How to Spend Their Nonclinical Postcall Time. Academic Medicine. 2016 Mar;91(3):395-400. 


\begin{abstract}
Purpose

As resident work hour policies evolve, residents' off-duty time remains poorly understood. Despite assumptions about how residents should be using their postcall, off-duty time (e.g., sleeping, studying), there is little research on how residents actually use this time and the reasoning underpinning their activities. This study sought to understand residents' nonclinical postcall activities when they leave the hospital, their decision-making processes, and their perspectives on the relationship between these activities and their well-being or recovery.
\end{abstract}

\title{
Methods
}

The study took place at a Liaison Committee on Medical Education-accredited Canadian medical school from 2012-2014. The authors recruited a purposive and convenience sample of postgraduate years 1-5 residents from six surgical and nonsurgical specialties at three hospitals affiliated with the medical school. Using a constructivist grounded theory approach, semi-structured interviews were conducted, audio-taped, transcribed, anonymized, and combined with field notes. The authors analyzed interview transcripts using constant comparative analysis and performed post hoc member checking.

\section{Results}

Twenty-four residents participated. Residents characterized their predominant approach to postcall decision-making as one of making trade-offs between multiple, competing, seemingly incompatible, but equally valuable, activities. Participants exhibited two different trade-off orientations: being oriented toward maintaining a normal life or toward mitigating fatigue.

\section{Conclusions}

The authors' findings on residents' trade-off orientations suggest a dual recovery model with postcall trade-offs motivated by the recovery of sleep or of self. This model challenges the dominant viewpoint in the current duty hours literature and suggests the duty hours discussion must be broadened to include other recovery processes. 


\section{Introduction}

Around the globe, resident work hour restrictions are either in place or under consideration in response to a growing body of evidence that suggests fatigue due to long working hours may be detrimental to residents' well-being and clinical performance. ${ }^{1-5}$ Extended working shifts have been linked to more frequent medical errors, ${ }^{6}$ as well as increased risks of percutaneous needlestick injuries and motor vehicle collisions among clinical trainees. ${ }^{1,2}$ Research in other contexts has suggested that prolonged sleep deprivation may lead to neurobehavioral performance impairment ${ }^{7,8}$ and stifle innovative and divergent thinking. ${ }^{9}$ Public opinion also seems to favor shorter working hours for doctors in training. ${ }^{10}$ Even as resident work hour policies evolve, however, residents' off-duty time remains poorly understood.

While it may seem logical that reduced resident working hours would lead to less fatigued residents and thereby increase patient safety, this has not been consistently demonstrated by the literature. Many studies question the patient safety benefit of reduced hours on the basis of an increase in patient handoffs; ${ }^{11-13}$ reduced learning opportunities that may negatively impact residents' education; ${ }^{13}$ and emerging ethical dilemmas for residents faced with the choice between abiding by duty hour policies or maintaining continuity of care. ${ }^{14}$ Another lingering issue is whether shorter working hours will result in residents who are better rested. ${ }^{1-3,15}$ There are those who suggest that even residents who abide by duty hour policies may fail to reap the benefits of shorter working hours if they pursue other "diversions" ${ }^{16}$ instead of sleeping and studying while off-duty. ${ }^{16-21}$ Certainly, there are compelling critiques on both sides of the duty hours debate, which is indicative of the complexity of this issue.

To complicate things further, Canada remains one of the few jurisdictions without nationally legislated resident work hour rules. ${ }^{22}$ Instead, resident contracts are negotiated between resident representatives and hospital employers within each province, which has led to variability in both the regulations and the degree to which they are enforced. ${ }^{22}$ In Quebec, for example, an arbitrator ruled that 24-hour call shifts violated the Canadian Charter of Rights and Freedoms and banned any shifts longer than 16 hours across the entire province. ${ }^{23}$ By contrast, resident contracts in Ontario, where this study took place, stipulate a maximum of 1 in 4 (in-hospital) and/or 1 in 3 (out of hospital) 24-hour shifts averaged over a 28-day period. ${ }^{24}$ They also indicate when residents should be dismissed from duty following a 24-hour overnight on-call shift, ${ }^{24}$ a term that is colloquially known as the "postcall day." The postcall day provides a valuable lens through which to explore how residents' work hours may inform their off-duty decisions because it is designated as protected off-duty time following an extended call shift. 
While much attention has been paid to the issue of residents staying to work postcall, to the best of our knowledge, only one study has specifically explored how residents decide what to do with their postcall time and the reasoning underpinning their activities. In that study, we employed a qualitative approach to understand how residents decide whether to leave the hospital postcall. ${ }^{25}$ We found that residents believed they were invoking values of patient safety and education, regardless of the postcall behavior they endorsed. ${ }^{25}$

Despite limited research, assumptions exist within the literature about what residents should be doing with their postcall, off-duty time (e.g., sleeping, studying). ${ }^{17-19}$ Most of these assumptions are expressed indirectly with limited empirical support. For example, when authors of one study found that residents' academic performance did not improve after duty hour reductions, they surmised that residents might have used their additional free time for socializing rather than studying. ${ }^{19}$ Another study cautioned that residents might not use their leisure time in "healthy ways," choosing instead to "participate in ... activities that could result in more fatigue." ${ }^{17}$ Such studies reflect a growing sense that "what [residents] do, or fail to do, with [their free] time may have real implications for ... residents' health and wellbeing." ${ }^{18}$ To inform the debate about how postcall time should be used, we need empirical data on what residents actually do postcall when they leave the hospital and why. To work toward addressing this gap, this study sought to understand residents' nonclinical postcall activities when they leave the hospital, their decision-making processes, and their perspectives on the relationship between these activities and their well-being or recovery.

\section{Methods}

We employed a constructivist grounded theory approach, a qualitative methodology well suited to exploring a complex social phenomenon that is not currently explained by any preexisting theory. ${ }^{26}$

The study took place at a Liaison Committee on Medical Education-accredited Canadian medical school from 2012-2014. During this time there were no changes to the national, provincial, or institutional resident duty hours policies. We recruited postgraduate years 1-5 residents whose schedules routinely included 24-hour on-call shifts from six surgical and nonsurgical specialties-general surgery, obstetrics and gynecology, orthopedic surgery, urology, internal medicine, and pediatrics - at three hospitals affiliated with the medical school. We chose these programs based on past research which indicated their intensity and frequency of on-call shifts were comparable ${ }^{25}$ and insider knowledge contributed by one investigator (T.S.T.), an obstetrics and gynecology resident at the medical school. The scheduling of call shifts for all residents in this cohort was expected to comply with the Professional Association of Residents of Ontario contract, which stipulates that in addition to their regular daytime duties, residents may work a 24-hour call shift an average of 1 in 4 (in hospital) and/or 1 in 3 (out of hospital) days over a 28-day period. ${ }^{24}$ 
We began with purposive sampling and convenience sampling to ensure that characteristics such as gender, postgraduate year, marital status, age, and parental status were represented across the programs. We invited residents to participate through recruitment emails and during weekly program-specific academic sessions and obtained informed consent from each participant. Participants did not receive any compensation or incentive for their participation.

One investigator (T.S.T.) conducted 24 individual, semi-structured interviews (for an interview outline, see Supplementary Digital List 1 from October-December 2012. Openended questions invited residents to describe their postcall activities and probed them for the reasons underpinning their postcall activities. Following grounded theory methodology, the interviews and analysis proceeded iteratively, allowing us to use the strategy of theoretical sampling, in which we sought new participants or inserted new prompts into the interview protocol to probe emerging issues or themes. ${ }^{26,27}$ Interviews were audio-taped, transcribed, anonymized, and combined with the investigator's accompanying field notes.

We conducted the analysis in three phases, beginning with line-by-line coding and using constant comparative analysis to develop focused codes. Joint discussions between two coinvestigators (T.S.T., L.L.) facilitated the coalescence of key concepts into major themes. Through further analytical discussions (T.S.T., L.L., P.W.T., T.D., J.N.), we developed an explanatory theory that accounted for the relationships among the themes. ${ }^{26}$ Data collection continued until no new theoretical insights emerged. ${ }^{28}$ In 2014, T.S.T. performed post hoc member checking, during interviews in a separate study of other residents at this medical school who fit the same inclusion criteria, which revealed that our findings resonated with these residents. We used NVivo 10 (QSR International, Doncaster, Victoria, Australia) for data management and interpretive data procedures. ${ }^{26}$

This study was approved by the Health Sciences Research Ethics Board at Western University (REB \#102769).

\section{Results}

A total of 24 postgraduate years 1-5 residents from across the six specialty programs participated. Of these, 12 were male. Other participant characteristics, such as age (range: 24-35 years), marital status (13 were married), or parental status (5 had dependents) were also represented across the programs. Quotations are identified with anonymous resident codes (e.g., R 020).

By definition, the postcall day immediately followed a 24-hour overnight on-call shift, which distinguished postcall days from other off-duty time. The temporal relationship between on- 
call shifts and postcall days meant that residents often situated their postcall experience by contrasting it with the nature of their on-call experience: "[While on call,] it was not uncommon to not eat until 10 p.m. at night and to not have time to go to the bathroom and to be completely overwhelmed" (R 005). Residents described their postcall behaviors as deliberate and purposeful. Being postcall provided an opportunity to exert greater personal control over their lives than during other times in their clinical schedule. Regardless of what postcall behaviors residents described, they expressed a strong sense that the potential need for restorative sleep was one of many demands competing for their postcall time and energy. In the context of this overarching sentiment, residents characterized their predominant approach to postcall decision-making as one of making trade-offs between multiple, competing, seemingly incompatible, but equally valuable, activities. Two orientations toward trade-offs among these activities were evident in the data: being oriented toward maintaining a "normal" life and being oriented toward mitigating fatigue. Although some residents expressed one orientation more consistently than the other, the majority of residents shifted orientations according to the circumstances of their postcall day. Consequently, trade-offs were predominantly informed by contextual factors, such as an awareness of feeling fatigued ("essentially hung over" [R 008]) or feeling functional ("fine to do a normal day" [R 020]), and varied accordingly. Using representative quotations, we define and illustrate the two orientations below.

\section{Oriented toward maintaining a normal life}

Trade-offs that were oriented toward maintaining a normal life represented situations in which residents were motivated to choose activities that permitted them to maintain what residents characterized as "normal human things" (R 004) involving their personal lives and relationships outside of the hospital. As a result, when making trade-offs within this orientation, sleep or rest during the postcall day was necessarily restricted to a few hours or sacrificed altogether. When operating within this orientation, residents were emphatic about the significance of the postcall day, as evidenced by the advice they would offer to incoming residents: "Love them. Love your postcall days" (R 022). It was "precious time" (R 022), which provided a rare chance to stray from routine: “... particularly when you're doing 26 hours on call ... your life could be work, sleep, work, sleep, that's all that you would be doing. I think you have to make sure that you do break that cycle" (R 012).

Many residents were motivated to "break that cycle" (R 012) by a desire to make time for social and family commitments. Residents offered two main explanations to justify the trade-off between recovering sleep and maintaining personal relationships. First, some residents reasoned that their long-and often unpredictable-work hours during normal working days made it difficult to make plans after a typical workday. In contrast, postcall days were guaranteed and more predictable; residents felt compelled to make use of the time: 
... there's [sic] definitely been opportunities where l've tried to sneak in family or friends time ... when you're as busy as we are, you take all these opportunities, and sometimes maybe you don't make the best decision for that weekend but when you're planning ahead of time, you just see this time that you have open. (R 006)

Making plans during the postcall day may have been opportune, but the decision to forfeit extra hours of sleep was not always easy:

Interviewer: Do you ever have difficulties waking up from your postcall sleep, if you do have plans?

Resident: Yeah, I usually regret making those plans. When my alarm starts going off, I go, why didn't I just plan to sleep all afternoon? But you've got to do it. (R 004)

Second, some residents were motivated to prioritize time with loved ones because they sensed that long work hours had already led them to miss out on quality time:

Before my son was born, I would sleep a lot more. But after he was born, I realized that, you know, when I was at work certainly I missed time with him growing up and things like that. I just decided that I wanted to spend time with him on those days when I had the opportunity to do so. (R 017)

Residents also described sacrificing time they could be resting to perform tasks that allowed them to keep their personal life in order. Some of their rationalizations were pragmatic: banks, dentists, and car repair shops are only open during normal business hours. As one resident reasoned, if it was not for postcall days, these services would be fairly inaccessible to residents:

Especially when you're on these busy services, you really almost need those postcall days to get what I call normal people's stuff done like get groceries, attend appointments, or things like that. I tend to book stuff for that time postcall because it's the only time I can really get stuff done like car maintenance, things like that. ( $R$ 001)

However, at other times, residents were motivated to restrict their sleep or rest because of a personal desire to feel productive. In this line of reasoning, sleeping or resting was an acceptable trade-off because it was less personally fulfilling:

I think I'm the type of person where I always like to be productive all the time, even though, probably what I should be doing is just resting ... I just couldn't see myself not taking advantage of the time to work out or go food shopping or just make food and do stuff that I need to do. I just can't see myself sleeping all day because it's just a waste of time. (R 013)

\section{Oriented toward mitigating fatigue}

Trade-offs that were oriented toward mitigating fatigue occurred in situations where recharging experiences, such as choosing to "crawl right into bed and sleep for as long as 
possible" (R 008) or engage in passive activities, took priority over tasks that required more energy expenditure, such as studying, socializing, or attending to normal life. While oriented toward fatigue mitigation, residents emphasized that taking a postcall day was necessary to compensate for the physical and cognitive demands of busy on-call shifts.

An interesting feature of this orientation was that, despite sharing a common intention to recuperate after prolonged sleep deprivation while on call, residents' postcall sleep practices varied. A few residents described choosing to sleep "for as long as possible" (R 008), while others deliberately restricted their daytime sleep with the intention of preserving their sleep-wake rhythm:

There's been a few times where I sleep until 7:00 [a.m.] or so if it's been a really rough night and I'm really exhausted, but generally, I try to get up. It's just because I know if I sleep too long then I won't be able to sleep at night, then I'll be exhausted the next day. (R 009)

There was a pervasive sense in the transcripts that choosing to sleep, or rather, that choosing not to do more immediately productive activities (e.g., studying or continuing to work) warranted further justification. For example, one might earn a break from studying by working long hours: "I don't do a lot of educational things postcall, I generally find I'm quite tired and I've just worked for 30 hours, so I feel like I deserve a small break" (R 022). Whereas other residents simply felt that studying was futile in light of postcall fatigue: "I know that I'm not really capable of good thought at that time if I were to read something or try to learn, it wouldn't be an optimum time to do it" (R 016).

Many residents felt conflicted about sacrificing valuable educational experiences by leaving the hospital and choosing to sleep or rest:

I'm of the opinion that the more volume you see and the more ... you've just got to be there to be able to see these cases because it's stuff that you can't read in the textbook ... so I try to stay as much as possible. However, if I'm not feeling it, like if I feel like crap and I feel sick or sneezy like I am right now, I'll forego the [operating room] and I'll just say tell my seniors or my other juniors that I'm going home, and that's my choice. I know my role and I know my rights. ( $R$ 015)

As this comment implies, anticipated criticism from colleagues further complicates residents' trade-offs. When residents feel that feeling "sick or sneezy" (R 015) will not be seen as a sufficient reason to choose sleep or rest, invoking the rules is perceived to be necessary for residents to justify their decision.

Postcall trade-offs in this orientation were more likely to be informed by past experience, than trade-offs described by residents while oriented to maintaining a normal life. At times, 
residents implied that they had learned the consequences of making trade-offs that sacrificed sleep or rest:

Even though I'm awake and have energy to do things, I'll know I'm going to get tired so I'Il [sic] just rather be at home so I can just fall into bed at that time, rather than being so stuck in a breakfast brunch place and then be like, I have to drive home now when I'm not as awake. (R 012)

One resident explained how her priorities similarly shifted toward a fatigue mitigation orientation later in her training, which required deliberate personal trade-offs:

So, from when I started eight years ago, I think I try to do less now postcall. Before I would try to schedule time with friends, schedule time with [my] boyfriend, go to the gym, study, and I think, now, I've just cleared away all the kind of personal stuff, and just focus on trying to get sleep and study. Whether that's good or not, I don't know, but I just found that I was constantly breaking plans. So, I did not want to be the unreliable person. I would rather just be the person that's not around for a while. (R 018)

\section{Discussion}

Residents in our study responded to competing demands on their postcall time by making trade-offs, which can provide insight into what it means for residents to recover. The duty hours literature $5,20,22,29,30$ tends to focus exclusively on the recovery of sleep, which can be at odds with the recovery of self.

\section{Recovery of sleep}

The orientation toward mitigating fatigue challenges the discussion around recovery in the research and grey (e.g., consensus reports ${ }^{22}$ ) literatures, in which recovery of sleep is presented as uniformly understood and enacted. The expectation that all residents can and should abide by "healthy sleep habits" ${ }^{30}$ and obtain "necessary levels of preventive and recovery sleep" ${ }^{30}$ is strongly promoted by the duty hours literature, in spite of conflicting evidence regarding the necessary amount of sleep. Where other studies have assumed that residents may be unwilling or unable to "recover their lost sleep" ${ }^{31}$ on postcall days, residents in our study agreed that postcall days were useful (and often necessary) to catch up on sleep. However, there was great variability in how residents translated this into practice. Even when residents are motivated to reduce their fatigue, some of them believed they got a better night's sleep if they did not go straight to bed postcall. Thus, recovery of sleep is characterized by calculated trade-offs involving decisions around when to sleep, how much to sleep, and when to remain awake, rather than by well-defined, predictable practices that apply to all residents. 


\section{Recovery of self}

Participants in our study seemed highly motivated to spend their postcall day doing things other than sleeping or resting, which suggests residents are working with a broader notion of recovery. We have named this broader notion of recovery the recovery of self. Within this recovery framework, residents are intending to reconnect with their identities, roles, and relationships that exist outside of the hospital. This resembles the practice of psychological detachment, where one deliberately mentally disengages from work to facilitate recovery from workplace demands. ${ }^{32}$ Research on psychological detachment in other high-demand workplaces suggests it may play a significant role in personal well-being and workplace performance. ${ }^{33}$ In fact, the inability to psychologically detach has been associated with emotional exhaustion, dissatisfaction, and poor sleep quality. ${ }^{33}$ Within residency training, Cranley found that residents tend to struggle with psychological detachment and hypothesized that workload may account for this difficulty. ${ }^{34}$ Similarly, based on a survey of residents' nonsleep, nonwork activities, Baldwin et al found a correlation between off-duty social isolation and depression, anxiety, stress, dissatisfaction, and increased rates of having made a self-reported fatigue-related error. ${ }^{18}$ This early research suggests recovery of self, through disengaging from work during off-duty hours and seeking opportunities to engage with other aspects of life, may have beneficial implications for residents' on-duty performance and wellness.

Through the recovery of self, residents also tended to the requisite maintenance tasks of adulthood. This resonates with Baldwin et al who propose that one benefit of increased offduty time lies in providing residents "the ability to better manage their lives." ${ }^{35}$ Other research has demonstrated that residents' perceptions about having the ability to secure "personal time away" are positively correlated with less perceived stress and greater career satisfaction. ${ }^{36}$ Whereas the recovery of sleep is about feeling less fatigued, the recovery of self is about reclaiming one's life outside of the hospital.

\section{Recovery and studying}

Studying did not feature predominantly in residents' accounts of how they spent their postcall time, but we cannot make any inferences about their study practices during other off-duty times. We believe this distinction is critical to avoid making assumptions about trade-offs between self-directed learning and quality of life for residents with reduced work hours. For those residents in our study who raised the issue of studying postcall, they often reasoned that their fatigue precluded them from engaging meaningfully in such a cognitively demanding task. Spending time with loved ones or tending to personal needs was feasible because it did not require the same cognitive resources. This observation fits within the proposed dual recovery model we proposed above to understand residents' postcall decision-making processes, as it suggests residents may not perceive studying as a recovery process, but rather as a task that exceeds their postcall cognitive resources. 


\section{Strengths and limitations}

Constructivist grounded theory does not make claims of generalizability nor is it intended to represent the entire spectrum of the studied population. ${ }^{26}$ While we had a theoretically informed sample of postgraduate years 1-5 residents from six surgical and nonsurgical specialty programs, our study included a single Canadian medical school, and our findings are situated within the local culture of that school. Therefore, we offer a preliminary dual recovery model whose transferability must be explored through further research in other settings. ${ }^{26}$ A single interviewer, who was concurrently enrolled in one of the sampled programs, conducted all of the interviews. In the context of constructivist grounded theory, this is a strength, as her insider status likely encouraged candid interview discussions and her own lived experiences contributed to the analytical insights gained. ${ }^{37}$ By engaging in reflexivity through reflective memoing, creating field notes, and participating in collaborative analysis with "outsiders" who offered alternative viewpoints, the interviewer remained attuned to the impact of her insider status. ${ }^{37}$

\section{Implications for future research and policies}

An important question for future research is the relationship between the two trade-off orientations and factors such as residents' demographics or program culture. Lopez and Katz identify a tension that exists "between the need for self-health and the professional ideals of altruism and self-sacrifice." ${ }^{38}$ Thus, the degree to which psychological detachment and other aspects of recovery of self are commensurate with the professional ethos of medicine also warrants exploration. From a policy perspective, the variability in how residents enact recovery of sleep is problematic. Although professional ideals of self-regulation privilege autonomy, the literature suggests self-assessment of fatigue becomes less accurate with increasing levels of fatigue. ${ }^{39,40}$ Genetic differences in sleep requirements further complicate matters. ${ }^{41}$ Because no two on-call shifts are alike, variation in recovery of sleep may also reflect adaptations to varying degrees of acute sleep deprivation. Work hour policies have tended to overlook the tension that emerges when residents must choose between abiding by duty hour policies, attending to their own needs, or attending to the needs of their patients. Because recovery of sleep is neither uniformly understood nor universally experienced, program leaders and the policies they follow should not assume that a sense of duty to recover sleep will necessarily lead to less fatigued, more alert residents.

\section{Conclusions}

This study not only addresses the evidence gap involving residents' nonclinical postcall activities but also begins to uncover the needs these activities are serving. We found that residents' used two trade-off orientations-maintaining a normal life or mitigating fatiguewhen making decisions about how to use their postcall days. These orientations were not static; residents reported shifting their predominant orientation according to the situation and accrued experience. These findings challenge the dominant viewpoint in the current 
duty hours literature, which has maintained a singular focus on sleep as the only path to recovering from working long hours. Our study suggests we must broaden the duty hours discussion to include other recovery processes. For the residents in our study, postcall tradeoffs were motivated by two distinct and competing forms of recovery-the recovery of sleep and the recovery of self. There is literature to support the importance of both, but further research is required to understand how they relate to one another.

Formulaic models and prescriptive duty hour policies tend to reduce the postcall experience to an accounting of hours of sleep and wakefulness. A dual model of recovery may explain why such policies can fall short of expectations.

\section{References}

1. Ayas NT, Barger LK, Cade BE, et al. Extended work duration and the risk of selfreported percutaneous injuries in interns. JAMA. 2006;296:1055-1062.

2. Barger LK, Cade BE, Ayas NT, et al. Extended work shifts and the risk of motor vehicle crashes among interns. N Engl J Med. 2005;352:125-134.

3. Parshuram CS, Dhanani S, Kirsh JA, Cox PN. Fellowship training, workload, fatigue and physical stress: A prospective observational study. CMAJ. 2004;170:965-970.

4. Lingenfelser T, Kaschel R, Weber A, Zaiser-Kaschel H, Jakober B, Küper J. Young hospital doctors after night duty: Their task-specific cognitive status and emotional condition. Med Educ. 1994;28:566-572.

5. Papp KK, Stoller EP, Sage $P$, et al. The effects of sleep loss and fatigue on residentphysicians: A multi-institutional, mixed-method study. Acad Med. 2004;79:394-406.

6. Landrigan $\mathrm{CP}$, Rothschild JM, Cronin JW, et al. Effect of reducing interns' work hours on serious medical errors in intensive care units. New Engl J Med. 2004;351:18381848.

7. Arnedt JT, Owens J, Crouch M, Stahl J, Carskadon MA. Neurobehavioural performance of residents after heavy night call vs after alcohol ingestion. JAMA. 2005;294:1025-1033.

8. Williamson AM, Feyer AM. Moderate sleep deprivation produces impairments in cognitive and motor performance equivalent to legally prescribed levels of alcohol intoxication. Occup Environ Med. 2000;57:649-655.

9. Harrison $Y$, Horne JA. One night of sleep loss impairs innovative thinking and flexible decision making. Organ Behav Hum Decis Process. 1999;78:128-145.

10. Blum $A B$, Raiszadeh $F$, Shea $S$, et al. US public opinion regarding proposed limits on resident physician work hours. BMC Med. 2010;8:33.

11. Peets A, Ayas NT. Restricting resident work hours: The good, the bad, and the ugly. Crit Care Med. 2012;40:960-966. 
12. Sen S, Kranzler HR, Didwania AK, et al. Effects of the 2011 duty hour reforms on interns and their patients: A prospective longitudinal cohort study. JAMA Intern Med. 2013;173:657-662; discussion 663.

13. Drolet BC, Christopher DA, Fischer SA. Residents' response to duty-hour regulationsA follow-up national survey. N Engl J Med. 2012;366:e35.

14. Szymczak JE, Brooks JV, Volpp KG, Bosk CL. To leave or to lie? Are concerns about a shift-work mentatlity and eroding professionalism as a result of duty-hour rules justified? Milbank Q. 2010;88:350-381.

15. Douglas NJ. Sleep, performance and the European Working Time Directive. Clin Med. 2005;5:95-96.

16. Rose SH, Curry TB. Fatigue, countermeasures, and performance enhancement in resident physicians. Mayo Clin Proc. 2009;84:955-957.

17. O'Malley PG, Khandekar JD, Phillips RA. Residency training in the modern era: The pipe dream of less time to learn more, care better, and be more professional. Arch Intern Med. 2005;165:2561-2562.

18. Baldwin DC Jr, Daugherty SR, Ryan PM, Yaghmour NA. What do residents do when not working or sleeping? A multispecialty survey of 36 residency programs. Acad Med. 2012;87:395-402.

19. Zaré SM, Galanko JA, Behrns KE, et al. Psychologic well-being of surgery residents after inception of the 80-hour workweek: A multi-institutional study. Surgery. 2005;138:150-157.

20. Veasey S, Rosen R, Barzansky B, Rosen I, Owens J. Sleep loss and fatigue in residency training: Areappraisal. JAMA. 2002;288:1116-1124.

21. Lund KJ, Alvero R, Teal SB. Resident job satisfaction: Will 80 hours make a difference? Am J Obstet Gynecol. 2004;191:1805-1810.

22. National Steering Committee on Resident Duty Hours. Fatigue, Risk, \& Excellence: Towards a Pan-Canadian Consensus on Resident Duty Hours. Ottawa, ON: The Royal College of Physicians and Surgeons of Canada; June 2013. http://www.royalcollege.ca/portal/page/portal/rc/common/documents/advocacy/fa tigue_risk_and_excellence.pdf. Accessed December 17, 2013.

23. Dussault C, Saad N, Carrier J. 16-hour call duty schedules: The Quebec experience. BMC Med Educ. 2014;14(Suppl 1):S10.

24. Professional Association of Residents of Ontario. Top Things to Know About Your Contract. http://www.myparo.ca/Top_Things_To_Know. Accessed January 1, 2015.

25. Taylor TS, Nisker J, Lingard L. To stay or not to stay? A grounded theory study of residents' postcall behaviors and their rationalizations for those behaviors. Acad Med. 2013;88:1529-1533.

26. Charmaz K. Constructing Grounded Theory: A Practical Guide Through Qualitative Analysis. 1st ed. Thousand Oaks, Calif: Sage Publications; 2006.

27. Strauss AL, Corbin JM. Basics of Qualitative Research: Techniques and Procedures for Developing Grounded Theory. 2nd ed. Thousand Oaks, Calif: Sage Publications; 1998. 
28. Morse JM. The significance of saturation. Qual Health Res. 1995;5:147-149.

29. Rosen IM, Bellini LM, Shea JA. Sleep behaviors and attitudes among internal medicine housestaff in a U.S. university-based residency program. Acad Med. 2004;79:407416.

30. Arora VM, Georgitis E, Woodruff JN, Humphrey HJ, Meltzer D. Improving sleep hygiene of medical interns: Can the sleep, alertness, and fatigue education in residency program help? Arch Intern Med. 2007;167:1738-1744.

31. Wilcox M. The Effects of Call Schedule on Mood and Sleep in Medical Interns and Residents [dissertation]. Norfolk, Va: Eastern Virginia Medical School; 1999.

32. Sonnentag S, Fritz C. The Recovery Experience Questionnaire: Development and validation of a measure for assessing recuperation and unwinding from work. J Occup Health Psychol. 2007;12:204-221.

33. Sonnentag S. Psychological detachment from work during leisure time: The benefits of mentally disengaging from work. Curr Dir Psychol Sci. 2012;21:114-118.

34. Cranley NM. Understanding time use, stress, and recovery among medical resident [master's thesis]. Chattanooga, Tenn: University of Tennessee at Chattanooga; 2012.

35. Baldwin DC Jr, Daugherty SR. Sleep deprivation and fatigue in residency training: Results of a national survey of first- and second-year residents. Sleep. 2004;27:217223.

36. Cedfeldt AS, Bower EA, English C, Grady-Weliky TA, Girard DE, Choi D. Personal time off and residents' career satisfaction, attitudes and emotions. Med Edu. 2010;44:977-984.

37. Dwyer SC, Buckle JL. The space between: On being an insider-outsider in qualitative research. Int J Qual Methods. 2009;8:54-63.

38. Lopez L, Katz JT. Perspective: Creating an ethical workplace: Reverberations of resident work hours reform. Acad Med. 2009;84:315-319.

39. Howard SK. Sleep deprivation and physician performance: Why should I care? Proc (Bayl Univ Med Cent). 2005;18:108-112; discussion 112-113.

40. Hawkins MR, Vichick DA, Silsby HD, Kruzich DJ, Butler R. Sleep and nutritional deprivation and performance of medical housestaff. J Med Educ. 1985;60:530-535.

41. Czeisler CA. Medical and genetic differences in the adverse impact of sleep loss on performance: Ethical considerations for the medical profession. Trans Am Clin Climatol Assoc. 2009;120:249-285. 


\section{Appendix}

Semi-Structured Interview Outline Used in a Study of Residents' Nonclinical Postcall Activities, Their Decision-Making Processes, and Their Perspectives on the Relationship Between These Activities and Their Well-being or Recovery at One Canadian Medical School, October-December 2012

- Demographics, including gender, program, and level of training (junior or senior)

- Frequency and intensity of call shifts

- Postcall responsibilities

- Postcall routines

- Speculation regarding colleagues' postcall pursuits

- Anticipated postcall routines after training

- Role of duty hour restrictions 



\section{Chapter 5 \\ Principles of Fatigue in Residency Education: A Qualitative Study}

Published as:

Taylor TS, Watling CJ, Teunissen PW, Dornan T, Lingard L. Principles of fatigue in residency education: a qualitative study. CMAJ Open. 2016 Apr 28;4(2):E200-4. 


\begin{abstract}
Background

Recent proposals to implement fatigue management strategies in residency education assume that medicine shares the view of other risk-adverse industries that fatigue is hazardous. This view is an essential underpinning of fatigue management strategies that other industries have embedded as part of their workplace occupational health and safety programs. This study sought to explore whether medicine shares this view, by asking how residents understand fatigue in the context of their training environment.
\end{abstract}

\title{
Methods
}

We interviewed 21 residents across 6 surgical and non-surgical programs, at one Canadian medical school in 2014. All participants met the inclusion criteria of routinely working $24 \mathrm{~h}$ call shifts while enrolled in their training program. Data collection and analysis occurred iteratively in keeping with constructivist grounded theory methodology, and informed theoretical sampling to sufficiency.

\section{Results}

Four predominant principles of fatigue captured how the social learning environment shaped residents' perceptions of fatigue. These included the conceptualization of fatigue as: (1) inescapable and therefore accepted, (2) manageable through experience, (3) necessary for future practice and (4) surmountable when required.

\section{Interpretation}

This study elaborates our understanding of how principles of fatigue are constructed and reinforced by the training environment. Whereas fatigue is seen as a collective hazard in other industries, our data show that, in residency training, fatigue may be seen as a personal challenge. Consequently, fatigue management strategies that conceptualize fatigue as an occupational threat may have limited impact on resident behavior and patient safety. 


\section{Introduction}

Emerging research has suggested that resident duty hour restrictions may have done more harm than good. ${ }^{1-4}$ In Canada, the National Steering Committee on Resident Duty Hours proposed fatigue management strategies as a promising alternative to prescriptive "one size-fits-all" resident duty hour restrictions. ${ }^{5,6}$ The final report advocated for new accreditation standards, which would require residency programs to "develop, and keep up to date, fatigue risk management plans" ${ }^{5,6}$ Empirical evidence supports the notion that prolonged sleep deprivation leads to performance impairment ${ }^{7-10}$ and fatigue management strategies would fulfill a need to maintain public accountability in the absence of duty-hour legislation. However, as Pattani and colleagues note, this mandate lacks important details about the design and implementation of fatigue management strategies. ${ }^{6}$

Unlike the explicit policies that limit resident duty hours in other countries, there is no model for fatigue management strategies in medical education, and research about effectively managing fatigue in residency contexts is scarce. Arora et al found that an educational seminar to improve sleep hygiene practices had minimal impact on residents' behaviour. ${ }^{11}$ Policies of protected sleep time during prolonged duty periods have shown inconsistent results. ${ }^{12,13}$ Additional studies have highlighted how the influence of local training culture can trump duty hour policy ${ }^{14}$ and alter perceptions of the impact of sleep deprivation. ${ }^{15}$ These varied perceptions and cultural influences have received little attention to date amid discussions of anticipated fatigue management strategies.

In other industries, such as transportation, aviation and the military, fatigue management strategies benefit from a uniform understanding of fatigue as an occupational threat. ${ }^{16}$ The fact that residents and faculty hold varied perceptions about the impact of fatigue on clinical performance, particularly within surgical contexts, suggests that fatigue may not be quite so straightforwardly understood in residency training. ${ }^{15,17}$ Until we know more about how fatigue is understood in residency training across multiple disciplines, we risk developing fatigue management strategies that are irrelevant and fail to address the existing shortcomings of duty hour restrictions. Thus, this study seeks to explore how residents understand fatigue in the context of their training environment.

\section{Methods}

We used a constructivist grounded theory approach, which is suitable for socially situated research questions. ${ }^{18}$

\section{Participant Selection and Setting}

We conducted 21 individual, semi-structured interviews at three hospitals within a single academic training centre with radiology, psychiatry, critical care, general surgery, pediatrics, 
internal medicine, and orthopedic surgery residents. We deliberately sampled across these programs because the nature of residents' on-call work varied and we wanted to include programs that have had limited representation in the existing duty hours literature. All participants were routinely scheduled to work $24 \mathrm{~h}$ call shifts, as per our inclusion criteria.

\section{Recruitment}

Recruitment, data collection and analysis took place between December 2013 and June 2014. Recruitment involved email and face-to-face invitations approved by each program director. In keeping with constructivist grounded theory methodology, we progressed from convenience to purposive and then theoretical sampling to sufficiency. ${ }^{19}$

\section{Data Collection}

One co-investigator (TT - a resident at one of the hospitals) conducted 20/21 interviews in person or over the phone at the participant's convenience, often at the hospital. A coinvestigator ( $L L$ - a non-clinician scientist) deliberately conducted one interview for the purposes of rigor, to ensure that TT's identity as a resident did not have a substantial impact on the information that participants chose to disclose during the open-ended interviews. ${ }^{20}$ To remain reflexively aware of how her insider experience informed the analysis, TT made regular memos and co-analyzed with non-insider members of the research team. ${ }^{18,21}$

\section{Analysis}

Analyzed data included transcripts of the audio-recorded interviews, alongside field notes and analytical memos written by TT. We followed the iterative process of data collection and analysis, which is characteristic of constructivist grounded theory [18]. This required revisions of the semi-structured interview guide (Appendix) in response to progressive refinement of the emerging theory. We chose not to confine the interviews to any specific definition of fatigue (e.g. physiological, cognitive, emotional, chronic, acute, etc.) to allow for a more inclusive representation of fatigue.

We began our analysis with initial grounded theory coding with gerunds, followed by constant comparative analysis, which led to a more conceptual coding framework [18]. Further refinement of this framework through collaborative analysis amongst coinvestigators (TT, LL, PT, TD, CW) resulted in the final emergent theory. NVivo ${ }^{\circledR}$ qualitative analysis software and MindNode Pro $^{\circledR}$, a mind-mapping tool, were used to organize the coding process.

\section{Ethics Approval}

We obtained research ethics approval from the institutional research ethics board at Western University (\#102769) Informed consent was obtained in writing from each participant. 


\section{Results}

Twenty-one participants were sampled from a range of postgraduate years (1-7) and included 13 male residents, 12 married residents, 6 residents with children and 13 seniorlevel residents, as defined by the individual programs.

Residents referred to various features of their training environment that informed how they recognized, discussed, and responded to fatigue in the context of residency training. Residents reported that "recognizing that you are tired" was always in tension with "also recognizing that there is a job to be done" (018). In fact, some perceived that a goal of wellness was incompatible with the training they had chosen: "I am in this not to ... how do I put it correctly? Not for wellness ... I would have picked a different career. I'm in here to become a good doctor. The best way I can do that is to spend the hours seeing the things that need to be seen." (005) Such reflections suggest that understandings of fatigue were socially informed by tacit messaging and normative expectations about what residency is about.

Four "principles of fatigue" captured these socially informed ways in which residents made sense of fatigue. Fatigue was seen as: (1) inescapable and therefore accepted, (2) manageable through experience, (3) necessary for future practice, and (4) surmountable when required. Each principle is described below and illustrated with salient quotations from the interviews, which are provided in Table 1.

Table 1. Four Principles of Fatigue

\begin{tabular}{|c|c|}
\hline Principle & Quotation (Anonymous Resident \#) \\
\hline $\begin{array}{l}\text { Fatigue is } \\
\text { inescapable and } \\
\text { therefore accepted }\end{array}$ & $\begin{array}{l}\text {...I think it's kind of expected. Everyone knows you're going to be tired (012) } \\
\text { I don't think, culturally, talking about being tired is really appropriate in my program. } \\
\text { We accept it... (013) }\end{array}$ \\
\hline $\begin{array}{l}\text { Fatigue is } \\
\text { manageable through } \\
\text { experience }\end{array}$ & $\begin{array}{l}\text { You just can't stand up anymore. You can't keep your eyes open anymore. You feel like } \\
\text { you are going to pass out or whatever. A lot of people have those sensations after } \\
\text { staying up for } 24 \text { hours. We learn to manage that. (017) } \\
\text { I'm sure people will disagree and this seems silly but being able to tolerate sleep } \\
\text { deprivation and being able to do high level performance while tired is trainable like } \\
\text { fitness or something, I think. (019) }\end{array}$ \\
\hline $\begin{array}{l}\text { Fatigue is necessary } \\
\text { for future practice }\end{array}$ & $\begin{array}{l}\text {...the program and consultants will make that statement, saying, we need to have a } \\
\text { residency program where our residents are tired, because they need to be trained for } \\
\text { the situation when they're in their community or they're in an environment where they } \\
\text { don't have the luxury of sleep (013) } \\
\ldots \text { in times of crisis, you need to still be able to make decisions and not freeze and be } \\
\text { like, oh, I'm tired. I have to go to bed. I think that is what part of this training is...we all } \\
\text { learn to manage this in some way, I think. We all learn. (005) }\end{array}$ \\
\hline
\end{tabular}




Fatigue is
surmountable when
required
required
I think recognizing that you are tired but then, also recognizing that there is a job to be done. You are looking after patients. And so someone is there for your services...So, you just get to a point where ... you are just able to put your own needs secondary. 'hey I'm tired. I'm not thinking quite the same and all of those things. But I have a job to do here.' (018)

Recently, as a senior resident you don't have as many nights where you are up all night but you have way more longer stretches where you are going three or four hours a night every night for 7 or 8 days. And you are amazed at the levels you can push yourself (019)

According to the principle of fatigue being inescapable and therefore accepted, fatigue is so pervasive that it is simply part of the job. Senior residents were predominant among those who endorsed the notion that fatigue is manageable through experience; they suggested that working while sleep deprived was a skill to be honed with practice. The principle that fatigue is necessary for future practice meant that working while fatigued was a valuable rite of passage to prepare for similar realities after residency. Residents across all sampled programs reinforced the idea that fatigue is surmountable when required, by suggesting that they could willfully persevere and continue to function in spite of fatigue.

The principle that fatigue is surmountable when required warrants further elaboration because it was prominent in participants' responses and is relevant to the concept of fatigue management. For many residents, fatigue was simply another challenge to overcome: "I think as long as you can stand up and stay awake and physically manage, then you can usually force your brain to work, even if it is harder to do and you may be more prone to mistakes..." (017) Surmounting fatigue wasn't always presented as onerous. At times, participants implied that it was a natural response to workplace demands: "Usually when the volume is high and you know you have that pressure, it's almost like there's so much adrenaline, that I don't really feel as fatigued at that point" (010).

While most residents agreed that fatigue would not stand in the way of doing what needed to be done, the principle of surmounting fatigue was not necessarily synonymous with providing high quality care. One resident reflected on this by saying, "Obviously we say we think we are doing a good job. But I think, maybe, you are just a little bit slower, less efficient. You could get things done faster and maybe more safely if people weren't as tired." (015) Various strategies within the workplace environment allowed participants to "push through" (018) in spite of fatigue. They described "filtering more to critical versus noncritical issues" (005), relying on "little check boxes" to remember details (017), delegating tasks amongst team members to "distribute the workload" when feasible (014), and going "into auto pilot" mode (010). Residents frequently spoke about how fatigue affected their mood and interactions with others: "I think we can all agree that the more fatigued we are, the more likely we are to have our social skills compromised." (010) This resident explained how the impact of fatigue on communication was perceived as advantageous in some 
circumstances: "I'm probably less articulate on a post-call breaking bad news but at the same time, I'll just slow down and it may seem like I'm more empathetic...which is really just because I'm having a hard time coming up with the words" (007)

In keeping with the principle that fatigue is surmountable when required, few residents directly attributed near misses or medical errors to fatigue. Residents' comments suggested that they typically needed to have negative outcomes drawn to their attention before they would attribute them to fatigue: "Until it was obvious that I was making technical mistakes, I probably wouldn't recognize it."(013) It seemed that fatigue was not a legitimate reason for making mistakes because it was deemed surmountable: "You know, being tired might be a valid excuse to put things off that can wait, but it's not an acceptable excuse for poor decision making. At least not in the medical culture, I think." (006)

Some residents pointed to systems-based limitations that implied that surmounting fatigue was something they felt "forced to do" (008). For instance, one resident commented on the lack of "resources in place for staff physicians to be able to say, 'hey I am tired today'...our groups aren't built that way... your colleagues will have to pick up the slack and you can't call in a substitute like you might in another profession."(003) Thus, residents' workplace learning environments reinforced the idea that it is both necessary and plausible to "tough it out" (003) and overcome the effects of fatigue.

There were discrepancies across these four principles, where residents either challenged the prevailing principle or offered a variation. One questioned how the pervasiveness of fatigue has remained acceptable in medical training: "But at what point do we become where that is okay? Because in other professions, it is not okay, so pilots or truck drivers... (018) A few residents disputed the idea that fatigue served a training purpose: "I don't believe we need to train people to perform well when we're tired...." (013) There were a few, typically extreme, scenarios in which residents described insurmountable fatigue. This resident recalled a time when his attending physician, as he put it, "pulled the parachute and left" (020):

[My staff] operated all day and then he was on call with me all night and operated and then the next day he operated all day... I think it was 42 hours straight in the operating room... He called another staff to help finish the [last] case for him because he couldn't go on anymore. He was pooched... (020)

By pushing the limits of these socially-accepted principles of fatigue, residents were reinforcing the existence of these principles while questioning their merit in the training environment. 


\section{Interpretation}

\section{Main Findings}

Our study describes 4 principles of fatigue that residents use to make sense of fatigue within the training environment: fatigue is understood as inescapable, manageable, necessary and surmountable. These principles are more than individual beliefs; they seem to be deeply engrained in the local training culture. And they reveal three serious problems, which must be faced before we can ensure the successful design and implementation of fatigue management strategies in residency education.

The first problem is that these principles of fatigue have been discredited as myth in other high performance industries such as aviation and transportation. ${ }^{22}$ There are both regulatory and organizational reasons for why these industries have outgrown the principles of fatigue that residents in our study subscribe to. At a regulatory level, fatigue was first legitimized as a safety priority during a Department of Transportation/Federal Highway Administration Safety Summit 20 years ago. ${ }^{22}$ Since then, high profile disasters such as "the Chernobyl nuclear reactor meltdown, the Exxon Valdez catastrophe, the Three Mile Island nuclear power station accident..." have clearly implicated fatigue as a "causal or contributory factor". ${ }^{23}$ Therefore, organizations that fail to implement sufficient fatigue management systems are liable to be found "criminally negligent in the event of an on-the-job mishap". ${ }^{22}$ Public visibility may be one distinguishing feature that has prompted other industries to adopt the stance that fatigue is an occupational safety threat, which in turn supports an explicit and formalized approach to fatigue management. By contrast, the consequences of fatigued residents are generally less public, with fewer casualties per fatigue-related incident, enabling continued skepticism in medical education about whether fatigue is dangerous in residency training. ${ }^{24}$

The second problem is that the principles revealed in our study characterize fatigue not as a threat, but as a challenge. Previous research has shown that surgical residents believe themselves to be resilient to the effects of sleep deprivation ${ }^{15}$ and that general surgery residents and faculty believe fatigue is irrelevant to patient care ${ }^{17}$ Our research suggests that this belief may permeate residency more broadly. Even residents who perceived that their performance was negatively affected by fatigue nevertheless believed there had been no meaningful impact on patient care. In addition to not seeing fatigue as a threat, our participants perceived it as a challenge: the ability to keep working while fatigued was presented as a necessary skill. One implication of this is that the responsibility for this skill lies primarily with the resident. This is in stark contrast to other industries, such as transportation and aviation, ${ }^{25}$ that approach fatigue as a collective threat, not as a personal challenge. 
The third problem is that residents cannot be expected to view fatigue as a threat when the working environment presents no acceptable alternative to working fatigued. Residents noted that there weren't any explicit provisions for addressing fatigue in the workplace, although there were established conventions for dealing with overwhelming patient volume, clinical uncertainty or procedural supervision. Studies of residency as a workplace training environment have shown that the workplace can implicitly preserve the status quo. ${ }^{26}$ As our data demonstrated, the unspoken message from the training environment was that fatigue must be surmountable, because it could not be helped.

\section{Limitations}

We conducted this research using a constructivist grounded theory methodology. This methodology is not intended to create a generalizable theory but, rather, to offer in-depth insight into a social phenomenon within a given context. We performed this research at a single centre and the local training culture necessarily informs our results. Further research that explores and elaborates our emergent theory in other contexts is needed. We relied on individual residents' account of experiencing fatigue rather than an objective measurement of fatigue because our research question was focused on their understanding. Consequently, this study does not quantify the prevalence of fatigue or attempt to measure its impact on patient care. We benefitted from having an insider (TT) who could provide analytical insights that were accessible to someone with lived experience ${ }^{21}$ as part of the research team. TT followed standard techniques for attending to her insider role throughout the analytical process. ${ }^{18,21}$

\section{Conclusion}

The success of fatigue-management strategies in other industries is based on the assumption that fatigue is uniformly understood as an occupational threat. Our results suggest that this assumption does not hold in residency. Under present conditions, the implementation of fatigue management strategies in residency training may not have a significant impact on resident fatigue or patient safety. Future research that explores whether existing principles of fatigue can be altered by changes within the training environment could bring us closer to successfully implementing effective fatigue management strategies.

\section{References}

1. Carpenter RO, Spooner J, Arbogast PG, Tarpley JL, Griffin MR, Lomis KD. Work hours restrictions as an ethical dilemma for residents: A descriptive survey of violation types and frequency. Current surgery. 2006;63(6):448-55. 
2. Sen S, Kranzler HR, Didwania AK, Schwartz AC, Amarnath S, Kolars JC, et al. Effects of the 2011 duty hour reforms on interns and their patients: a prospective longitudinal cohort study. JAMA internal medicine. 2013;173(8):657-62.

3. Desai SV, Feldman L, Brown L, Dezube R, Yeh HC, Punjabi N, et al. Effect of the 2011 vs 2003 duty hour regulation-compliant models on sleep duration, trainee education, and continuity of patient care among internal medicine house staff: a randomized trial. JAMA Intern Med. 2013;173(8):649-55.

4. Parshuram CS, Amaral AC, Ferguson ND, Baker GR, Etchells EE, Flintoft V, et al. Patient safety, resident well-being and continuity of care with different resident duty schedules in the intensive care unit: a randomized trial. CMAJ. 2015;187(5):321-9.

5. National Steering Committee on Resident Duty Hours. Fatigue, Risk and Excellence: Towards a Pan-Canadian Consensus on Resident Duty Hours. Ottawa, Ontario: The Royal College of Physicians and Surgeons of Canada; 2013. p. 1-52.

6. Pattani R, Wu PE, Dhalla IA. Resident duty hours in Canada: past, present and future. Canadian Medical Association Journal. 2014;186(10):761-5.

7. Arnedt JT, Owens J, Crouch M, Stahl J, Carskadon MA. Neurobehavioural performance of residents after heavy night call vs after alcohol ingestion. JAMA. 2005;294(9):1025-33.

8. Ayas NT, Barger LK, Cade BE, Hashimoto DM, Rosner B, Cronin JW, et al. Extended work duration and the risk of self-reported percutaneous injuries in interns. JAMA. 2006;296(9):1055-62.

9. Van Dongen HPA, Maislin G, Mullington JM, Dinges DF. The cumulative cost of additional wakefulness: Dose-response effects on neurobehavioral functions and sleep physiology from chronic sleep restriction and total sleep deprivation. Sleep. 2003;26(2):117-26.

10. Sugden C, Housden CR, Aggarwal R, Sahakian BJ, Darzi A. Effect of pharmacological enhancement on the cognitive and clinical psychomotor performance of sleepdeprived doctors: a randomized controlled trial. Annals of surgery. 2012;255(2):222-7.

11. Arora VM, Georgitis E, Woodruff JN, Humphrey HJ, Meltzer D. Improving sleep hygiene of medical interns: Can the sleep, alertness, and fatigue education in residency program help? Archives of Internal Medicine. 2007;167(16):1738-44.

12. Arora V, Dunphy C, Chang VY, Ahmad F, Humphrey HJ, Meltzer D. The effects of onduty napping on intern sleep time and fatigue. Annals of Internal Medicine. 2006;144(11):792-8.

13. Richardson GS, Wyatt JK, Sullivan JP, Orav EJ, Ward AE, Wolf MA, et al. Objective assessment of sleep and alertness in medical house staff and the impact of protected time for sleep. Sleep. 1996;19(9):718-26.

14. Taylor TS, Nisker J, Lingard L. To stay or not to stay? A grounded theory study of residents' postcall behaviors and their rationalizations for those behaviors. Academic medicine. 2013;88(10):1529-33. 
15. Woodrow SI, Park J, Murray BJ, Wang C, Bernstein M, Reznick RK, et al. Differences in the perceived impact of sleep deprivation among surgical and non-surgical residents. Medical education. 2008;42(5):459-67.

16. Dawson D, Chapman J, Thomas MJ. Fatigue-proofing: a new approach to reducing fatigue-related risk using the principles of error management. Sleep Med Rev. 2012;16(2):167-75.

17. Coverdill JE, Bittner JG, Park MA, Pipkin WL, Mellinger JD. Fatigue as impairment or educational necessity? Insights into surgical culture. Acad Med. 2011;86(10 Suppl):S69-72.

18. Charmaz K. Constructing Grounded Theory: A practical guide through qualitative analysis. Los Angeles: Sage Publications; 2006.

19. Morse JM. The Significance of Saturation. Qualitative Health Research. 1995;5(2):147-9.

20. Thurmond VA. The point of triangulation. Journal of nursing scholarship. 2001;33(3):253-8.

21. Corbin Dwyer S, Buckle JL. The Space Between: On Being an Insider-Outsider in Qualitative Research. International Journal of Qualitative Methods. 2009;8(1):54-63.

22. Caldwell JA, Caldwell JL. Fatigue in Aviation: A Guide to Staying Awake at the Stick. Burlington, VT: Ashgate Publishing Company; 2003. 157 p.

23. Col. Watt CG. Aircrew Fatigue Management. Montgomery, AL: Air War College, Maxwell Airforce Base, 2009.

24. Osborne R, Parshuram CS. Delinking resident duty hours from patient safety. BMC Med Educ. 2014;14 Suppl 1:S2.

25. Dawson D. Fatigue research in 2011: from the bench to practice. Accident; analysis and prevention. 2012;45 Suppl:1-5.

26. Teunissen PW. Experience, trajectories, and reifications: an emerging framework of practice-based learning in healthcare workplaces. Adv Health Sci Educ Theory Pract. 2014. 


\section{Appendix: Final Interview Guide}

1. What does a busy call shift look like for you?

2. How do you organize your call shift when it's busy? (e.g. How do you decide what to do first?)

3. If you realize that you can't do it all, how do you decide what to defer or postpone?

4. How do you decide if a task is unnecessary?

5. Does that look any different when you're not on call?

6. Have you ever felt unsafe? (When do you feel unsafe?)

7. Are their certain parts of your job that you perform just as safely (effectively), whether it's during the daytime or while on call at night?

a. Has this always been the case, or was it different when you were earlier in your residency?

8. Some residents have said that when they're postcall, they would feel safe to perform certain clinical duties but not others - what are your thoughts about this?

9. Looking to the future, how will you decide what to do on your postcall days? (What do your staff routinely do?)

10. What advice would you give to a more junior resident about how to handle their call shift?

a. If there's more to do than you can do - rationales

b. How do you decide what is unnecessary

c. When to ask to help and who to ask and how to ask for help?

11. If you take call with a junior resident - do you consider the junior's level of safety when delegating tasks? 


\section{Chapter 6}

\section{Work Hour Regulations Complicate Residency Education: Lessons About the Social Construct of Fatigue in Europe}

Submitted to Academic Medicine as:

Taylor TS, Teunissen PW, Dornan T, and Lingard L. Work hour regulations complicate residency education: lessons about the social construct of fatigue in Europe. 


\begin{abstract}

\section{Purpose}

Although work hour regulations have been posed as a solution to the problem of fatigued medical trainees, there is growing concern about their effectiveness. Canada remains one of the few Western jurisdictions without legislated regulation. Recent research in this particular context suggests that fatigue is a complex social construct, rather than simply a lack of sleep. Thus, this study set out to explore how regulations and fatigue are understood in countries with established work hour frameworks, to better inform other jurisdictions looking to address trainee fatigue.
\end{abstract}

\title{
Methods
}

The authors employed a constructivist grounded theory approach to data collection and analysis. From 2015-2016 they conducted individual, semi-structured interviews with 13 postgraduate trainees from four European countries with established work hour regulations

\section{Results}

Trainees reported that they were commonly fatigued. They also violated the work hour restrictions for various reasons. Although they understood the regulations were explicitly meant to ensure safe patient care and optimize trainee wellbeing, they described implicit meanings (e.g. monitoring for trainee efficiency) and unintended consequences (e.g. losing a sense of vocation) as well.

\section{Conclusions}

Work hour regulations carry multiple, conflicting meanings for trainees that are captured by three predominant rhetorics: the rhetoric of patient safety, the rhetoric of wellbeing and the rhetoric of efficiency. Tensions exist within each of those rhetorics, which reveal that managing fatigue within clinical training environments is complex. Straightforward solutions, our findings suggest, are unlikely to solve the problem of fatigue, assure patient safety, and improve trainee wellbeing. 


\section{Introduction}

Long working hours have been a long-standing tradition within postgraduate medical education across many contexts. However, extended periods of sleep deprivation from working long shifts leads to fatigue-related impairment. ${ }^{1-3}$ Thus, across North America, efforts to address the problem of fatigued medical trainees have focused on restricting trainee work hours. Although Canada currently lacks national legislated work hours for trainees, the Accreditation Council for Graduate Medical Education has restricted continuous duty periods to 16 hours within a maximum 80-hour work week in the United States since $2011 .{ }^{4}$ Duty hour reforms remain controversial in these contexts. Researchers continue to question the merits of such restrictions amid concerns that reduced work hours compromise training ${ }^{4,5}$ and reduce "clinical commitment". ${ }^{6861}$ However, it has also been suggested that Europe resolved the issue of doctors' hours with the implementation of the European Working Time Directive (EWTD), which restricts shifts to 13 hours with a maximum 48-hour work week. ${ }^{7}$

In 1998, the EWTD was legislated to "protect the health and safety of all workers in the European Union". Medical trainees were initially exempt from the regulations. ${ }^{8}$ 1 $B y 2009$, however, all medical training programs were expected to have implemented EWTD compliant call schedules or rotas. Critics of the EWTD suggest that it has not improved patient care or optimized training. ${ }^{9-11}$ The empirical data is conflicting in this regard. Cappuccio et al $^{12}$ demonstrated that an EWTD compliant rota could reduce medical errors in non-procedural based specialties. The authors acknowledged that their study was not intended to assess the educational impact of a 48-hour work week. In contrast, a survey of surgical trainees and consultants revealed predominantly negative perceptions of the EWTD, despite authors' acknowledgement that, "the benefits to lay people appear self evident" ${ }^{13}$ p296 Three cohorts of UK medical graduates also offered their opinions of the EWTD and questioned whether it was truly in the best interest of trainees. ${ }^{14}$ The conflicting literature suggests that there are no simple answers to a problem as complex as trainee fatigue and working hours.

Our understanding of fatigue in medical trainees has expanded beyond seeing it as merely an emotional or physical state, to consider fatigue as a social construct. ${ }^{15}$ This has implications for work hour reform because it calls attention to the social context in which trainees are embedded. As we continue to debate the merits and impact of work hour reform in North America, ${ }^{4,16,17}$ it is worthwhile to consider what we can learn from the European experience as a different social context. Existing research related to the EWTD has tended to focus on the experiences of trainees within a single specialty ${ }^{12,13,18}$ and many studies are confined to a single setting. ${ }^{14,19,20}$ We sought to explore how trainees across multiple training programs and jurisdictions at varying stages of implementing the EWTD 
understood these regulations in their workplace contexts in order to inform debates about the relative merits of duty hour restrictions in other contexts.

\section{Methods}

We used a constructivist grounded theory (CGT) approach to qualitative research because of the socially situated nature of the research question. ${ }^{21}$ We conducted semi-structured interviews with 13 postgraduate trainees from Ireland, the Netherlands, the United Kingdom and Denmark over a 1-year period from 2015-2016.

English-speaking trainees were recruited from various medical training institutions within the sampled countries via personal communication through the research team's contacts in the medical education community. During data collection, the issue of work hours was also receiving a great deal of attention in the UK as part of the Junior Doctor's strike and contract negotiations. ${ }^{22}$ After beginning with convenience sampling we shifted to purposeful sampling, which was informed by the iterative analysis. ${ }^{23}$ Our intention in sampling from multiple countries was not to compare across them. Rather we aimed to sample for sufficient variation in the work hour policy, which was the studied phenomenon. Therefore, we limited our sampling to European countries that were at varying stages of implementation of the European Working Time Directive. We stopped collecting new data when we felt that we had achieved sufficient information power based on the high quality dialogue with, and specificity of, the informants. ${ }^{24}$

One investigator (TT) conducted the semi-structured, individual interviews over Skype . Interviews were recorded and transcribed verbatim, with identifying names or places subsequently removed from the transcripts. TT recorded synchronous field notes with annotations not captured by the transcripts. Analysis proceeded iteratively, in keeping with CGT methodology and we revised the interview guide to reflect and further refine the emerging analytical insights. ${ }^{25}$ After a period of open-coding by one investigator (TT) and through a process of constant comparative analysis, early codes were collapsed into major categories. ${ }^{25}$ All co-investigators participated at this stage of the analysis onward, through discussions of categories and illustrative examples, which shaped the developing coding structure and directed theoretical sampling. Throughout this process, TT managed the data using a combination of NVivo ${ }^{\circledR}$ and MindNodePro ${ }^{\circledR}$ software.

Rigorous CGT necessitates that the researcher is explicit about how their perspectives shape the research at all stages. ${ }^{25}$ The primary investigator (TT) is a Canadian Obstetrician/Gynecologist who began this research during her residency training. She had conducted previous research with Canadian medical residents related to fatigue and work 
hour regulations. She engaged in reflexivity about her position in the research by way of memo-writing and analysis with her co-investigators.

Ethics approval for this study was obtained from the Principal Investigator's institution, Western University (REB\# 102769).

\section{Results}

Our data set included 7 male and 6 female trainees working in Denmark, the Netherlands, the United Kingdom and Ireland, sampled from various training levels while enrolled in the following programs: Anesthesia, General Surgery, Obstetrics \& Gynecology, Pediatrics, General Internal Medicine, Nephrology and Cardiology. All participants were training under the legislation of the European Working Time Directive (EWTD). Three main findings emerged from the analysis. First, trainees described working while fatigued as a commonplace occurrence that was perceived as largely unproblematic. Second, trainees described choosing to work beyond their scheduled hours. Third, trainees understood the regulations in many different ways and they identified inconsistencies between the perceived intent of the EWTD and how they experienced it in practice. Each of these findings will be elaborated in the following paragraphs. Salient quotations and corresponding anonymous participant code (\#\#\#) are provided to illustrate key findings.

Across all studied contexts, trainee fatigue was an accepted reality. Trainees provided many examples of the ways in which fatigue was evident day to day, such as exhibiting poor communication, being "totally unkind" (008), feeling reluctant to get out of bed and see patients, or struggling to remain coordinated during surgery. There was a sense that fatigue was commonplace, yet not freely spoken about, and certainly not a justification for substandard work:

"... we're kind of all tired all the time, but people don't really say it. I mean, people say, I'm tired, but they don't say, 'oh, I can't do that because I'm tired." (003)

Despite its pervasiveness in the clinical environment, many trainees felt that fatigue did not warrant further contemplation: "There isn't so much navel gazing or reflection either on the presence of tiredness or even how that might be modifying how you work." (008) They reported that such "navel gazing" about fatigue was futile because there was nothing to be done about it, as this resident pointed out: "When I've decided to do the thing, I have to finish it up... I can't just say, well, I'm tired, I have been on call, so I can't go to that important meeting." (002) Others questioned the relevance of fatigue as a safety threat within their own practice, sometimes because they did not want to imagine that fatigue might be an issue, as this trainee reflected: 
"In my experience, when I've worked particularly long hours, I can still do my job but... things like driving home become more difficult... I don't think, as doctors, we like to think we ever cause harm to our patients... I really dislike the idea that my standard of care at 8:00 a.m. and 4:00 a.m. would be different. (010)

Thus, fatigue was a familiar experience for trainees across all sampled contexts though it was seen as variably problematic or relevant to their clinical duties.

Trainees chose to work beyond scheduled hours, which occurred more frequently for some than others. Regardless of how frequently they chose to work past their shift, trainees provided a range of justifications for doing so. One justification was patient care: "If you had been involved in a particularly complicated case...then that might keep you there because you are so involved that you need to talk to people afterwards..." (006). Other justifications offered for working beyond the rules were to fulfil tacit expectations ("If you want to work here afterwards, you need to do this" 007); satisfy educational goals ("...you do want to be there for the stuff that's going to improve your training" 003); or compensate for an understaffed team ("it's usually so busy that you want to help your colleagues... And you would feel bad to leave them with all the work..." 013). Thus, trainees described a mismatch between their scheduled work hours and the actual time they spent at work providing patient care or gaining educational experience.

The regulations took on varied meanings, across which there was a disconnect between the perceived intentions of the regulations and how trainees experienced them in practice. For instance, trainees commonly identified that the regulations were intended to prevent them from experiencing fatigue-related impairment: "My perspective on the work hour regulations is about safety, safety of patients and safety of trainees." (009) However, trainees felt that the regulations imposed unnecessary constraints that interfered with providing patient care on their own terms: "That's difficult because you want to give the best care to your patient and then you feel penalized... that, oh, you must go home." (009) As the previous quote demonstrates, the safety value of the regulations was diminished if trainees felt the rules interfered with providing "the best" patient care. When reflecting on the implications of enforced regulations, another trainee reported, "If somebody just tells you that's how it is, you have to do it, but then you lay off some of the responsibility for doing some not optimal work." (007) Disruptions to continuity of care surfaced as a particularly undesirable consequence perceived by trainees:

"You don't have the same continuity with your patients or your teams... Whereas, on the old system, there was much more continuity, so you knew your department, you knew your team..." (010) 
Continuity was valued because it was thought to enable "a better feel for the patient" (003). Thus, the perceived threat to continuity imposed by the regulations contradicted their intended purpose as a safety mechanism.

Some trainees perceived that the regulations also carried meaning about the time that clinical work should take; in this context, staying longer than the regulated work hours could imply inefficiency. Fear of being criticized for being a "poor time manager" (009) led some trainees to question whether they should work beyond their scheduled hours, even for the sake of continuity: "There's lots of kind of hearsay ...about what happens if you put in your [actual] hours ... they'll come back to you and say you're not an efficient F1 doctor." (001) Conversely, those who were able to work within the regulations had a sense of accomplishment: "When I talk to my colleague residents, they often ask me... how can it be that you are finished at 5:00? I just work effectively, in my opinion, and get your priorities straight." (011) Other trainees found that the regulations highlighted the fiscal burden of working outside the restrictions: "...because of the economic climate, we are not allowed to have extra hours if we in any way can help it" (007) So, while the work hour restrictions were explicitly understood as intending to promote a patient safety agenda, there was a tacit understanding that the rules also functioned as a barometer for efficient work practices.

Another meaning of working hour regulations was protection against exploitation. However, trainees perceived that this intent could simultaneously undermine their vocational autonomy. Generally, the regulations were appreciated for calling attention to the issue of excessively long working hours:

"...before the European Working Time Directive came in and the monitoring, there was no impetus to look at the hours you were working. There was no drive. So when monitoring came in and the hospitals got fined for being outside the European Working Time Directive, that was the first time ever people said, 'you need to go home now.'" (010)

One trainee emphasized the intended benefits for trainees' wellbeing, when she acknowledged, "... there's a reason we should be going home... in the longer term, it's probably better for your health if you do go home and have a better work/life balance."(001) And yet the same trainee, like many others, found the rules unacceptably restrictive:

"I'm quite obsessive. I like knowing what's going on with my patients, so if my patients needed stuff doing I would stay. Sometimes I got quite frustrated when I kept getting told to go home" (001) 
Trainees received this message from other colleagues, occasionally consultants and sometimes nurses. The trade-off between personal satisfaction and abiding by work hour regulations was noticed at the workplace level as well:

"We're starting to see more and more junior doctors leaving the hospital work because they find they can't have the life they would like to have in the departments... They don't find that they have any autonomy on work. It's the employer who decides everything and the workload is too high..." (002)

Trainees found the regulations rigid and overbearing, which detracted from the intention to prevent them from being overworked.

\section{Discussion}

We set out to understand the nature and impact of EWTD regulations as perceived by trainees who experience it day to day. Our results reflect the "dazzlingly complex moral, social, intellectual, and cultural enterprise of academic medicine"26 p141 in which participants worked and trained - a context in which work hour regulations are seen to have both intended and unintended effects.

Our findings suggest that work hour regulations do not solve the problem of trainees working to the point of fatigue. Other researchers have come to similar conclusions in both Europe and North America. ${ }^{19}$ Douglas reported that $81 \%$ of trainees experienced fatigue despite maintaining an EWTD compliant rota. ${ }^{10} \mathrm{~A}$ cohort of U.S. general surgery residents scored similarly on a standardized assessment of sleepiness before and after implementation of work hour regulations. ${ }^{27} \mathrm{~A}$ literature review by Morrow et al prompted the question of whether fatigue can be managed by simply restricting work hours. ${ }^{28}$ There are many possible explanations to account for the persistence of fatigue in spite of work hour regulations. Landrigan argues that issues of "circadian misalignment and chronic sleep deprivation" also need to be taken into account. ${ }^{2}$ It may be that inter-individual differences in tolerance to sleep deprivation are contributing. ${ }^{29}$ Other factors, such as proportion of nighttime shift work and personal demands outside of the workplace also influence fatigue and sleep opportunities. ${ }^{20,30,31}$ These explanations center on the notion of fatigue as a primarily physical or emotional phenomenon determined by hours of sleep and work. However, fatigue can also be understood as a social construct. ${ }^{15}$ The sense that fatigue is pervasive yet must not interfere with clinical duties, as suggested by our findings, is one example of how fatigue is socially constructed. This approach to understanding fatigue allows us to consider more broadly why fatigue persists despite work hour regulations. 
Across the varied meanings of work hour regulations understood by trainees, we found three rhetorics: the rhetoric of patient safety, the rhetoric of wellbeing and the rhetoric of efficiency. By identifying these as rhetorics, we are acknowledging that these meanings were not only descriptive but also constructive: that is, they shaped peoples' attitudes and their actions. These rhetorics have implications for understanding the effects of regulations in medical training contexts both inside and outside of the EWTD.

The rhetoric of patient safety that was apparent in our results is well-established in the literature. ${ }^{5,32,33}$ Within this rhetoric, patient safety is both used to justify and also to challenge the regulations. It sets up a false dichotomy wherein patients can either be cared for by a succession of unfamiliar yet well-rested trainees, or by a fatigued and potentially impaired trainee providing continuous care. Neither situation is ideal. To resolve this false dichotomy, we must critically examine the two main underlying assumptions. First, there is good reason to question the notion that reducing work hours alone will necessarily result in rested trainees ${ }^{15,26}$ The second assumption worth examining is the belief that safe care is contingent upon individual continuity of care. Indeed, fragmented care is believed to be problematic because of inadequate transfer of information from one provider to the next. ${ }^{34}$ Trainees in our study echoed this assumption and generally maintained that individual continuity of care was synonymous with safer care. However, team-based concepts of continuity have shown promise in reducing adverse events from patient handoffs. ${ }^{35}$ The success of structured team-based handover strategies requires a reframing of continuity in which team members share the responsibility. ${ }^{36,37}$ Thus, before implementing work hour regulations in other contexts, it is worthwhile to explore how continuity is defined in the workplace. A deliberate move towards team-based models of continuity, as Starmer et al $\left.\right|^{35}$ have modeled, might shift the patient safety discourse from rhetoric to reality.

The rhetoric of wellbeing is also described by the literature on resident work hours, which has primarily focused on the negative impact of extended work hours on trainee wellbeing. ${ }^{1,30,38}$ In spite of well-intentioned regulations, many trainees across procedural and non-procedural programs felt that their sense of vocation was compromised. Trainees perceived that they had lost aspects of their role that made them professionals, including autonomy and self-regulation. Similar reservations have been demonstrated among surgical trainees who identified long working hours as a rite of passage. ${ }^{39,40}$ Thus, the rhetoric of wellbeing is complicated by this perceived threat to the professional ethos. Others have demonstrated that individuals' autonomy over work hours is a significant predictor of "job satisfaction, lack of fatigue, and social functioning". 41 p27 In fact, this relationship is maintained, regardless of the total hours worked. ${ }^{42}$ Given that wellbeing, like fatigue, is a complex social construct, policy-makers in other contexts should consider dimensions of wellbeing that align with professional values when implementing work hour regulations. 
Although the first two rhetorics and the tensions they produce are well defined by the duty hour regulation literature, the rhetoric of efficiency is less clearly defined. Our findings suggested that some trainees felt pressured to complete their work within the allotted time, in order to avoid being labeled as inefficient. Disturbingly, trainees in a different study also reported that the threat of "being labeled with 'poor time keeping' on end-of-rotation assessment" was a strategy used by Trusts to ensure that trainees reported only compliant work hours. ${ }^{14 \mathrm{p} 5}$ In contrast, research situated in the Canadian context found that trainees believed they were demonstrating a commitment to the profession by working beyond their scheduled shift; efficiency was not an immediate concern. ${ }^{43}$ An important consequence of the rhetoric of efficiency is the phenomenon of work compression, in which trainees are expected to perform the same amount of work with fewer resources in fewer hours. ${ }^{14}$ As Boodman notes, "Residents live in the cracks of a broken health care system. They get things done." $44 \mathrm{p} 4$ Certainly, being efficient and getting things done is not inherently problematic, unless it comes at the cost of quality, as some of our participants suggested. The rhetoric of efficiency has surfaced in other aspects of medical education as well. In their critical discourse analysis of resident feedback, Renting et al discovered that efficiency "emerged as an important attribute of physicians." ${ }^{\prime 4}$ p375 This rhetoric has implications beyond duty hour reform, particularly regarding professional development. An overemphasis on being an efficient labourer could undermine other roles, such as being a compassionate physician, which sometimes comes at the cost of efficiency.

Like all qualitative research, this study is situated within a given context that inevitably shaped our findings. One salient aspect of our study context was the contemporaneous junior doctors strike in the UK, which brought issues related to labour rights and work hours to the forefront. ${ }^{22}$ Trainees who were affected by the junior doctors' contract turmoil may have had a different perspective on work hour regulations than those who were unaffected. Our recruitment via personal communication also led us to key informants who were all connected, in some way, to the medical education scholarly community. Had we recruited individuals outside of this community, different meanings of the regulations may have emerged.

\section{Conclusions}

In our exploration of how trainees across four European countries understand existing work hour regulations, we found three rhetorics that are complicated by inherent tensions. Trainees in our study perceived a disconnect between what the EWTD was explicitly intended to accomplish and how they experienced its effects on their practice. Trainees accepted the tensions within each of the rhetorics, which suggests that some of these tensions may be functional despite seeming problematic. This is likely a reflection of the complexity of the academic environment, a complexity that allows trainees to abide by the 
regulations to serve one purpose and challenge the regulations to uphold another purpose. We also found that the regulations did not eliminate trainee fatigue. One possible explanation is that duty hour reform is designed to address the physical or cognitive aspects of fatigue, while overlooking the social constructs of fatigue. These insights are useful regardless of whether a given jurisdiction is contemplating work hour reform, loosening restrictions or maintaining existing regulations as they highlight the limitations of straightforward interventions to solve complex problems.

\section{References}

1. Ayas NT, Barger LK, Cade BE, et al. Extended work duration and the risk of selfreported percutaneous injuries in interns. JAMA. 2006;296(9):1055-1062.

2. Landrigan C. Effect of lack of sleep on medical errors. In: Cappuccio FM, Michelle; Lockley, Steven, ed. Sleep, Health, and Society: From Aetiology to Public Health. United Kingdom: Oxford University Press; 2010:382.

3. Arnedt JT, Owens J, Crouch M, Stahl J, Carskadon MA. Neurobehavioural Performance of Residents After Heavy Night Call vs After Alcohol Ingestion. JAMA. 2005;294(9):1025-1033.

4. Bilimoria KY, Chung JW, Hedges LV, et al. National Cluster-Randomized Trial of DutyHour Flexibility in Surgical Training. N Engl J Med. 2016;374(8):713-727.

5. Ahmed N, Devitt KS, Keshet I, et al. A systematic review of the effects of resident duty hour restrictions in surgery: impact on resident wellness, training, and patient outcomes. Annals of surgery. 2014;259(6):1041-1053.

6. Swanwick T. Informal learning in postgraduate medical education: from cognitivism to 'culturism'. Medical education. 2005;39(8):859-865.

7. Collier R. Sleepless in the surgical ward. CMAJ. 2009;180(11):1095-1096.

8. Temple J. Resident duty hours around the globe: where are we now? BMC Med Educ. 2014;14 Suppl 1:S8.

9. Murray A, Pounder R, Mather H, Black C. Junior doctors' shifts and sleep deprivation. Bmj. 2005;330(7505):1404-1404.

10. Douglas NJ. Sleep, performance and the European Working Time Directive. Clinical Medicine. 2005;5(2):95-96.

11. Datta ST, Davies SJ. Training for the future NHS: training junior doctors in the United Kingdom within the 48-hour European working time directive. BMC Med Educ. 2014;14 Suppl 1:S12.

12. Cappuccio FP, Bakewell A, Taggart FM, et al. Implementing a 48 h EWTD-compliant rota for junior doctors in the UK does not compromise patients' safety: assessorblind pilot comparison. QJM. 2009:hcp004.

13. Morris-Stiff GJ, Sarasin S, Edwards P, Lewis WG, Lewis MH. The European Working Time Directive: One for all and all for one? Surgery. 2005;137(3):293-297. 
14. Clarke RT, Pitcher A, Lambert TW, Goldacre MJ. UK doctors' views on the implementation of the European Working Time Directive as applied to medical practice: a qualitative analysis. BMJ open. 2014;4(2):e004390.

15. Taylor TS, Watling CJ, Teunissen PW, Dornan T, Lingard L. Principles of fatigue in residency education: a qualitative study. CMAJ Open. 2016;4(2):E200-E204.

16. Parshuram CS, Amaral AC, Ferguson ND, et al. Patient safety, resident well-being and continuity of care with different resident duty schedules in the intensive care unit: a randomized trial. CMAJ. 2015;187(5):321-329.

17. Maniatis T. Resident duty-hour reform: moving beyond "change for change's sake". Canadian Medical Association Journal. 2015;187(5):309-310.

18. Tucker P, Brown M, Dahlgren A, et al. The impact of junior doctors' worktime arrangements on their fatigue and well-being. Scandinavian journal of work, environment \& health. 2010:458-465.

19. Brown $M$, Tucker $P$, Rapport F, et al. The impact of shift patterns on junior doctors' perceptions of fatigue, training, work/life balance and the role of social support. Quality \& safety in health care. 2010;19(6):e36.

20. Tucker $\mathrm{P}$, Bejerot $\mathrm{E}$, Kecklund $\mathrm{G}$, Aronsson $\mathrm{G}$, Åkerstedt T. The impact of work time control on physicians' sleep and well-being. Applied ergonomics. 2015;47:109-116.

21. Watling CJ, Lingard L. Grounded theory in medical education research: AMEE Guide No. 70. Medical teacher. 2012;34(10):850-861.

22. Lancet T. Brexit and junior doctors' contracts: the real threats to the NHS. The Lancet. 2016;388(10041):211.

23. Patton MQ. Qualitative evaluation and research methods. SAGE Publications, inc; 1990.

24. Malterud K, Siersma VD, Guassora AD. Sample Size in Qualitative Interview Studies Guided by Information Power. Qualitative health research. 2015:1049732315617444.

25. Charmaz K. Constructing grounded theory. Sage; 2014.

26. Caldicott CV, Holsapple JW. Training for fitness: reconsidering the 80-hour work week. Perspectives in biology and medicine. 2008;51(1):134-143.

27. Lindeman BM, Sacks BC, Hirose K, Lipsett PA. Multifaceted longitudinal study of surgical resident education, quality of life, and patient care before and after July 2011. J Surg Educ. 2013;70(6):769-776.

28. Morrow G, Burford B, Carter M, Illing J. The impact of the Working Time Regulations on medical education and training: Literature review. Report for the General Medical Council. 2012.

29. Czeisler $\mathrm{C}$. Ethical considerations for the scheduling of work in continuous operations: Physicians in training as a case study. In: Cappuccio FM, Michelle; Lockley, Steven, ed. Sleep, Health \& Society. From Aetiology to Public Health. United Kingdom: Oxford University Press; 2010:435-456.

30. Baldwin DC, Daugherty SR. Sleep deprivation and fatigue in residency training: results of a national survey of first- and second-year residents. Sleep. 2004;27(2):217-223. 
31. Taylor TS, Nisker J, Teunissen PW, Dornan T, Lingard L. Recovery of Sleep or Recovery of Self? A Grounded Theory Study of Residents' Decision Making Regarding How to Spend Their Nonclinical Postcall Time. Academic Medicine. 2016;91(3):395-400.

32. Businger AP, Laffer $U$, Kaderli R. Resident work hour restrictions do not improve patient safety in surgery: a critical appraisal based on 7â€\%oyears of experience in Switzerland. Patient safety in surgery. 2012;6(1):17.

33. Baldwin K, Namdari S, Donegan D, Kamath AF, Mehta S. Early effects of resident work-hour restrictions on patient safety: a systematic review and plea for improved studies. The Journal of bone and joint surgery American volume. 2011;93(2):e5.

34. Petersen LA, Brennan TA, O'Neil AC, Cook EF, Lee TH. Does housestaff discontinuity of care increase the risk for preventable adverse events? Annals of internal medicine. 1994;121(11):866-872.

35. Starmer AJ, Spector ND, Srivastava R, et al. Changes in medical errors after implementation of a handoff program. New England Journal of Medicine. 2014;371(19):1803-1812.

36. Arora VM, Reed DA, Fletcher KE. Building continuity in handovers with shorter residency duty hours. BMC Med Educ. 2014;14 Suppl 1:S16.

37. Arora VM, Farnan JM, Humphrey HJ. Professionalism in the era of duty hours. JAMA. 2012;308(21):2195-2196.

38. Barger LK, Cade BE, Ayas NT, et al. Extended work shifts and the risk of motor vehicle crashes among interns. The New England journal of medicine. 2005;352(2):125-134.

39. Coverdill JE, Bittner JG, Park MA, Pipkin WL, Mellinger JD. Fatigue as impairment or educational necessity? Insights into surgical culture. Acad Med. 2011;86(10 Suppl):S69-72.

40. Brooks JV, Bosk CL. Remaking surgical socialization: Work hour restrictions, rites of passage, and occupational identity. Social Science \& Medicine. 2012;75(9):1625-1632.

41. Costa G, Sartori S. Flexible work hours, ageing and well-being. International Congress Series. 2005;1280:23-28.

42. Cedfeldt AS, Bower EA, English C, Grady-Weliky TA, Girard DE, Choi D. Personal time off and residents' career satisfaction, attitudes and emotions. Med Educ. 2010;44(10):977-984.

43. Taylor TS, Nisker J, Lingard L. To stay or not to stay? A grounded theory study of residents' postcall behaviors and their rationalizations for those behaviors. Academic medicine : journal of the Association of American Medical Colleges. 2013;88(10):1529-1533.

44. Boodman S. Waking up to the problem of fatigue among medical interns. Los Angeles Times2001:S1.

45. Renting N, Dornan T, Gans RO, Borleffs JC, Cohen-Schotanus J, Jaarsma ADC. What supervisors say in their feedback: construction of CanMEDS roles in workplace settings. Advances in Health Sciences Education. 2016;21(2):375-387. 

Chapter 7

Discussion 
Residents and training hospitals exist in a symbiotic relationship. Because of this longstanding and mutually beneficial arrangement, substantial changes to residency training are difficult to implement and often met with resistance. Restrictions to resident work hours represent one such proposed change. These restrictions are based on the notion that the traditional training model, where residents work an unlimited amount of hours, is harmful to patients and trainees because it leads to fatigued trainees. This oversimplified stance fails to account for the many ways in which resident work hours and fatigue intersect with other training issues including educational considerations (supervision, opportunities for learning), wellbeing (consequences of exhaustion, burnout), and service provision (labour rights, patient safety).

This thesis set out to explore fatigue as a social phenomenon and its relevance to workplace interventions intended to mitigate fatigue, including work hour restrictions and fatigue management plans. The research was situated in different postgraduate training contexts. The Canadian context was characterized by inconsistently enforced, non-legislated work hour rules. In contrast, the European context was characterized by long-standing, enforced work hour legislation. Within the Canadian context, working longer hours was seen as a way of demonstrating commitment to patients and the profession. But in the European context, working later was equated with inefficiency. Based on my findings across these contexts, fatigue is indeed a social phenomenon that is both pervasive and covert. Both Canadian and European trainees described a collective reluctance to speak openly about fatigue within the clinical training environment. This shared finding underlines the utility of seeing fatigue as a social phenomenon when faced with the problem of mitigating fatigue. By naming the social dimensions of fatigue, as I have done in this thesis, the barriers to authentically managing fatigue in the clinical workplace become more apparent. This has implications for medical training in jurisdictions at all stages of work hour reform, whether regulations are being contemplated, implemented or revised. For example, interventions that focus solely on hours of work are insufficient to manage such a multi-dimensional construct. Work hour restrictions can bring awareness to the reality of fatigue in practice, but they do not eliminate fatigue. Solutions must account for the fact that trainees are social beings that need to recover themselves as much as they need to recover sleep after a night shift. Effective solutions require changes at the level of the clinical training environment rather than relying solely on trainees to carry the responsibility of keeping fatigue at bay.

Throughout all four studies, residents also vividly described their individual, lived experiences of fatigue during training. Publishing constraints precluded this aspect of my research from being included in the manuscripts; however, I offer some salient examples here as a way of illustrating the pervasiveness of fatigue among trainees. These quotes come from two data sets, one that formed the basis for chapters 3 and 4 and the other that led to chapter 5 . The quotes are followed by a number indicating resident participant code. Manifestations of physical cues included "headaches"(013), "dozing off every five or ten 
minutes" during sign-over rounds (006), feeling "essentially hungover" (008) or deferring certain tasks "for the morning guys because the manual dexterity doesn't come around"(007). For some residents, experiencing fatigue was signalled by changes in affect, such as "the stress associated with feeling so tired" (010) or being "really cranky" (004). Others noticed their impatience during clinical interactions: "I just have less patience for those types of conversations, especially if they don't go the way I want them to, like the patient has a lot of questions or doesn't understand or is upset. I don't have the patience for that when I'm tired" (017). Many residents perceived that the cognitive demands of clinical tasks were experienced differently when fatigue was at play. Memorable cognitive indicators included "little things that you forget to do" (012), an awareness of "starting to fuddle things up" (014) by confusing patient histories, "finding it's just taking you longer to figure out what you want to do with the patient" (016) or being "more prone to lose your train of thought...and get distracted by things and then lose your place in whatever algorithm you have" (003). As these quotations indicate, residents remained tuned-in to the physical, emotional and cognitive dimensions of their fatigue.

Although much has been said about the issues of resident work hour restrictions from an individual perspective in the literature, a sociocultural perspective offers a useful way of considering these socially embedded problems. Therefore, in this chapter, I will return to the four key debates involving resident work hour reform and reconsider them through a sociocultural lens to demonstrate the utility of this perspective.

\section{Is Sleep Deprivation Dangerous?}

In the thesis introduction, I established that this line of inquiry questions whether or not a sleep-deprived individual is hazardous within the clinical workplace. In attempting to settle this debate, researchers have drawn upon diverse fields including chronobiology, ${ }^{1}$ genetics, ${ }^{2}$ experimental psychology ${ }^{3}$ and simulation. ${ }^{4,5}$ These fields all seek to objectively quantify the impact of sleep deprivation on an individual's performance. Indeed, the debate about sleep deprivation in medical training is largely predicated on the notion that a sleep-deprived person is more likely to commit a medical error. The following paragraphs will take a different perspective by considering this debate in the context of the workplace, a sociocultural setting.

A sociocultural perspective must consider what is meant by sleep deprivation within a given context, rather than assuming a shared understanding of this concept across all contexts. In their sociological exploration of sleep, Williams et al also called attention to this gap, by suggesting that, "we need to know much more about people's own definitions and normative expectations regarding 'ideal', 'adequate', or 'enough' sleep, which themselves may be context dependent." $6(\mathrm{p} 4)$ Furthermore, sleep deprivation may hold different significance across different medical education contexts. It has been seen as a surrogate for professional dedication ${ }^{2}$ and conceptualized as an educational training tool in surgical 
training contexts. ${ }^{7}$ My research adds to these existing conceptualizations of sleep deprivation in medical training by highlighting a collective sense that sleep deprivation leading to fatigue is both commonplace and, in many cases, unavoidable. In conceptualizing sleep deprivation as unavoidable, some residents struggled to see it as problematic. These socially-situated notions warrant consideration, as they shape perceptions of whether sleep deprivation is dangerous, regardless of what the empirical data suggest.

Even if we assume a straightforward understanding of sleep deprivation, as some have done, proving whether it is dangerous in the clinical workplace remains challenging. Certain undesirable consequences of sleep deprivation may not register as overtly dangerous in the clinical training environment. For instance, while studying the social constructions of fatigue, we found that residents readily admitted to strained social interactions with colleagues and other professionals when they were fatigued. Residents described feeling apathetic, frustrated and impatient. When it came to patient care, residents were even less troubled about the impact of these affective aspects of their fatigue than they were about the possibility of technical mishaps or diagnostic errors. Thus, perceptions about the potential dangers of fatigue in the clinical setting were narrowly defined and limited to concerns about the impact of fatigue on cognitive or technical function.

Ultimately, workplace culture defines what is considered dangerous and unacceptable. By extension, it also delineates innovative from deviant behaviour ${ }^{8}$ and dictates which skills must be preserved at all costs and which ones are extraneous. Whereas the clinical workplace has tended to focus on cognitive or technical errors, the business industry has considered other social consequences of fatigue. For example, increased hostility and impaired self-control due to sleep deprivation have been associated with deviant workplace behaviour. ${ }^{9}$ There is good reason to suspect that fatigue has unfavourable social consequences in the clinical workplace as well. Yet, this aspect of fatigue is seen as less problematic and perhaps less visible than other implications of fatigue related to cognitive dysfunction. It is well established that the clinical training culture tends to privilege medical expertise above other physician roles. ${ }^{10}$ As long as communication and collaboration are secondary roles, the fatigue-induced unraveling of trainees' social skills will likely remain overlooked.

While it could be argued that one apathetic or frustrated trainee may not have a profound impact on patient care, the impact of an exhausted and emotionally labile team of healthcare professionals bears further consideration. Reason cautions that, "the psychological precursors of an error (that is, inattention, distraction, preoccupation, forgetting, fatigue and stress) are probably the last and least manageable links in the chain of events leading to an error." ${ }^{11(p 84)}$ That "chain' extends beyond the medical members of a team. And, unfortunately, fatigue is not problem that is unique to medical trainees and physicians within the healthcare context. ${ }^{12}$ 
Although the medical education literature rarely makes reference to fatigue among nurses, fatigue is a patient safety issue identified in the nursing literature. ${ }^{12,13}$ There is far less ambiguity about the dangers of fatigue in the nursing literature. ${ }^{13}$ Furthermore, there is greater emphasis placed on social implications of fatigue, such as compassion fatigue and high attrition rates from work-related fatigue among nurses. ${ }^{14}$ Given that nurses are not immune to fatigue in the workplace, medical education must also consider the impact of fatigued nurses interacting with fatigued residents. For instance, team members may engage in different practices to mitigate their fatigue, and these practices may interact or interfere with one another in impactful ways. One particularly salient example of this was evident in my Canadian research but was not featured in my published manuscripts. Many residents felt that nurses often sent non-urgent pages overnight, which disrupted any chance of sleep during residents' 24-hour shifts. Residents were convinced that this was a consequence of the fact that nurses worked 12-hour shifts and did not appreciate that residents' hours were different. This dynamic suggests that we must also grapple with the implications of sleep deprivation at the level of a clinical unit or care delivery team.

Given that trainee sleep deprivation is complicated by the team context of patient care, we need to consider distribution of responsibility for potential dangers associated with fatigue. Distribution of responsibility is reflected in Reason's hazard framework. ${ }^{15}$ This well-known framework is predicated on the notion that errors are the final consequence of multiple defects that come into alignment in an otherwise functional system. Many trainees in my research felt that there were very few circumstances in which their erroneous actions would directly result in harm to patient care. They willingly acknowledged that fatigue might lead them to work more slowly or overlook a particular detail, but there was a general sense that the system contained sufficient checks and balances to prevent these oversights from reaching patients and causing harm. Findings from other high-stakes industries can help us to critique this assumption. One compelling study by the aviation industry showed that fatigued, post-duty flight crews performed better than the rested crew, even though individuals in the post-duty crew made more errors than individuals in the rested crew. ${ }^{16}$ Further analysis revealed that the post-duty team demonstrated more effective communication, which compensated for the higher individual error rate, presumably because they had already logged many hours together. ${ }^{16}$ This research seems to support my participants' assumptions that the system protected against errors due to their fatigue: familiarity and stability within teams seems to compensate for increased risk of individual error and the otherwise troublesome social interactions. Unfortunately, healthcare teams are characteristically both unstable and unpredictable, ${ }^{17}$ so it is not clear that these findings are transferrable to our setting, and trainees' sense of a protective team system may be inappropriate. Further research is needed to determine whether efforts to achieve more stable or consistent teams in healthcare can mitigate the risk of fatigued healthcare providers. 
And finally, we cannot afford to overlook the larger societal context in which medical training is situated. One salient example of this is society's current obsession with sleep and fatigue. Recent sociological work has described this obsession, which is evident in the "nearly five thousand apps that come up when you search 'sleep' in the Apple App Store, more than 15 million photos under \#sleep on Instagram, ... and more than 24 million under \#tired." ${ }^{18}$ One emerging discourse positions sleep as a tool that enables us to "regain control over our out-of-kilter lives" and urges society to "join the sleep revolution" ${ }^{18}$ Although there are growing, collective concerns about an epidemic of sleep deprivation, it is unclear whether we are truly worse off than our predecessors. ${ }^{6}$ When it comes to quality and quantity of sleep, we have benefitted from modern day luxuries including shelter and heat possibly more than we have suffered from the chronic use of smartphones and other technologies. ${ }^{6}$ Yet, as sociologist Williams points out, "sleep(iness) is now being problematized if not politicized in contemporary society through discourses of risk, if not crisis or catastrophe..." ${ }^{19(p 13)}$ Consequently, the public has developed strongly held beliefs about the perils of sleep-deprived physicians. ${ }^{20}$ Given that physicians and trainees are held accountable to society, as long as the public believes that sleep deprivation is inherently dangerous, it may not matter whether the profession resolves the debate otherwise.

\section{Does Resident Training Suffer from Work Hour Restrictions?}

This line of inquiry questions whether work hour restrictions detract from residency training, leading to inexperienced and incompetent practicing physicians. With few exceptions, this debate tends to be approached from an individualistic perspective. Characteristically, researchers and stakeholders are seeking clarity about the impact of fewer consecutive working hours on competence as it pertains to individual residents. In the thesis introduction, I noted a sociocultural component to this debate that has received less attention in the literature. I highlighted how implicit messaging in the training environment can influence perceptions about the quality of training. In paragraphs that follow, I will revisit this issue while introducing additional salient sociocultural considerations.

Residents can be considered relative newcomers to a community of practice and therefore legitimate peripheral participation ${ }^{21}$ is a useful lens to use when exploring issues of residency training. Within this framework, learning is conceptualized as legitimate, peripheral participation within a given community of practice. ${ }^{21}$ This is a dynamic framework in which "learners are transformed through participation in the community [just as] their participation, in turn, transforms the community." ${ }^{22(p 64)}$ Thus, this sociocultural learning perspective calls attention to aspects of the training environment that enable or impede trainees' legitimate, peripheral participation.

Work hour restrictions intersect with issues of legitimate, peripheral participation at many levels. Most straightforwardly, there is the issue of restrictions lessening participation 
through limiting trainee exposure to the workplace and the activities therein. This concern is well-established in the literature ${ }^{23}$ and was reflected in my research, which indicated that some trainees chose to stay beyond their shift in order to gain more workplace experience. However, my study also found that other trainees did not feel their educational needs would be met by working longer hours. There were two socially mediated influences that informed these differing positions. Firstly, as a community of practice, the training program influenced trainees' sense of what counted as valuable learning opportunities. For example, many surgical trainees suggested that the operating room was more likely to provide novel learning opportunities. This was valued above ambulatory experiences, which were perceived to be interchangeable learning opportunities. Secondly, many trainees who saw the educational merit in staying believed that long work hours were a reality of their future practice.

The argument that working long hours is justified because it reflects future practice patterns points to a more complicated relationship between work hour restrictions and legitimate, peripheral participation. In looking through a sociocultural lens, it becomes apparent that medical educators, "give or deny students opportunities to participate and learn to fit into their roles". ${ }^{24(p 133)}$ When it comes to work hour restrictions, the implication is that medical educators may preferentially grant such opportunities to trainees who endorse and enact shared ideas. ${ }^{25}$ Trainees implicitly learn that they stand to benefit from sharing the same opinions about work hours as their preceptors, even when those opinions conflict with existing policy and degrade the perceived quality of their training. ${ }^{25}$ These sociocultural forces mediate both the training experience and the trainees' perceptions of those experiences.

Although the core premise of the larger debate centers on training as it pertains to trainees' medical knowledge and skill, the impact of work hour restrictions also relates more broadly to issues of professionalism and identity development. Working long hours for the sake of doing so, rather than to obtain exposure to further learning opportunities, may serve a purpose in certain training contexts. Brooks and Bosk found that working long hours was valued as a rite of passage for surgical trainees. ${ }^{26}$ Consequently, work hour restrictions challenged the collective occupational identity of surgical trainees because it excluded them from the rite of passage upheld by their preceptors. ${ }^{27}$

Preceptors are increasingly called upon to pass judgment about trainees' professionalism. Assessment then becomes another tacit mechanism by which trainees learn what is valued and what it takes to become a full participant within the community. However, evaluating professionalism is inherently problematic. ${ }^{28}$ First, there are many different viewpoints and inconsistencies between assessors about what is actually being judged (e.g. traits, attitudes or behaviour). ${ }^{28}$ Second, professional ideals are not static. Medicine has a long tradition of lamenting lost professional values and skills in the modern trainee. ${ }^{29}$ Altruism, for example, 
"is perceived to be in decline in the current generation". ${ }^{30}$ And yet, according to analysis of codified documents, altruism has been increasingly de-emphasized over the past century. ${ }^{30}$ The recent era of work hour restrictions has also been criticized for reinforcing, "certain contemporary societal attitudes that are antagonistic to the traditional values of medicine... [with] an emphasis on personal lifestyle and care of the patient second." ${ }^{31(\mathrm{p} 658)}$ Preceptors who cherish the traditional values are likely to favour trainee behaviours such as coming in early and staying late, even when doing so is in violation of working hour restrictions (and may not be in patients' best interests). ${ }^{28}$ There is great temptation to cling to a misremembered and nostalgic past, particularly when it comes to passing judgment about professional conduct. ${ }^{29}$ Unless today's preceptors can overcome this temptation, we risk becoming stagnant, rather than moving forward towards a "new professionalism" which includes respecting personal limits. ${ }^{32}$

Another perspective on work hour regulation and identity development posits that long working hours provide a mechanism to ensure that trainees learn how to manage their onand off-duty time effectively. ${ }^{28}$ Some have argued that working long hours teaches trainees to "weigh and choose between competing priorities, such as self-care...professional autonomy and the patient's and public's best interest". ${ }^{33(p 135)}$ This assumes that clinicians who trained in earlier eras of unrestricted work hours have learned how to strike this balance. The burnout literature would suggest otherwise. Longer work hours have been associated with greater conflicts at home, higher rates of depression and workplace error. ${ }^{34-}$

${ }^{36}$ High attrition rates have also been attributed to unfavourable work hours and lifestyle. ${ }^{37,38}$ Coulehan and Williams highlight another undesirable consequence of long work hours on trainees' professional identity. They caution that excessive work hours is one of many perceived sacrifices that, "engender[s] a sense of entitlement to high income, prestige, and social power..." ${ }^{38 \text { (p11) }}$

Baldwin and Daugherty offer a counter position by proposing that reduced hours provide trainees with adequate space that is necessary to learn how to manage their lives. ${ }^{39}$ This resonates with my second study, where even mundane errands took priority over sleep for some residents as they sought to establish their place in the world outside of the hospital. Although this was a legitimate form of recovery, residents' long work hours meant that maintaining a normal life came at the cost of sleep. Although residents in a study by Ratanawongsa, Wright and Carrese saw residency as a time of temporary imbalance, the authors question whether the imbalance is indeed temporary. ${ }^{40}$ The habits and behaviours established during residency that reinforce an imbalance are likely to persist beyond the training years.

\section{Do Work Hour Restrictions Compromise Patient Care?}

This line of inquiry considers whether restricting resident work hours has a negative impact on patient care due to interruptions in continuity of care from patient handoffs. In the duty 
hours literature, continuity is typically perceived as the responsibility of one individual, usually the resident on the clinical team. Within this framework, the medical trainee plays a critical role as the primary custodian of a patient's history, course in hospital and plan of care. It follows that the trainee's absence from the team compromises patient care. Although this individualistic conceptualization of continuity aligns with professional ideals including self-sacrifice, it can also reinforce maladaptive behaviours such as presenteeism. ${ }^{41}$ In the following paragraphs, I will challenge the notion that continuity is an individual's responsibility and consider additional sociocultural implications of this stance in an era of work hour restrictions.

Across all of my studies, trainees held a predominantly individualistic perception of continuity. This is consistent with other research, such as a qualitative study demonstrating that residents valued the "Iongitudinal experience with patients" afforded by night float call models which strengthened their ability as individuals to provide continuous care. ${ }^{42}$ Reid et al's broad literature review also highlighted a shared assumption that "enduring contact with a single provider is linked with stronger relationships, better information transfer and uptake, and more consistent management." ${ }^{\text {"3(p. iii) }}$ One discrepant example from my nonCanadian cohort of participants bears further consideration here. Unlike his peers, who struggled to handover unfinished patient care duties at the end of a shift, one trainee reported that he was always able to leave work on time. I challenged him on this point, by citing his colleagues who were compelled to stay, often for what they perceived to be continuity of care. In reply, he endorsed an alternative model of continuity: "... I believe that if one person can't be exchanged, the system is flawed. So, I don't believe in people who can be missed because that is a symptom of a flawed system." This resonates with calls for a new professionalism wherein "patient ownership is not relegated to an individual, but shared among a group of team members." ${ }^{32(\text { 2196) }}$ Admittedly, this shift will not be easy in light of deeply entrenched professional ideals that prioritize the individual above the collective. $^{44}$

Outside of the primary discourses on duty hour restrictions, however, more expansive notions of continuity exist. Management continuity includes, "the provision of timely and complementary services within a shared management plan." ${ }^{\text {43(p iii) }}$ The nursing and mental health literature places greater emphasis on this version of continuity. ${ }^{43}$ It may be that work hour restrictions are the very impetus needed to force a re-examination of professional ideals that no longer serve their intended purpose. For example, traditional, cherished professional ideals maintain that the physician is the ultimate authority. Yet, the patient safety literature considers this a barrier to achieving ultra-safe health care. ${ }^{45}$ If continuity of care was a shared responsibility embodied by the team rather than an individual, the coming and going of individual team members, whether due to shift work or illness, would not threaten patient care. 
Patients are an important, albeit often overlooked, part of the sociocultural milieu that shapes and sustains notions of continuity of care. Both patients and physicians are quite invested in the notion of the patient-physician relationship; it implies a stable, dyadic relationship that patients have come to expect. ${ }^{46}$ The perpetuation of this construct further complicates the debate about resident work hours and patient care, although this has not been part of the discussion so far, even in my own research. If we redefine continuity as a shared entity, we also need a language or construct that captures how the patient might have a relationship with a team instead of primarily with an individual provider.

\section{Can Fatigue be Managed?}

So far we have established that sleep deprivation is not benign and that work hour restrictions are in conflict with traditionally held views about what quality training and patient care look like in the clinical environment. As long as these are the realities of training and practice, fatigue will also be a reality in the clinical workplace. It follows that we must consider whether or not fatigue can be managed.

While many industries identify fatigue as an occupational health and safety concern, medicine has tended to focus on individuals' duty to manage their own fatigue. Researchers have called for educational interventions to "encourage improved sleep hygiene among residents", ${ }^{47(\mathrm{p} 31)}$ although the impact of such interventions has been limited. ${ }^{48}$ Despite evidence to the contrary, fatigue management also tends to assume that trainees are both willing and able to accurately self-assess their own fatigue and its performance implications. 39,49,50 Thus, when fatigue management is primarily the trainee's responsibility, solutions remain focused on fixing the trainee without addressing the sociocultural factors that are also at play. The following paragraphs will explore the implications of an individualistic approach to fatigue management and then I will close by highlighting how a sociocultural perspective calls our attention to different solutions.

With the duty of managing fatigue left to the individual, it is unsurprising that wakefulnesspromoting agents, or cognitive enhancers, have gained increasing popularity in the clinical workplace. Ten percent of surveyed medical students admitted to using non medically indicated prescription stimulants ${ }^{51}$ and $5 \%$ of surveyed anesthesia residents reported using a substance other than caffeine to maintain wakefulness while on call. ${ }^{47}$ A primary example of this is Modafinil, a non-amphetamine wakefulness-promoting medication currently approved for narcolepsy and shift work disorder. ${ }^{52}$ While some might argue that it is no different from caffeine, the most abused drug in the world, ${ }^{4}$ it has become a controversial issue. Promising research in medical education suggests that Modafinil may compensate for some of the cognitive deficits associated with acute sleep deprivation. ${ }^{3}$ Of course, not everyone agrees with the use of cognitive enhancement "based on philosophical or ethical grounds". ${ }^{53(p 113)}$ Policies have not kept pace with the use of these cognitive enhancers in medical training and clinical practice. In fact, mounting claims about the efficacy and low 
side effect profile of Modafinil have left some researchers wondering whether one day clinicians and trainees will be expected to take such medication in the name of patient safety. $^{54}$

Although it may be tempting to solve the problem of fatigued trainees by medicating them, rather than revising their work hours, neither solution fully addresses the multi-faceted nature of fatigue. Fatigue is physical, emotional, cognitive and social. Acknowledging fatigue as a social construct allows us to understand why interventions that focus on simple solutions do not straightforwardly solve the problem of fatigued trainees. When it comes to fatigue management approaches, effective solutions account for the social constructs of fatigue. For instance, my third study demonstrated that residents may not see fatigue as hazardous to patient care and resident wellbeing. Solutions that assume otherwise are likely to be taken up superficially. We must continue to invest time upfront to understand the social context in which we are applying strategies or tools that are intended to address trainee fatigue. If we continue to focus on work hours and rely on individuals to manage their fatigue, without accounting for the social milieu, then we will likely be left wondering why residents are not any more rested and why patients are not any safer.

\section{Limitations}

Although constructivist grounded theory is well-suited for the socially-situated research questions of this thesis, there are inherent methodological limitations worth acknowledging here. Firstly, constructivist grounded theory, like most qualitative research, does not make generalizability claims. The emergent theory that was co-constructed by the research participants, myself and my co-investigators is not meant to be generalizable to other contexts. Transferability, on the other hand, is an established feature of rigorous qualitative research. By providing rich descriptions of the context in which this research was situated, we aim to support other researchers to explore the findings' transferability to their context. ${ }^{55}$ The first three studies were situated within a single institution and therefore the findings will necessarily be shaped by the local training culture. Similarly, the final study that sampled from four European countries does not presume generalizability of the results across Europe or even throughout the sampled countries. In providing salient details of the study context, however, I enable other researchers to assess whether the theory is likely to fit within their context or if further research in their context is necessary.

Secondly, the semi-structured interview format elicits participants' representations of their experiences rather than directly visualizing their choices or behaviours. This aligns with my constructivist approach to the research, which focuses on understanding participants' perceived reality. For instance, in the first study that asked how residents decide whether to stay or go after a 24-hour shift, I was interested in understanding the underlying rationalizations for residents' decisions rather than determining the actual decision that was 
made. This is consistent with my methodological choice, as constructivist grounded theory values the interaction between the researcher, the researched and their co-constructed findings. ${ }^{56}$

This leads me to my third point, which is that my lived experience as a resident undoubtedly shaped the course of this research, as I discussed in Chapter 2. In many ways, my insider status was a strength, as it provided access to participants and likely enhanced their candidness during interviews. However, being an insider required the use of particular analytical maneuvers to heighten my own awareness of how this status came to bear on the research process. For example, I have my own stance on fatigue, which is informed by my collective experiences as a resident within a demanding training program. Engaging in reflexivity through analytical memoing and co-analysis with non-insiders helped keep me attentive to my personal stance on fatigue. It was sometimes difficult to refrain from inadvertently imposing that stance on the data, so that, at varying stages of the research process, I would write memos as a way of making my view explicit, even to myself. Sometimes this led me to return to the transcripts and re-read them or even re-code them while assuming an opposing stance, just to see what might emerge. Other times it led to critical analytical discussions with my non-insider colleagues who offered other ways of seeing. Thus, in keeping with constructivist grounded theory, I recognize that I am unable to fully remove myself from the research. By explicitly situating myself in the research as I have done throughout this thesis, I invite the reader to account for my role in the identified findings as they engage with the research.

Finally, my sociocultural theoretical orientation was helpful in that it guided my approach to the research including data collection and analysis. This was a deliberate choice, as I outlined in Chapter 2, because this orientation is underrepresented in the duty hours literature. However, as with any theoretical orientation, it also meant that there were undoubtedly features of the studied phenomena that were overlooked because of my theoretical lens. ${ }^{57}$ One way of dealing with this inevitable uncertainty is to return to the research with a different theoretical orientation that reveals alternative aspects of the studied phenomena. ${ }^{57}$

\section{Future research}

Throughout this thesis, I have alluded to areas of future research that will enable stakeholders within medical education to authentically address the issue of fatigued physicians and trainees. In this section, I will highlight a few key directions that I believe are essential next steps.

(1) Exploring how practicing physicians manage fatigue

My research was deliberately situated in the postgraduate medical education context. However, through the course of the work, I realized that we also understand very little about how practicing physicians navigate the boundaries between work and life in the context of 
their own fatigue. This is a particularly pressing issue in the Canadian context since work hour regulations for practicing physicians are nonexistent. These regulations may be a reality of the future. It is also essential that we understand how fatigue is managed (or not) by practicing physicians.

(2) Finding positive deviants among us

Given that some permutation of resident work hour regulations is likely here to stay, it behooves us to find the positive deviants among us. ${ }^{58}$ Positive deviants are those individuals or groups that are subject to the same constraints as everyone else, but have found a way to manage fatigue and work within duty hour restrictions in ways that do not compromise patient care or resident education. My research offered a glimpse into understanding how these positive deviants operationalize their solutions would offer helpful insights to change the status quo.

(3) Consider the implications of fatigued teams

Due to the prevalence of team-based care, further research that explores how fatigue plays out in the context of teams is critical. Such research would be informed by other industries such as aviation and military to build on their established practices for enhancing team based performance in high-stakes environments. However, important considerations that are unique to healthcare will need to be dealt with, including the lack of team consistency and stability. Additionally, it is important to understand how fatigue is socially negotiated among team members from professions with varied and potentially conflicting approaches to fatigue and its management.

\section{Summary}

We have every reason to believe that sleep deprivation is not beneficial to trainees or the patients they care for. Designing and enforcing work schedules that are aligned with circadian principles may address sleep deprivation but it is unlikely to eliminate the problem of fatigued trainees. By making the social constructs of fatigue explicit, it exposes these constructs to scrutiny. Not only do existing social constructs enable the status quo but they also divert our attention from the systems-level issues that further reinforce these notions of fatigue. At present, fatigue is not a shared problem to be managed across all levels of the healthcare system. Instead, trainees are tasked with the responsibility of overcoming their fatigue or sacrificing time with loved ones to make up for lost sleep. Fortunately, there are ways to move forward from here. By acknowledging fatigue in analysis of medical errors and near misses, the threat of fatigue will be made more visible. Training programs should implement contingency plans that residents are empowered to employ in the event that they are not fit for duty due to fatigue. Rather than dismissing fatigue as a sign of vulnerability or necessary rite of passage, supervisors must consider fatigue as a barrier to fitness for duty in themselves and their trainees. Over time, interventions that reflect the complexity of medical education and fatigue will hopefully give rise to a more authentic approach to managing fatigue. 


\section{References}

1. Van Dongen Hans Pa, Maislin G, Mullington JM, Dinges DF. The cumulative cost of additional wakefulness: Dose-response effects on neurobehavioral functions and sleep physiology from chronic sleep restriction and total sleep deprivation. Sleep. 2003;26(2):117-126.

2. Czeisler CA. Medical and Genetic Differences in the Adverse Impact of Sleep Loss on Performance: Ethical Considerations for the Medical Profession. Transactions of the American Clinical and Climatological Association. 2009;120:249-285.

3. Sugden C, Housden CR, Aggarwal R, Sahakian BJ, Darzi A. Effect of pharmacological enhancement on the cognitive and clinical psychomotor performance of sleepdeprived doctors: a randomized controlled trial. Annals of surgery. 2012;255(2):222227.

4. Howard SK. Sleep deprivation and physician performance: Why should I care? Paper presented at: Baylor University Medical Centre Proceedings; 2005; Dallas.

5. Stratton A, Furey A, Hogan M. The effect of sleep deprivation on a resident's situational awareness in a trauma scenario. Journal of orthopaedic trauma. 2014;28(7):e160-163.

6. Williams S, Meadows R, Arber S. The sociology of sleep. Sleep, health and society: from aetiology to public health. Northamptonshire, Great Britain: Oxford University Press; 2010:275-299.

7. Coverdill JE, Bittner JG, Park MA, Pipkin WL, Mellinger JD. Fatigue as impairment or educational necessity? Insights into surgical culture. Acad Med. 2011;86(10 Suppl):S69-72.

8. Cristancho SM, Apramian T, Vanstone M, Lingard L, Ott M, Novick RJ. Understanding Clinical Uncertainty: What Is Going on When Experienced Surgeons Are Not Sure What to Do? Academic Medicine. 2013;88(10):1516-1521.

9. Christian MS, Ellis AP. Examining the effects of sleep deprivation on workplace deviance: A self-regulatory perspective. Academy of Management Journal. 2011;54(5):913-934.

10. Whitehead CR, Austin Z, Hodges BD. Flower power: the armoured expert in the CanMEDS competency framework? Adv Health Sci Educ Theory Pract. 2011;16(5):681-694.

11. Reason J. Human Error. Cambridge University Press; 1990.

12. Hughes RG, Rogers AE. Are You Tired?: Sleep deprivation compromises nurses' health-and jeopardizes patients. AJN The American Journal of Nursing. 2004;104(3):36-38.

13. Rogers $A E$. The effects of fatigue and sleepiness on nurse performance and patient safety. In: RG H, ed. Patient Safety and Quality: An Evidence-Based Handbook for Nurses. Rockville (MD): Agency for Healthcare Research and Quality 2008. 
14. Liu Y, Wu LM, Chou PL, Chen MH, Yang LC, Hsu HT. The Influence of Work-Related Fatigue, Work Conditions, and Personal Characteristics on Intent to Leave Among New Nurses. Journal of Nursing Scholarship. 2016;48(1):66-73.

15. Reason J. Understanding adverse events: human factors. 1995.

16. Foushee $\mathrm{H}$, Lauber J, Baetge $\mathrm{M}$, Acomb L. Crew Factors in Flight Operations, III: The Operational Significance to Short-Haul Air Transport Operation (NASA Technical Memorandum 88322). Moffett Field, CA: NASA Ames Research Center. 1986.

17. Lingard L, McDougall A, Levstik M, Chandok N, Spafford MM, Schryer C. Representing complexity well: a story about teamwork, with implications for how we teach collaboration. Medical education. 2012;46(9):869-877.

18. Huffington A. The Sleep Revolution: Transforming Your Life, One Night at a Time. Harmony; 2016.

19. Williamson aM, Feyer aM. Moderate sleep deprivation produces impairments in cognitive and motor performance equivalent to legally prescribed levels of alcohol intoxication. Occupational and environmental medicine. 2000;57(10):649-655.

20. Blum $A B$, Raiszadeh $F$, Shea $S$, et al. US public opinion regarding proposed limits on resident physician work hours. BMC medicine. 2010;8:33.

21. Lave J, Wenger E. Situated learning: Legitimate peripheral participation. Cambridge university press; 1991.

22. Mann KV. Theoretical perspectives in medical education: past experience and future possibilities. Med Educ. 2011;45(1):60-68.

23. Ahmed N, Devitt KS, Keshet I, et al. A systematic review of the effects of resident duty hour restrictions in surgery: impact on resident wellness, training, and patient outcomes. Annals of surgery. 2014;259(6):1041-1053.

24. Helmich E, Dornan T. Do you really want to be a doctor? The highs and lows of identity development. Med Educ. 2012;46(2):132-134.

25. Hafferty FW. Duty hours, distant voices, and an alternative future. Archives of Surgery. 2012;147(6):496-497.

26. Brooks JV, Bosk CL. Remaking surgical socialization: Work hour restrictions, rites of passage, and occupational identity. Social Science \& Medicine. 2012;75(9):1625-1632.

27. Szymczak JE, Veazey Brooks J, Volpp KG, Bosk CL. To Leave or to Lie? Are Concerns about a Shift-Work Mentatlity and Eroding Professionalism as a Result of Duty-Hour Rules Justified? The Milbank quarterly. 2008;88(3):350-381.

28. Ginsburg S. Duty hours as viewed through a professionalism lens. BMC Med Educ. 2014;14 Suppl 1:S15.

29. Dhaliwal G. The Greatest Generation. JAMA. 2015;314(22):2353-2354.

30. Haddara W, Lingard L. Exploring the premise of lost altruism: content analysis of two codes of ethics. Advances in Health Sciences Education. 2016:1-14.

31. O'Neill JA, Jr. Surgical education: foundations and values. I Am Coll Surg. 2009;208(5):653-662. 
32. Arora VM, Farnan JM, Humphrey HJ. Professionalism in the era of duty hours. JAMA. 2012;308(21):2195-2196.

33. Catherine V, James W, Caldicott CV, Holsapple JW. Training for Fitness : Reconsidering the 80-Hour Work Week Training for Fitness reconsidering the 80-hour work week. 2008;51(1):134-143.

34. Fletcher KE, Reed DA, Arora VM. Patient safety, resident education and resident wellbeing following implementation of the 2003 ACGME duty hour rules. J Gen Intern Med. 2011;26(8):907-919.

35. Lindeman BM, Sacks BC, Hirose K, Lipsett PA. Multifaceted longitudinal study of surgical resident education, quality of life, and patient care before and after July 2011. J Surg Educ. 2013;70(6):769-776.

36. Balch CM, Shanafelt TD, Dyrbye L, et al. Surgeon distress as calibrated by hours worked and nights on call. Journal of the American College of Surgeons. 2010;211(5):609-619.

37. Leibrandt TJ, Pezzi CM, Fassler SA, Reilly EF, Morris JB. Has the 80-hour work week had an impact on voluntary attrition in general surgery residency programs? J Am Coll Surg. 2006;202(2):340-344.

38. Coulehan J, Williams PC. Conflicting professional values in medical education. Cambridge Quarterly of Healthcare Ethics. 2003;12(01):7-20.

39. Baldwin DC, Daugherty SR. Sleep deprivation and fatigue in residency training: results of a national survey of first- and second-year residents. Sleep. 2004;27(2):217-223.

40. Ratanawongsa N, Wright SM, Carrese JA. Well-being in residency: a time for temporary imbalance? Med Educ. 2007;41(3):273-280.

41. Baldwin P, Dodd M, Wrate R. Young doctors' health-II. Health and health behaviour. Social science \& medicine. 1997;45(1):41-44.

42. Sun N-Z, Gan R, Snell L, Dolmans D. Use of a night float system to comply with resident duty hours restrictions: Perceptions of workplace changes and their effects on professionalism. Academic Medicine. 2016;91(3):401-408.

43. Reid RJ, McKendry R, Haggerty J. Defusing the Confusion: Concepts and Measures of Continuity of Health Care: Final Report. Canadian Health Services Research Foundation= Fondation canadienne de la recherche sur les Services de santé; 2002.

44. Lingard L. What we see and don't see when we look at 'competence': notes on a god term. Advances in Health Sciences Education. 2009;14(5):625-628.

45. Amalberti $R$, Auroy $Y$, Berwick $D$, Barach P. Five system barriers to achieving ultrasafe health care. Annals of internal medicine. 2005;142(9):756-764.

46. Waibel S, Henao D, Aller M-B, Vargas I, Vázquez M-L. What do we know about patients' perceptions of continuity of care? A meta-synthesis of qualitative studies. International Journal for Quality in Health Care. 2011:mzr068.

47. Hanlon JG, Hayter MA, Bould MD, Joo HS, Naik VN. Perceived sleepiness in Canadian anesthesia residents: a national survey. Canadian journal of anaesthesia = Journal canadien d'anesthesie. 2009;56(1):27-34. 
48. Arora VM, Georgitis E, Woodruff JN, Humphrey HJ, Meltzer D. Improving sleep hygiene of medical interns: Can the sleep, alertness, and fatigue education in residency program help? Archives of Internal Medicine. 2007;167(16):1738-1744.

49. Dorrian J, Lamond N, Dawson D. The ability to self-monitor performance when fatigued. Journal of Sleep Research. 2000;9(2):137-144.

50. Veasey S, Rosen R, Barzansky B, Rosen I, Owens J. Sleep loss and fatigue in residency training: a reappraisal. JAMA : the journal of the American Medical Association. 2002;288(9):1116-1124.

51. Tuttle JP, Scheurich NE, Ranseen J. Prevalence of ADHD diagnosis and nonmedical prescription stimulant use in medical students. Academic Psychiatry. 2010;34(3):220223.

52. Rose SH, Curry TB. Fatigue, countermeasures, and performance enhancement in resident physicians. Mayo Clinic proceedingsMayo Clinic. 2009;84(11):955-957.

53. Kudlow P. Self-prescription: brainpower from a bottle. CMAJ. 2013;185(2):112-113.

54. Paparodis R. Fatigue, countermeasures, and performance enhancement in resident physicians. Mayo Clinic proceedings. 2010;85(3):301; author reply 301-302.

55. Lincoln YS, Guba EG. The constructivist credo. Left Coast Press; 2013.

56. Charmaz K. Constructing grounded theory. Sage; 2014.

57. Helmich E, Boerebach BC, Arah OA, Lingard L. Beyond limitations: Improving how we handle uncertainty in health professions education research. Medical teacher. 2015;37(11):1043-1050.

58. Pascale RT, Sternin J, Sternin M. The power of positive deviance: How unlikely innovators solve the world's toughest problems. Vol 1: Harvard Business Press; 2010. 

Summary 
Around the world, work hour restrictions have been considered the primary solution to the problem of fatigued physicians and trainees. Unlike Europe or the United States, Canada lacks unifying, national legislations for resident work hours and existing regulations are variably imposed. Research into work hour restrictions has been abundant in the past 30 years, and largely centers on proving or disproving whether these restrictions have achieved their intended outcomes. Such research asks whether restrictions have reduced resident fatigue, resulting in better-rested, safer trainees and patients. This thesis moves away from an individualistic approach to understanding fatigue in the context of resident work hour restrictions. Instead of trying to prove or disprove whether such restrictions are effective, it considers the sociocultural aspects of medical training that have otherwise remained peripheral to the dominant discourse about work hour restrictions. Broadly, the main research question explores fatigue as a social phenomenon and its relevance to workplace based strategies for managing fatigue, namely work hour restrictions.

Chapter 1 maps out four predominant lines of inquiry within the resident work hour restriction literature and highlights their relevance to the overall thesis: (1) Is Sleep Deprivation Dangerous? (2) Does Resident Training Suffer From Work Hour Restrictions? (3) Do Work Hour Restrictions Compromise Patient Care? And (4) Can Fatigue Be Managed? Multiple positions are outlined within each line of inquiry. This culminates in a reframing of fatigue as a social and collective phenomenon, which is not evident in the dominant discourses of the literature. The central research questions of the thesis are presented. Firstly, how do residents decide to stay or go following a 24-hour call shift? Then, what do residents do when they leave the hospital following a 24-hour call shift, how do they make those decisions and how do they understand them in the context of their own wellbeing? Also, how is fatigue socially constructed in the clinical training environment? And finally, how are work hour regulations understood in the European context and how do they shape the social construction of fatigue? The chapter finishes by providing an overview of the international, national and local contexts in which the thesis is situated.

Chapter 2 introduces two key theoretical frameworks and the methodology of constructivist grounded theory, after situating the researcher within the research. It describes how the research questions emerged from and were informed by lived experiences that shaped the research at every step, including data collection and analysis. Analytical memos are included to illustrate reflexivity and its influence on theory refinement. Sociocultural perspectives are increasingly common in medical education and this theoretical orientation provides a useful lens through which to consider socially situated research questions. Social constructivism is a complementary theoretical framework that acknowledges multiple, shared realities embedded within a given social milieu. This chapter concludes with a description of constructivist grounded theory and provides justification for this methodology on the basis of socially situated research questions that are not explained by existing theories. 
Chapter 3 explores residents' decision-making at the end of a 24-hour call shift in the Canadian context. Using constructivist grounded theory, semi-structured interviews were conducted with a total of 24 residents across six surgical and non-surgical training programs at one Canadian medical school. Understanding resident decision-making as they transitioned from on- to off-duty provided insight into the sociocultural forces that are likely to shape how residents navigate future duty hour policies. Cultural norms emerged as the predominant influence over whether residents decided to stay or go following their call shift. However, when justifying their decision, residents invoked values of patient safety and educational merit, regardless of whether they were choosing to stay or go. This key finding suggests that adherence to future duty hour policies is not simply a question of individual residents upholding correct values. Instead, it points to aspects of the training environment that could be modified so that staying or going is less of an individual, values-based decision.

Chapter 4 examines residents' decision-making related to off-duty time after deciding to leave the hospital. Due to the richness and depth of the data set from Chapter 3 , the same data was analyzed with this research question in mind. Decision-making was characterized by making trade-offs. Within these trade-offs, residents prioritized according to one of two orientations: oriented to maintaining a normal life or oriented to mitigating fatigue. This research provided two main contributions to the literature. First, it highlighted two distinct and competing forms of recovery and, while there is evidence for both of these processes as separate entities, this is the first model that considers both forms of recovery. Second, these findings called into question the predominant notion that work hour restrictions will only be beneficial if residents use additional "free time" for sleep. It strongly suggests that work hour regulations that focus on an accounting of work and sleep hours without ensuring that residents have opportunities to manage the day to day aspects of their lives are unlikely to improve resident wellbeing and recovery from the workplace.

Chapter 5 moves away from residents' individual decision-making to focus on the shared social constructs of fatigue in the clinical workplace. Using constructivist grounded theory, semi-structured interviews were conducted with a total of 21 residents across seven surgical and non-surgical training programs at one Canadian medical school. This research was inspired by findings from the earlier interviews and a noticeable shift in the conversation about work hours in Canada whereby policy-makers had shifted their focus away from prescriptive restrictions in favour of fatigue risk management plans. Residents rarely framed fatigue as a safety threat that negatively impacted their clinical performance. Instead, four principles of fatigue emerged that centred on the notion of fatigue as a personal challenge to be overcome. These social constructs of fatigue expose potential barriers to the implementation of fatigue risk management plans and suggest that there is much work to be done in making the risks of fatigue more evident in the clinical workplace. 
Chapter 6 expands upon and enriches the theories that had been constructed within the Canadian data by exploring the experiences of European trainees from different contexts, who have long-standing work hour regulation. Using constructivist grounded theory, semi-structured interviews were conducted with 13 residents across five surgical and non-surgical training programs from four European countries, which included Denmark, United Kingdom, Ireland and the Netherlands. Although the social constructs of fatigue that emerged generally resonated with our Canadian data, the varied meanings of work hour regulations was a striking finding. Some of the meanings are well established in the European literature, including concerns about sacrificing trainee autonomy and compromising continuity of care. However, the efficiency discourse, in which staying late is evidence of inefficiency, was a distinctive meaning that emerged. This study also suggests that the working time directive neither solves the problem of trainee fatigue nor the issue of trainees deciding whether to stay or go at the end of a shift. It appears that the sociocultural milieu takes primacy over policy, which warrants further attention.

Chapter 7 returns to the four predominant lines of inquiry within the resident work hour restriction literature and reframes each debate from a sociocultural perspective. New questions emerge, including whether fatigue needs to be considered at the level of the care delivery team and if more stable or consistent teams might compensate for the threat of fatigued individuals. When considering the implications of work hour restrictions on resident training and patient safety, a sociocultural perspective calls attention to professional ideals that may no longer serve their intended purpose. After establishing that trainee sleep deprivation is problematic and that work hour restrictions challenge avowed professional merits, this chapter grapples with the question of whether fatigue can be managed. It acknowledges that fatigue management is inherently complicated by the multifaced nature of fatigue. It follows that interventions must account for the social aspects of fatigue if they are to have any impact on the issue of fatigued trainees. The chapter concludes with a discussion of the limitations and affordances of the chosen methodology. This is followed by a call for future research that: (1) explores how practicing physicians manage fatigue, (2) seeks out positive deviants and (3) considers the implications of fatigued teams. 
Samenvatting 
Het beperken van arbeidstijden wordt wereldwijd gezien als de voornaamste oplossing voor het probleem van vermoeide artsen en artsen in opleiding tot specialist (aios). In tegenstelling tot Europa of de Verenigde Staten heeft Canada geen overkoepelende nationale wetgeving waarin de arbeidstijden van aios worden bepaald en aan bestaande regelgeving wordt op diverse manieren invulling gegeven. In de afgelopen 30 jaar is er veel onderzoek gedaan naar arbeidstijdbeperkingen, waarbij de nadruk hoofdzakelijk lag op het bewijzen dat deze beperkingen wel of juist niet tot het gewenste resultaat hebben geleid. Bij dergelijk onderzoek wordt de vraag gesteld of beperkingen geleid hebben tot minder vermoeidheid onder aios waardoor zij beter uitgerust zijn en veiliger zijn voor zowel zichzelf als voor patiënten. Om vermoeidheid in de context van arbeidstijdbeperkingen van aios te kunnen begrijpen, neemt dit proefschrift afstand van een individualistische benadering. In plaats van te trachten te bewijzen dat dergelijke beperkingen wel of niet effectief zijn, richt het zich op de sociaal-culturele aspecten van de medische opleiding die anders hun marginale plek in de heersende discussie over arbeidstijdbeperkingen zouden hebben behouden. In grote lijnen onderzoekt de hoofdvraag vermoeidheid als een sociaal verschijnsel en het belang daarvan voor strategieën ter beheersing van vermoeidheid op de werkplek, namelijk arbeidstijdbeperkingen.

Hoofdstuk 1 geeft een overzicht van de vier onderzoekslijnen die de literatuur over arbeidstijdbeperkingen van aios domineren en bespreekt hun relevantie voor het proefschrift in zijn geheel: 1) Is slaaptekort gevaarlijk?, 2) Lijdt de vervolgopleiding onder arbeidstijdbeperkingen?, 3) Brengen arbeidstijdbeperkingen de patiëntenzorg in gevaar? en 4) Kan vermoeidheid worden aangepakt? Binnen elke onderzoekslijn worden de verschillende standpunten uiteengezet. Dit leidt tot een nieuwe interpretatie van vermoeidheid als een sociaal en collectief verschijnsel, wat nog niet eerder uit de heersende discussie van de literatuur naar voren is gekomen. De centrale onderzoeksvragen van dit proefschrift worden geïntroduceerd. Ten eerste, hoe besluiten aios om te blijven of te gaan na een 24-uursbereikbaarheidsdienst? Vervolgens, wat doen aios zodra zij het ziekenhuis verlaten na een 24-uursbereikbaarheidsdienst, hoe komen zij tot deze beslissingen en hoe begrijpen zij de invloed ervan op hun eigen welzijn? En ook, hoe wordt vermoeidheid sociaal geconstrueerd in de klinische opleidingsomgeving? En tenslotte, hoe wordt de arbeidstijdenregelgeving begrepen in de Europese context en hoe beïnvloedt deze de sociale beeldvorming van vermoeidheid? Het hoofdstuk wordt afgesloten met een overzicht van de internationale, nationale en plaatselijke contexten waarin het proefschrift geplaatst wordt.

Hoofdstuk 2 introduceert twee belangrijke theoretische kaders en de constructivistische gefundeerde theoriebenadering na plaatsing van de onderzoekster in het onderzoek. Het beschrijft hoe de onderzoeksvragen voortkwamen uit en ingegeven werden door beleefde ervaringen die het onderzoek bij elke stap, waaronder de dataverzameling en -analyse, vormgaven. Analytische memo's worden bijgevoegd ter illustratie van reflexiviteit en de invloed daarvan op de theorieverfijning. Sociaal-culturele perspectieven worden 
steeds gangbaarder in het medische onderwijs en deze theoretische benadering biedt een handzame bril waardoor we sociaal geplaatste onderzoeksvragen kunnen beschouwen. Sociaal constructivisme is een complementair theoretisch kader dat het bestaan van meerdere, gedeelde realiteiten binnen een bepaald sociaal milieu erkent. Dit hoofdstuk sluit af met een beschrijving van constructivistische gefundeerde theorie en onderbouwt de keuze voor deze onderzoeksmethode op basis van sociaal geplaatste onderzoeksvragen die niet door bestaande theorieën worden beantwoord.

Hoofdstuk 3 onderzoekt de besluitvorming onder aios aan het einde van een 24uursbereikbaarheidsdienst in een Canadese setting. Aan de hand van constructivistische gefundeerde theorie namen we semigestructureerde interviews af bij in totaal 24 aios van zes chirurgische en niet-chirurgische medische vervolgopleidingen aan één Canadese medische faculteit. Door te begrijpen hoe aios tot het besluit komen de dienst te beëindigen, verkregen we meer inzicht in de sociaal-culturele krachten die waarschijnlijk beïnvloeden hoe aios met toekomstig arbeidstijdenbeleid zullen omgaan. Of de aios besloten te blijven of te gaan na hun bereikbaarheidsdienst bleek voornamelijk beïnvloed te worden door culturele normen. Bij het beargumenteren van hun besluit noemden de aios echter waarden van patiëntveiligheid en leerzaamheid, ongeacht of ze besloten om te blijven of te gaan. Deze voornaamste bevinding suggereert dat naleving van toekomstig arbeidstijdenbeleid niet enkel een kwestie is van individuele aios die de juiste waarden hooghouden. In plaats daarvan wijst het naar aspecten van de opleidingsomgeving die veranderd zouden kunnen worden, zodat het besluit om te blijven of te gaan minder op waarden is gebaseerd.

Hoofdstuk 4 bestudeert hoe aios besluiten hun vrije tijd in te vullen na te hebben besloten het ziekenhuis te verlaten. Gezien de omvang en diepgang van de gegevens die we voor hoofdstuk 3 hadden verzameld, werden deze zelfde gegevens geanalyseerd met deze onderzoeksvraag in gedachten. De besluitvorming werd gekenmerkt door het vinden van een balans. Aios vonden deze balans door een van de volgende twee doelen te prioriteren: het behouden van een normaal leven of het verminderen van vermoeidheid. Dit onderzoek leverde twee belangrijke bijdragen aan de literatuur. In de eerste plaats belichtte het twee verschillende en tegenstrijdige vormen van herstel en, ook al bestaat er bewijs voor deze beide processen als afzonderlijke eenheden, dit is het eerste model dat met beide vormen van herstel rekening houdt. Ten tweede trokken deze bevindingen het overheersende denkbeeld in twijfel dat arbeidstijdbeperkingen alleen zullen baten als aios de extra "vrije tijd" gebruiken om te slapen. De bevindingen wijzen er sterk op dat arbeidstijdvoorschriften die gestoeld zijn op een rekensom van arbeids- en slaapuren, zonder aios de garantie te bieden dat zij de mogelijkheid hebben om de dagelijkse aspecten van hun leven te verwerken, waarschijnlijk het welzijn van aios en hun herstel van de werkplek niet zullen verbeteren. 
Hoofdstuk 5 wendt zich af van de besluitvorming van individuele aios om zich te richten op de gedeelde sociale beeldvorming van vermoeidheid op de klinische werkplek. Aan de hand van constructivistische gefundeerde theorie namen we semigestructureerde interviews af bij in totaal 21 aios van zeven chirurgische en niet-chirurgische medische vervolgopleidingen aan één Canadese medische faculteit. Dit onderzoek kwam voort uit de bevindingen van de eerdere interviews en uit een duidelijke verschuiving in de discussie over arbeidstijden in Canada waar beleidsmakers in plaats van de arbeidstijden aan banden te leggen hun aandacht vestigden op vermoeidheidsrisicobeheerplannen. Aios beschreven vermoeidheid zelden als een gevaar voor de veiligheid dat hun klinische prestaties negatief beïnvloedde. In plaats daarvan kwamen er vier zienswijzen van vermoeidheid bovendrijven die het begrip "vermoeidheid" interpreteerden als een persoonlijke uitdaging die overwonnen moest worden. Deze sociale beeldvormingen van vermoeidheid zouden de invoering van vermoeidheidsrisicobeheerplannen mogelijk kunnen belemmeren en suggereren dat er nog veel gedaan moet worden om mensen bewuster te maken van de risico's van vermoeidheid op de klinische werkvloer.

Hoofdstuk 6 bouwt voort op en verrijkt de theorieën die op basis van de Canadese data waren geconstrueerd door te onderzoeken wat de ervaringen zijn van Europese aios uit verschillende contexten die al geruime tijd bekend zijn met arbeidstijdenregelgeving. Aan de hand van constructivistische gefundeerde theorie namen we semigestructureerde interviews af bij 13 aios van vijf chirurgische en niet-chirurgische medische vervolgopleidingen in vier Europese landen, waaronder Denemarken, het Verenigd Koninkrijk, lerland en Nederland. Hoewel de sociale beeldvormingen van vermoeidheid die naar voren kwamen veel gelijkenissen vertoonden met de Canadese data, viel op dat er verschillend gekeken werd naar de arbeidstijdenregelgeving. Sommige van deze zienswijzen zijn duidelijk bewezen in de Europese literatuur, zoals zorgen over de opoffering van de zelfstandigheid van de aios en het in gevaar brengen van de continuïteit van de zorg. De discussie over efficiëntie bracht echter een nieuwe betekenis te berde, namelijk dat laat blijven van inefficiëntie getuigt. Dit onderzoek suggereert ook dat de arbeidstijdenrichtlijn geen oplossing biedt voor het probleem van vermoeidheid onder aios, noch voor de kwestie van aios die besluiten te blijven of te gaan aan het einde van een dienst. Het lijkt erop dat het sociaal-culturele milieu zwaarder weegt dan beleid, iets wat verdere aandacht vraagt.

Hoofdstuk 7 keert terug naar de vier onderzoekslijnen die de literatuur over arbeidstijdbeperkingen van aios domineren en herformuleert elke discussie vanuit een sociaal-cultureel perspectief. Daarbij rijzen nieuwe vragen, zoals of vermoeidheid op het niveau van het zorgverleningsteam gezien moet worden en of stabielere en consequentere teams het gevaar van vermoeide individuen kunnen ondervangen. Wanneer we nadenken over de gevolgen van arbeidstijdbeperkingen voor de opleiding en patiëntveiligheid, laat een sociaal-cultureel perspectief ons zien dat professionele idealen hun gewenste doel wellicht niet meer dienen. Na vastgesteld te hebben dat slaaptekort bij aios voor problemen zorgt en 
dat arbeidstijdbeperkingen de verwerving van erkende professionele vaardigheden bemoeilijkt, worstelt dit hoofdstuk met de vraag of vermoeidheid aangepakt kan worden. Het erkent dat het aanpakken van vermoeidheid van nature complex is door de veelzijdige aard van vermoeidheid. Dientengevolge moeten interventies de sociale aspecten van vermoeidheid aanpakken als ze het probleem van vermoeide aios ook maar enigszins willen oplossen. Het hoofdstuk wordt afgesloten met een bespreking van de voor- en nadelen van de gekozen methode. Dit wordt gevolgd door een oproep tot nader toekomstig onderzoek dat: 1) onderzoekt hoe praktiserende artsen omgaan met vermoeidheid, 2) succesvolle alternatieve aanpakken opspoort, en 3) kijkt naar de gevolgen van vermoeide teams. 

Valorisation 
The research presented in this thesis has relevance that extends beyond resident work hour restrictions. As I outlined in the Discussion chapter, there are plenty of opportunities for future research, which include exploring issues of fatigue among practicing physicians and healthcare teams. Rather than revisiting these considerations, I will first acknowledge the knowledge translation that I have engaged in during the course of my research and then elaborate on further anticipated practical implications of this work.

\section{Knowledge Translation}

Over the past four years, I have disseminated my research through presentations at local, national and international levels within the medical education research community. This has amounted to a total of 20 presentations. At the national and international levels, this included the International Conference on Residency Education, Association for Medical Education in Europe, Canadian Conference on Medical Education and Association of Academic Professionals in Obstetrics \& Gynecology. Locally, I presented my research at the Centre for Education Research \& Innovation and during medical grand rounds within the Department of Obstetrics \& Gynecology and the Department of Medicine at my training institution. I also shared my research as an invited speaker within the Best Practices in Education Research lecture series at the University of Toronto.

In addition to these well-established forums for disseminating research, I sought opportunities for knowledge translation through other means at both local and national levels. Early on during my doctoral studies, I accepted an invitation to participate in a national consensus committee meeting hosted by the Royal College of Physicians and Surgeons of Canada. This meeting was attended by all members of the expert working groups who were tasked with the challenge of deciding how Canada would address the issue of trainee fatigue and work hours at the postgraduate level. That experience reaffirmed the relevance of my research, as it was clear that there was still much to be understood about the problem of trainee fatigue. Subsequently, I was invited to join a new expert working group on fatigue risk management plans, which was established by the Royal College of Physicians and Surgeons of Canada. Through my ongoing involvement in this working group, my research on fatigue as a social construct has helped to shape emerging policies on how to manage fatigue. I will elaborate on this contemporary and influential aspect of my research in the paragraphs that follow.

\section{Addressing the Taboo}

One of the key findings from this research was that many trainees felt that it was taboo to talk about fatigue, especially in a meaningful way that acknowledges the potential for harm. The medical training environment lacks a sanctioned language and acceptable forum for talking about fatigue as hazardous. One way to address the taboo would be to acknowledge fatigue and sleep deprivation alongside other well-established threats such as communication errors as part of existing dialogues about quality assurance. The morbidity 
and mortality conferences conducted by many training programs are an appropriate forum for serious, open discussions of fatigue and the role that it plays as a patient safety threat. Another practical approach is to make fatigue more visible by having trainees wear coloured wristbands, for example, that correspond with the number of hours they have been on shift. This approach was used in South Africa and instituted by the junior doctors as a form of protest after one of their colleagues was killed in a motor vehicle crash while driving home fatigued after a long shift ${ }^{1}$. Unless we experiment with such opportunities to make fatigue visible and worthy of discussion, we have little hope of seeing fatigue as a hazard to be managed.

\section{Consider the system}

Residents, program directors, faculty and hospital administrators are collectively responsible for preserving existing social constructs of fatigue; thus, they are an essential part of any movement to incite change. Currently, there is much greater emphasis placed on the responsibility of individual trainees, rather than the system, to solve the problem of managing fatigue. The notion that fatigue can be overcome if an individual is motivated enough to rise to the challenge is one salient example. A comprehensive approach to fatigue management must combat this unsubstantiated, yet pervasive rationale. Work schedules that are aligned with sleep physiology principles are only the first step. Such schedules displace some of the burden for managing fatigue from individual trainees but only if issues of work compression and inadequate handover are also addressed. Existing frameworks for managing fatigue in the training environment rely on the trainee to will him or herself into overcoming the fatigue. Instead, programs would benefit from feasible and non-punitive contingency plans in the event that a trainee finds him or herself impaired from fatigue, regardless of work schedules. This might include having an extra, more senior resident or supervisor available from home to provide back up, making it more acceptable for trainees to reach out for help. Although this will require creative reorganization of human resources, such policies send a clear message that fatigue-related impairment must be taken seriously. By shifting our attention away from individual trainees to consider the role of the system, new solutions emerge that may help to reduce the overall impact of fatigue in medical education.

\section{Managing Energy}

This research demonstrated that residents engage in various forms of recovery that serve a purpose beyond making up for lost hours of sleep. Managing energy, or recovering, is simply another way of thinking about mitigating fatigue. This realization has implications beyond the training environment since the recovery routines established during residency are likely to persist during independent practice as well. This has certainly been the case for many of my colleagues and for me. In light of current epidemics of burnout in health care providers, off-duty time during residency provides a necessary opportunity for trainees to establish intentional self-care practices. Although self-care needs are very personal and 
individualized, there is a role for the system to support trainees addressing these needs. Opportunities exist at multiple levels. First, residents should be educated about existing principles of good sleep hygiene, including strategic caffeine intake and napping. Second, environmental changes are warranted that allow healthy decisions to be the default, easy decision. This might include having a workout facility within the hospital, providing access to call rooms so trainees can take a nap before driving home fatigued and serving nutritional food during morning handover so that residents are less inclined to stop by the drivethrough on their way home. Finally, programs should consider instituting policies that allow for personal time away, at the discretion of the trainee. Residents appreciate this autonomy as recognition of their maturity and professionalism. It leads to greater workplace satisfaction, regardless of whether they actually take the time off. ${ }^{2}$

\section{Summary}

Through this research, I have learned that successful change implementation requires that we consider a problem from multiple perspectives and take a careful inventory of the multidimensional sociocultural forces at play. I now maintain a sense of skepticism about straightforward solutions to complex, socially situated problems because I have seen how easily unintended consequences can detract from intended benefits. These realizations will continue to shape my conversations about fatigue and working hours with my near-peers in the clinical workplace as well as my co-committee members in the Fatigue Risk Management Plan Working Group.

\section{References}

1. Sidley P. South African doctors protest long shifts by wearing coloured wristbands. British Medical Journal Publishing Group; 2016.

2. Cedfeldt AS, Bower EA, English C, Grady-Weliky TA, Girard DE, Choi D. Personal time off and residents' career satisfaction, attitudes and emotions. Med Educ. 2010;44(10):977-984. 


\section{Acknowledgements}

The mind determines what's possible. The heart surpasses it. - Pilar Coolinta

As you may have noticed, I have been blessed with an unbelievably stellar supervisory team. Whatever stars came into alignment to bring these three individuals together, I'll never know, but I am eternally grateful. Each of them invested their time, energy and wisdom into this venture, wholeheartedly, from the beginning to the end. With any luck, this thesis marks the start of many future collaborations.

Lorelei, I am inspired by your ambition, your incredible gift with words and your ability to see potential in others that they cannot see for themselves. All that I have accomplished would not have been possible without your encouragement and patient mentorship. That's right. I used the M-word and I meant it! Thank you from the bottom of my heart.

Pim, It was such a pleasure getting to know you. As a fellow obstetrician-gynecologist and medical education scholar, I felt a sense of kinship right away. I have benefitted tremendously from your thoughtful, learner-oriented approach to supervision. I cannot imagine achieving this feat without your valuable insight and genuine reassurance in times of uncertainty.

Tim, You have been a most spirited and supportive supervisor from the very beginning. Thank you for challenging me to expand beyond my comfort zone at pivotal moments along the way. Your enthusiasm and optimism were more appreciated (and contagious!) than you could ever know.

In many ways, the scientists, researchers and administrative members at the Centre for Education Research \& Innovation (CERI) at the Schulich School of Medicine \& Dentistry became my unofficial fourth supervisor. These outstanding, brilliant individuals created a safe learning environment in which I was welcomed to share new ideas, seek out advice and embrace the inevitable hurdles along the way. 
This thesis would not have been possible without the articulate, insightful trainees who took time out of their hectic schedules to participate in interviews. I must also thank my summer research student, Tishara Wijayanayaka, who brought a new perspective to the international data. As a trainee in the Department of Obstetrics \& Gynecology at the Schulich School of Medicine \& Dentistry, I was fortunate to have colleagues and supervisors who accommodated my unconventional journey through residency. The financial support I received through the Faculty Support for Research in Medical Education at Schulich School of Medicine \& Dentistry along with the Royal College of Physicians and Surgeons of Canada Robert Maudsley Fellowship for Studies in Medical Education enabled me to remain focused on my research and to disseminate my work internationally.

When it comes to the generosity and support of my family and friends, there are no words that could possibly capture how much this has meant to me. Leslie Skeith, my bullet journal comrade, our coffee dates were just the boost I needed to make it through the final stretch. Lisa Fadden, my dear fellow Fluvogian, thank you for sharing your wealth of knowledge (and love of Beanitos) with me. Shannon and Rob Arntfield, thank you for your friendship and for teaching me the importance of creating a balanced life. Marika Marty, you have been by my side through it all and I cannot imagine it any other way. Heather, dear sister, you are one in a million and an ongoing source of inspiration for me. Mom and Dad, you have been an unfaltering source of support from the start. Thank you for instilling in me a sense of curiosity (Dad) and love of reading (Mom) that have opened many doors, which have led to life-changing experiences. 


\section{Curriculum Vitae}

Taryn Taylor completed medical school and residency in Obstetrics \& Gynecology at Western University. She is currently a Senior Fellow in the Department of Innovation in Medical Education while studying Simulation Education through the University of Ottawa Skills and Simulation Centre.

Dr. Taylor discovered her passion for medical education during her residency while enrolled in the Clinical Investigator Program at the Schulich School of Medicine \& Dentistry, Western University. Through the support of this program, she was able to pursue doctoral studies during her clinical training. As a junior Clinician-Scientist in medical education, Dr. Taylor provided resident representation on the Association of Academic Professionals in Obstetrics \& Gynecology (APOG) Education Innovation Committee. In 2014, she was awarded the Royal College of Physicians and Surgeons of Canada Robert Maudsley Fellowship for Studies in Medical Education. Dr. Taylor also received the 2016 Award for Excellence in Teaching from the Department of Obstetrics \& Gynecology at Western University, which remains one of her proudest achievements.

If she is not in the hospital or working on research, Dr. Taylor is happiest at the climbing gym or practicing her flying trapeze tricks. She also enjoys spoiling her friends' kids whenever she can squeeze in a visit! 
